\title{
Preliminary Design of a \\ Tandem-Mirror-Next-Step Facility
}

C. C. Damm, J. N. Doggett, R. H. Bulmer, W. S. Neef, G. W. Hamilton, A. E. Sherwood, S. Szybalski, B. M. Boghosian, G. A. Carlson, R. W. Moir, W. L. Barr, J. L. Erickson," R. S. Devoto, T. H. Batzer, and C. L. Hanson

Manuscript date: December 18, 1980

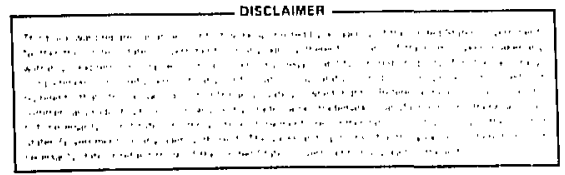

"Permanent address: Grumman Aerospace Corporation, Bethpage, NY.

LAWRENCE LIVERMORE LABORATORY University of California • Livermore, California • 94550 


\section{CONTENTS}

Abstract $\ldots \ldots \ldots \ldots \ldots \ldots \ldots \ldots \ldots \ldots \ldots \ldots \ldots \ldots \ldots \ldots \ldots \ldots \ldots \ldots \ldots \ldots \ldots \ldots \ldots \ldots \ldots, 1$

1. Introduction $\ldots \ldots \ldots \ldots \ldots \ldots \ldots \ldots \ldots \ldots \ldots \ldots \ldots \ldots \ldots \ldots \ldots \ldots \ldots \ldots$

2. Performance Guidelines and Basis for Design $\ldots \ldots \ldots \ldots \ldots \ldots \ldots \ldots \ldots$

3. Overall Facility Description $\ldots \ldots \ldots \ldots \ldots \ldots \ldots \ldots \ldots \ldots \ldots \ldots \ldots \ldots$

Physics and Engineering Parmeters $\ldots \ldots \ldots \ldots \ldots \ldots \ldots \ldots \ldots \ldots \ldots \ldots 13$

Power-Flow Diagrama $\ldots \ldots \ldots \ldots \ldots \ldots \ldots \ldots \ldots \ldots \ldots \ldots \ldots \ldots \ldots \ldots$

Cost Estimate $\ldots \ldots \ldots \ldots \ldots \ldots \ldots \ldots \ldots \ldots \ldots \ldots \ldots \ldots \ldots \ldots \ldots \ldots \ldots \ldots \ldots$.

4. Physics Considerations for THNS Parameter selection ............ 27

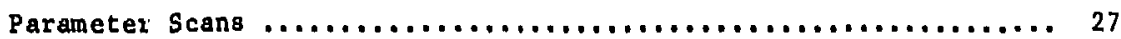

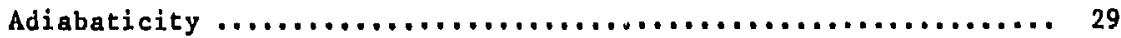

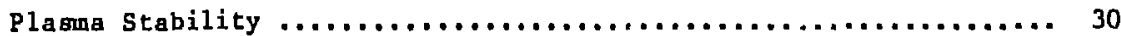

Gas Balance and Vacuum $\ldots \ldots \ldots \ldots \ldots \ldots \ldots \ldots \ldots \ldots \ldots \ldots \ldots \ldots \ldots$

Confinement of $a-$ Particles $\ldots \ldots \ldots \ldots \ldots \ldots \ldots \ldots \ldots \ldots \ldots \ldots \ldots \ldots . \ldots$

5. Plasma Heating and Barrier Pumping ....................... 39

Neutral Beams $\ldots \ldots \ldots \ldots \ldots \ldots \ldots \ldots \ldots \ldots \ldots \ldots \ldots \ldots \ldots \ldots \ldots \ldots \ldots . \ldots . \ldots . \ldots$

Electron Cyclotron Resonant Heating (ECRH) $\ldots \ldots \ldots \ldots \ldots \ldots \ldots \ldots \ldots 4$

6. Engineering Design $\ldots \ldots \ldots \ldots \ldots \ldots \ldots \ldots \ldots \ldots \ldots \ldots \ldots \ldots \ldots \ldots \ldots$

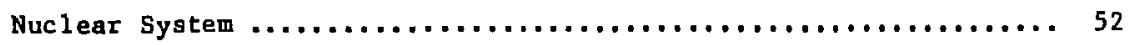

Magnet system $\ldots \ldots \ldots \ldots \ldots \ldots \ldots \ldots \ldots \ldots \ldots \ldots \ldots \ldots \ldots \ldots \ldots$

Vessel system $\ldots \ldots \ldots \ldots \ldots \ldots \ldots \ldots \ldots \ldots \ldots \ldots \ldots \ldots \ldots \ldots \ldots \ldots \ldots, 68$

Fueling and heating $\ldots \ldots \ldots \ldots \ldots \ldots \ldots \ldots \ldots \ldots \ldots \ldots$

Vacuum Pumping $\ldots \ldots \ldots \ldots \ldots \ldots \ldots \ldots \ldots \ldots \ldots \ldots \ldots \ldots \ldots \ldots$

Direct Converters $\ldots \ldots \ldots \ldots \ldots \ldots \ldots \ldots \ldots \ldots \ldots \ldots \ldots \ldots \ldots \ldots$

Central-Cell Blanket and Shield .................... 77

End-Cell shields $\ldots \ldots \ldots \ldots \ldots \ldots \ldots \ldots \ldots \ldots \ldots \ldots \ldots \ldots \ldots \ldots \ldots$

Alternate Concept fur the Central-Cell Blanket and Module .... 80 
Nuclear Auxiliary Systems $\ldots \ldots \ldots \ldots \ldots \ldots \ldots \ldots \ldots \ldots \ldots \ldots \ldots \ldots \ldots \ldots$

Cryoplant $\ldots \ldots \ldots \ldots \ldots \ldots \ldots \ldots \ldots \ldots \ldots \ldots \ldots \ldots \ldots \ldots \ldots \ldots \ldots \ldots \ldots, 8 \ldots$

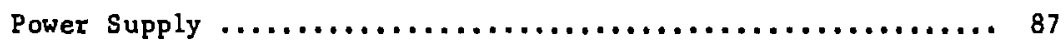

Tritium system $\ldots \ldots \ldots \ldots \ldots \ldots \ldots \ldots \ldots \ldots \ldots \ldots \ldots \ldots \ldots \ldots \ldots$

Thermal Power Conversion $\ldots \ldots \ldots \ldots \ldots \ldots \ldots \ldots \ldots \ldots \ldots \ldots \ldots$

Controls and Instrumentation $\ldots \ldots \ldots \ldots \ldots \ldots \ldots \ldots \ldots \ldots \ldots$

Maintenance $\ldots \ldots \ldots \ldots \ldots \ldots \ldots \ldots \ldots \ldots \ldots \ldots \ldots \ldots \ldots \ldots \ldots \ldots$

Plant Facilities ................................ 96

site $\ldots \ldots \ldots \ldots \ldots \ldots \ldots \ldots \ldots \ldots \ldots \ldots \ldots \ldots \ldots \ldots \ldots \ldots \ldots \ldots \ldots \ldots \ldots$

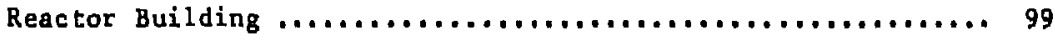

Ancillary structures $\ldots \ldots \ldots \ldots \ldots \ldots \ldots \ldots \ldots \ldots \ldots \ldots \ldots \ldots \ldots 1$

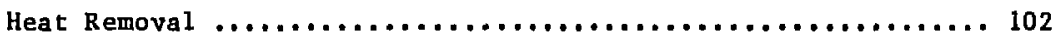

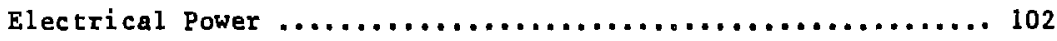

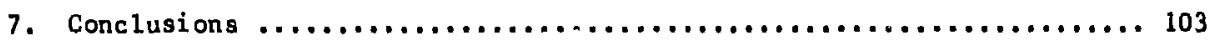

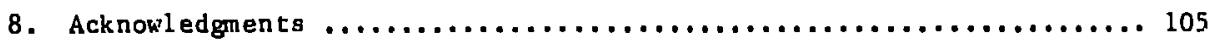

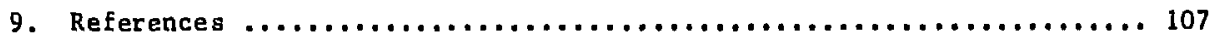


Fig. 1. Phased operation of TMNS. Initial D-T burn atudies

(a) are followed by test of the blanket module (b). The full blanket and power conversion apparatus are added $l$ ater (c).

Fig, 2. Diagram showing timing of TMNS project stages relative

to elements of the mirror program, as described in The National Mirror Fusion Program Plan. 6

Fig. 3. Magnet configuration and resulting profile of the on-axis intensity of the vacuum field. Points $M$ are the inner mirror peaks; points $M$ and $N$ define the yin-yang cell, and points $N$ and $O$ define the barrier cell. Also shown are limiting flux lines corresponding to a central-cell plasma radius of $0.83 \mathrm{~m}$.

Fig. 4. Schematic representation for reference-case parameters

of (a) the magnetic field $B$ and (b) potential distributions $\phi$. Calculated values are shown in parentheses. Points (A) and (B) identify the peak potential and the center of the thermal barrier. Locations of ECRH injections ace also shown.

Fig. 5. Power balance for initial operation with no power conversion. All powers are in MW. Fusion power

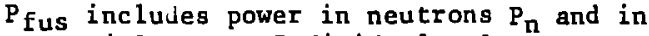
$\alpha$-particles $P_{\alpha}$. Individual values $\eta$ are overall conversion efficiencies, and $M$ is the neutron blanket multiplication factor.

Fig. 6. Power balance with full energy recovery and conversion. Symbols are defined in caption to Fig. 5.

Fig. 7. Typical parameter scans: (a) variation of $Q$ with $T_{i c}=T_{e c}$ for central-cell length $L_{c}=50 \mathrm{~m}$, neutron wall loading $=0.5 \mathrm{Mh} / \mathrm{m}^{2}$, and fusion power $P_{\text {fus }}=200 \mathrm{MW}$; and (b) variation of $Q$ and $P_{\text {fus }}$ with $\Gamma$ for $I_{c}=50 \mathrm{~m}$ and $T_{e c}=T_{i c}=50 \mathrm{keV}$.

Fig. 8. Marginal stability boundary for ballooning modes in TMNS. For this calculation, $\beta_{b}=0.3$.

Fig. 9. Variation in machine performance with $\beta_{c}$ for $\beta_{p}=0.7$ and $\beta_{b}=0.5$. Note rapid degradation with redu: ed $\beta_{c}$.

Fig. 10. Particle-flow chart for TMNS reference case. Pump beam (LEPB, MEPB, and HEPB) fractions and neutral-beam (NB) fractions entering the cenrral cell are net (fueling) values. Flows are totals that include both ends. 
Fig. 11. Gas-flow chart based on particle flows shown in

Fig. 10. Neutral-beam injectors supply 10-A gas

from each module.

Fig. 12. An injector module suitable for the 150-keV HEPB of

THNS. The ion source, emitting $12 \mathrm{~A}$ of $\mathrm{D}^{-}$in a 24by $100-\mathrm{cm}$ area, is compatible with the development goals of existing negative-ion programs. The neutralizer, bending magnet, beam stops, and gaspumping system are shown to scale.

Fig. 13. An injector module suitable for the purified $66-\mathrm{keV}$ MEPB of TMNS. Note the purification magnet between the $i$ on source and the neutralizer. The primary beam must be $\mathrm{D}^{+}$rather than $\mathrm{D}^{-}$For two reasons: because a relatively high beam density is required, and because the 10-year construction schedule does not allow time for major new developments.

Fig. 14. Elevation of one end of TMNS showing the following components: (a) central cel1; (b) transition coil and structure; (c) yin-yang coil and structure (d) thermal barrier; (e) barrier cell with barrier coil and structure; (f) a $D^{-}$HEPB (there will be six modules at each end); ( $g$ ) a $D^{+}$MEPB (there will be four modules at each end, top and bottom; and ( $h$ ) a $D^{+}$ LEPB (there will be three modules at each end). Also, shown are (i) the neutron blanket, ( $j$ ) radiation shields, and $(k)$ the plasma direct converter.

Fig. 15. The nuclear system of TMNS. Magnet identification numbers are shown in parentheses, e.g., yin-yang magnets (M1, M2). The ECRH injection points (A) and (B) are identified on Fig. 4.

Fig. 16. Neutral-beam trajectory into the yin-yang pair in the end cell. The insert shows the beam profile at the conductor. Note the beveling of the conductor pack to allow passage of the beams.

Fig. 17. Enlarged view of the end-cell region of the TMNS nuclcar system depicted in Fig. 15, showing plasma $f$ an and HEPB and barrier-cell beam lines.

Fig. 18. Enlarged view of the end-cell region of the TMNS nuclear system in Fig. 15 showing the location of the MEPB and LEPB lines.

Fig. 19. Computer drawing of the TMNS magnet configuration.

Fig. 20. Cross section at the mirror throat of the yin-yang magnets ( $M 1$ and $M 2$ in Fig. 15). 
Fig. 21. Detailed cross section of one of the neutral-beam

injectors in Fig. 16 (including the $80-\mathrm{kV}$ starter beams) and showing the beam array for injection into the yin-yang cell.

Fig. 22. External support structure for one of the magnets

in the yin-yang pair (magnet $M 1$ ).

Fig. 23. The intercoil support structure: (a) plan view, and (b) elevation.

Fig. 24. A cryopumping panel used as part of the continuous cryopumping aystem devised for IMNS.

Fig. 25. A degassing pump used for repumping gas driven off the cryopanels.

Fig. 26. Conceptual representation of the plasma direct converter

Fig. 27. Modular unit of the plasma direct converter.

Fig. 28. Cross section through a hlanket and shield module.

Each module is $2 \mathrm{~m}$ long. Tritium is bred in the blanket, which is composed of stainless-steel pods filled with granul... $\mathrm{Li}_{2} \mathrm{O}$. High-pressure helium cools the blanket and removes the tritium. The shield is water-cooled lead concrete.

Fig. 29. Alternate design for a blanket and shield module. Each of these modules is $9 \mathrm{~m}$ long. As explained in the text, this module might be less costly and easier to maintain than the design described in Ref. 3 and shown in Fig. 14.

Fig. 30. Plan view of possible arrangement of facilities for performing remote maintenance on the $9-\mathrm{m}-1$ ong $\mathrm{rlanket}$ and shield modules.

Fig. 31. Flow diagram showing the heat-removal and tritiumrecovery system for the 9-m-long blanket and shield module. The helism coolant is pressurized at 61 atm and has a velucity of about $50 \mathrm{~m} / \mathrm{s}$ at the $\mathrm{Li}_{2} \mathrm{O}$ cannisters. The lensity of the $\mathrm{Li}_{2} \mathrm{O}$ is $88 \%$.

Fig. 32. Cross section of a $\mathrm{Li}_{2} \mathrm{O}-\mathrm{filled}$ cannister and pressurized-He jacket within an 8-in.-diam steam tube. In and out pipes for the steam are not shown.

Fig. 33. Cross section of an 8-in.-diam steam tube containing seven $\mathrm{Li}_{2} \mathrm{O}-\mathrm{fi} 11 \mathrm{ed}, 8-\mathrm{in}_{-}-\mathrm{o.d.}$ canisters.

Fig. 34. Cross section of $1-m$-thick blanket assembly showing placement of steam-tube units. Larger tubes are 10-3/4 in. 0.d., smaller are 8 in. 0.d. 
Fig. 35. The TMNS tritium system. The diagram shows the various functions of the system and their interrelationships. Individual functions are described in detail in the next four illustrations.

Fig. 36. The fuel-cleanup system.

Fig. 37. The blanket-conlari, tritium-extraction system.

Fig. 38. The isoto,e-separation system. The cryogenic distillacion columns (the splitter and strippers) operate at 20 to $26 \mathrm{~K}, 101 \mathrm{kPA}$; the equilibrators operate at $300 \mathrm{~K}, 101 \mathrm{kPA}$.

Fig. 39. The effluent-processing oystem.

Fig. 40. Removal of the HEPB ion source from TMNS: (a) a shielded apparatus replaces the shield cap and (b) the ion source has been removed.

Fig. 41. Conceptual site plan for the TMNS facility. Heavy dashed lines show two magnetic field contours around the facility. 
Table 1. Cost comparison of TMNS with INTOR. 6

Table 2. TMNS performance guidelines. 12

Table 3. Physics parameters. 14

$\begin{array}{lr}\text { Table 4. TMNS plasma power balance. } & 18\end{array}$

Table 5. TMNS costa (effective November 6, 1980).a 23

Table 6. Nuclear system cost breakdown. $\quad 24$

Table 7. TMNS neutral-beam specifications. 40

Table 8. Maximum values of fringing magnetic field at the 43 locations of injectors and neutralizers.

Table 9. ECRH requirements for the reference case of TMNS. 48 [Points (A) and (B) may be found on Fig. 4.]

Table 10. TMNS work breakdown structure (WBS). 51

Table 11. Magnet system physical parameters (52 coils total). 59

Table 12. Magnet system operating currents. 60

Table 13. Lobe-spreading forces on C-coils. 64

Table 14. Weights of coils and structure. 65

Table 15. Intercoil forces. 66

Table 16. Comparison between MFTF-B and TMNS magnets. 68

Table 17. Neutral-beam sources (for one end of machine only). 71

Table 18. TMNS nuclear auxiliary system (level 2 WBS). 86

Table 19. Categories of maintenance. 95

Table 20. TMNS plant facilities (level 3 WBS). 98 


\title{
Preliminary Design of a \\ Tandem-Mirror-Next-Step Facility
}

\author{
ABSTRACT
}

The Tandem-Mirror-Next-Step (TMNS) facility is designed to demonstrate the engineering fensibility of a tandem-mirror reactor. The facility is based on a deuterium-tritıum (D-T) burning, tandem-mirror device with a fusion power output of $245 \mathrm{MW}$. The fusion power density in the central cell is $2.1 \mathrm{MW} / \mathrm{m}^{3}$, with a regultant neutron wall loading of $0.5 \mathrm{~mW} / \mathrm{m}^{2}$. Overall machine length is $116 \mathrm{~m}$, and the effective central-cell length is $50.9 \mathrm{~m}$. The magnet system includes end celis with yin-yang magnets to provide magnetohydrodynamic (MHD) stability and thermal-barrier cells to help achieve a plasma $Q$ of 4.7 (where $Q=$ fusion power/injected power). Neutral beams at energies up to $200 \mathrm{keV}$ are used for plasma heating, fueling, and barrier pumping. Electron cyclotron resonant heating at 50 and $100 \mathrm{GHz}$ is used to control the electron temperature in the barriers. Based on the resulting engineering design, the overall cost of the facility is estimated to be just under \$l billion. Unresolved physics issues include ce:cral-cell B-limits against MHD ballooning modes (the assumed reference value of $B$ exceeds the current theory-derived limit), and the removal of thermalized a-particles from the plasma. 
$-2-$ 


\section{INTRODUCTION}

We have undertaken a study to develop the features of a "next:-step" device in nur tandem-mirror program--a step beyond the Mirror Fusion lest Facility (MFTF-B) tandem experiment ${ }^{l, 2}$ on the path to a full-scale tandemmirror fusion reactor (TMR). ${ }^{3}$ This report presents the results of our first attempt to define the Tandem-Mirror-Next-Step facility (hereafter TMNS), with the study pursued in sufficient detail to evaluate the cost and technical difficulty of proceeding with such a project. We have taken TMNS to be a steady-state, deuterium-tritium (D-T) burning tandem mirror, have selected a set of physics parameters to match the performance guidelines, and have executed an engineering layout of the machine and facility.

As a basis for our design, we have examined a straight-forward extension of the MFTF-B to a larger tandem device. Although we anticipate that study efforts now underway at Lawrence Livermore National Laboratory (LLNL) will eventually lead to higher-performance, axisymmetric end cells, adoption of the MFTF-B end-cell design for TMNS in the present study allows us to define a devise that includes the major elements somon to any TMNS facility: centralcell nuclear system, neucral-beam heating, thermal-barrier pumping, electron cyclotron resonant heating (ECRH) components, direct converter, cryogenic vacuum system, tritium-handling, and zemote maintenance. The study thus provides an expeditious way of evaluating some of the component engineering designs, technology requirements, and costs of a 'mall D-T burning tandem mirror. We expect that substitution of improved end-cell magnets in future design iterations will result in relatively minor changes to the overall facility layout.

Our tandem design employs the thermal-barrier concept to enhance the efficiency of generating confining potentials in the end cells. This concept will be tested first in the reconfigured Tandem Mirror Experiment (TMX Upgrade) ${ }^{4}$; later the scaling will be examined in MFTF-B. We extrapolated to the TMNS parameter range using the physics model developed for MFTF-B. Given this basis, our study indicates that a tandem device with end-plugging potentials sufficient to ignite, or nearly ignite, the central cell could be constructed in the 1980's using near-term technology. The key items of technology development required are $12-\mathrm{T} \mathrm{Nb}_{3} \mathrm{Sn}$ superconductor, 200-keV negative-ion-tased neutral beams, and $100-\mathrm{GHz}$ gyrotrons. 
Construction and operation of such a facility at the reference parameter level would constitute a demonstration of "engineering feasibility" for the tandem mirror reactor since, in principle, it would then only be necessary to lengthen the central cell (which is a uniform solenoid) to achieve any desired fusion power output. However, evaluation of our preliminary design shows that it falls short of the desired performance level in several important respects.

First, the performance of tandem mirrors at higli $\beta$ ( $\beta$ is the ratio of plasma pressure to magnetic field pressure) is predicted to be limited by the onset of magnetohydrodynamic (MHD) ballouning modes. Applying current: theoretical methods to our magnetic field and density profiles, we calculate a limit for stability against these ballooning modes at $\beta_{c}=\beta_{b} \approx 0.3$, where $\beta_{c}$ and $\beta_{b}$ refer to the certral cell and the barrier cell, respectively. For our reference case, however, we assune $\beta_{c}=\beta_{b}=0.5$. The implication is that the device performance will be limited by the ballooning modes to a fusion power and a neutron wall loading of about $1 / 3$ the reference values, since reaction rates in the central cell go as $\beta_{c}^{2}$. Impiovement of the predicted $\beta-1$ imit may be realized when the effects of finite ion gyroradius, known to be stabilizing, are included in the analysis. Nevertheless, the susceptibility of the tandem mirror to these ballooning modes strongly motivates our study for development of improved end-cell designs for both TMNS and TMR, which is subject to similar constraints.

A second short-coming of the present design is that it does not establish a method for removing thermalized fusion $\alpha$-particles--a necessity Eor steadystate operation. Other studies have suggested that $\alpha$-particles, after they have deposited most of their energy in the reacting plasma, may undergo a resonant radial diffusion in the transition fields between the quadrupole end-cell magnets and the solenoidal central cell. This selective loss process is not yet verified in detail. Neither could we find a way to implement a selective removal of $\alpha$-particles by charge exchange with neutral "pump" beams in the barrier cell, as suggested earlier for the TMR. The required pump-beam access was not possible in our gemetry. However, this latter method of $\alpha$-particle removal may well be feasible in a cifferent end-cell ccnfiguration, and has already been shown to be compatible with the cusp version of an axisyrmetric TMR end cell. 
Finally, as part of our design evaluation, we have carried out a preliminary cost estimate for the TMNS facility, arriving at a total approaching $\$ 1$ billion.* This estimate is perhaps best put in perspective by comparing it with the preliminary cost estimate for the reference (U.S.) INTOR design. ${ }^{5}$ Table 1 makes this comparison by including an elongated version of TMNS for which we estimated costs by simply using the estimated $\$ 3.2$ million/m centralcell cost (including building, etc.) to extrapolate the reference cost estimates. Although it is evident that our cost is not grossly out of line, it is certainly higher than we would like. Not unexpectedly, a large part of the cost for TMNS is in the end cellg--about $\$ 305$ million per end cell--mainly due to the high-field $\mathrm{Nb}_{3} \mathrm{Sn}$ yin-yang magnets. This further motivates our ongoing effort to identify and develop lower-cost, axisymmetric end cells.

Comparison of TMNS costs with those for a reactor is difficult because one can anticipate downstream economies as advanced technologies mature-$\mathrm{Nb}_{3} \mathrm{Sn}$ superconductor, microwave heating equipment, etc. are certain to decrease in unit price. In projecting TMNS to a TMR however, it should be noted that the size and cost scaling for the end-cell magnets is not great. Although the plasma diameter may roughly double for a reactor, this only increases the magnet diameter by 10 to $15 \%$ because of the large and relatively unchanged shielding thickness. Since the magnetic field strength of TMNS already equals that expected for TMR, scaling costs as $\propto B^{2} r^{2}$ would indicate an end-cell magnet only 20 to $30 \%$ more expensive for TMNS than for a reactor.

In view of the two technical difficulties described above, and in anticipation of realizing a significant cost reduction, we have decided not to extend the present study to the next level of engineering design but rather to concentrate an equivalent effort on the development of improved end cells. With such a development in hand, our study would provide the vasis for an expeditious design of an improved Tr.ss facility--one that meets all physics and engineering criteria, at a favorable projected cost.

*American system: 1 billion $=10^{9}$. 
Table 1. Cost comparison of TMNS with INTOR.

\begin{tabular}{|c|c|c|c|}
\hline & U.S. INTOR $^{a}$ & $\begin{array}{c}\text { TMNS } \\
\text { (reference design) }\end{array}$ & $\begin{array}{c}\text { TMNS } \\
(\text { elongated })^{b} \\
\end{array}$ \\
\hline Fusion power $\left(\mathrm{MW}_{\mathrm{th}}\right)$ & 720 & 245 & 700 \\
\hline Wall lnading $\left(M W / m^{2}\right)$ & 1.6 & 0.5 & 0.5 \\
\hline Length $(m)$ & 31 (circumference) & 50 & 150 \\
\hline Plasma radius (m) & 1.4 & 0.8 & 0.8 \\
\hline Injected power & $75^{c}$ & 50 & 50 \\
\hline$Q^{d}$ & $-c$ & 5 & 14 \\
\hline Cost (billions of $\$$ ) & $1.5^{\mathrm{e}}$ & 1.0 & 1.3 \\
\hline
\end{tabular}

aref. 5 .

bsee text.

CFor INTOR, ignition is assumed. Startup power is supplied in a 15-s pulse. To drive current in steady-state, similar $\mathrm{CW}$ power is required, yielding an equivalent $Q \approx 10$.

$\mathrm{d}_{\mathrm{Q}} \equiv$ fusion power/injected power.

epreliminary estimate; includes some contingency. 


\section{PERFORMANCE GUIDELINES AND BASIS FOR DESIGN}

Our basic objective in selecting a IMNS performance specification is to take a significant step beyand MFTF-B toward a power-producing TMR. The overall strategy for fusion power development is naturally to minimize the time, effort, and cost to reach comercial application. Large step aizes in a sequence of development machines imply large step costs and high risk, but perhaps shortened overall pach. The size of the TMNS step is clearly a matter for judgment, depending not only on enticipated physics and technological capability at a given moment, but also on the number and magnitude of additional steps to be taken before commercialization.

A further discussion of the development plan for mirrors, given in The National Mirror Fusion Program Plan (NMFPP), ${ }^{6}$ includes the relation of the mirror program to the national fusion plan. We have attempted to keep the present guidelines consistent with the NMFPP; however, beyond that we have not explicitly attempted to detail the steps between l'MNs and a demonstration plant. The results of the present study, presented in terms of an estimated facility cost and an evaluation of technical difficulty, can be used to calibrate our ambition on successive TMNS design iterations, and perhaps help to define the ensuing TMR development sequence.

We assume that the basic physics for TMNS will have been demonstrated in TMX Upgrade and possibly in other near-term tandem experiments and will therefore provide a foundation for a firm TMNS conceptual design. The MFTF-B experiment, scheduled for operation in about 1985, will scale the physics to a regime approaching energy breakeven $(Q \approx 1)$, thereby demonstrating "scientific feasibility" for the tandem approach to fusion power. As a next step, TMNS is designed primarily to demonstrate the engineering feasibility of a TMR. By this, we mean that the machine will demonstrate all features of a tandem-mirror power reator, but not necessarily at full levels of fusion power density and wall loading. In order to make our feasibility demonstration convincing, however, and to ch:ain experience relevant to construction and operation of a power-producing reactor, we have selected these parameters to be within a factor of about 5 of the values specified for a full-scale iMR. ${ }^{3}$ 
Other featues to be demonstrated are implied in the steady-state operation of a D-T burning tandem-mirror device. These include the following: recycling; Safe tritium $\left(\mathrm{T}_{2}\right)$ handling system for fueling, pumping, and

- Remote maintenance equipment for servicing and repair after activation;

- Impurity and helium-ash removal system;

- $\mathrm{T}_{2}$ breeding method (blanket development); and

- Nirect energy conversion of end-loss flux.

Reactor-grade end cells will be necessary to provide magnetic and electric fields of adequate intensity to confine the high-pressure reacting plasma in the central cell. With good enough confinement, the central-cell plasma will reach ignition. In this event, the overall $Q$ ( $Q \equiv$ fusion power/ injected power) of a tandem mirror varies linearly wich central-cell length, since fusion power scales directly with this dimension and end-cell (injected) power is fixed. We will aim for this condition so that a successful TMNS could in principle be scaled to a power-producing configuration by simply lengthening the central cell. (We can of course anticipate that an actual demonstration plant would involve size scaling as well as improvements in design over TMNS that would move toward a regime of economic feasibility.)

Examination of possible TMNS parameters showed us that, subject to our physics assumptions, a $Q$ value in the range of 4 to 5 could be achieved with a central-cell length only modestly longer than MFTF-B (50 $\mathrm{m}$ versus $32 \mathrm{~m}$ ). Given adequate component efficiencies, such a $Q$ value allows the possibility of closing the power loop, and perhaps generating a few megawatts surplus, by adding the recessary power conversion equipment. Somewhat arbitrarily, we have chosen this specification $(Q \approx 5)$ for our reference case, a value certainly within a factor of 5 of that needed for a TMR. The cost implications of a longer or shorter central cell (with correspondingly higher or lower Q) will emerge from our study.

Although the central cell may be ignited, requirements for power to the end cells make tandem mirrors driven devices. Input power to operate the facility therefore becomes a design consideration, for initial capital cost, for operating cost and, since the initial machine will not include power conversion equipment, for the ability of the local utility to supply the needed power. Considering power-supply efficiencies and plasma $Q$ values, we have 
chosen a fusion power output for TMNS in the range of 200 to $300 \mathrm{MW}$ (thermal). We find that this leads to a power input requirement that is reasonable on all three counts listed above.

Having neither a firm target cost for the TMS project nor a priori knowledge of the resulting cost estimate, we did not allow cost considerations to dominate the specifications, However, several factors were specified at least partly on the basis of limiting the cost:

A wall loading flux less than that of TMR was selected as described above.

- Central-cell length is kept short, consistent with $Q \approx 5$.

- No specification for high machine availability is made, such as would be needed to develop a neutron fluence for materials testing. We assume that this is the function of an Engineering Test Facility (ETF), and that incorporation of a similar requirement for TMNS would be expensive. (Neither is the present TMNS design optimum for such a mission.)

- Our design allows for a phased approach to machine operation at full capability, thus minimizing initial investment. Initial D-T operation would be without $T_{2}$ breeding or fusion-power recovery, requiring only a (relatively) cold first wall. Blanket sections for testing breeding and thermal recovery in the modular central cell could be added later, possibly drawing on ETF experience simplified to take advantage of mirror geometry. Finally, a full $\mathrm{T}_{2}$ breeding blanket and power-conversion equipment could be added. Such a phased operation is shown schematically in Fig. 1.

The technology to be utilized for TMNS should be reactor relevant and must be available to match the proposed construction schedule. The schedule is selected to mesh with the on-going tandem-mirror confinement studies, as described in The National Mirror Fusion Program Plan ${ }^{6}$ and shown in Fig. 2. (Because the "project definition" phase cannot be considered complete at this time, the start of "pre-conceptual design" is delayed beyond that shown.) The plan sets a start for capital funding of IMNS in Fiscal Year 1985, with initial operation of the facility in January 1991. The schedule will, of course, vary with the pace of the national fusion program; however, for the purpose of selecting technological limits, this timescale definition is adequately precise. Taking cognizance of development programs already in place in the Department of Energy Office of Fusion Energy (DOE/OFE), and 
(a)

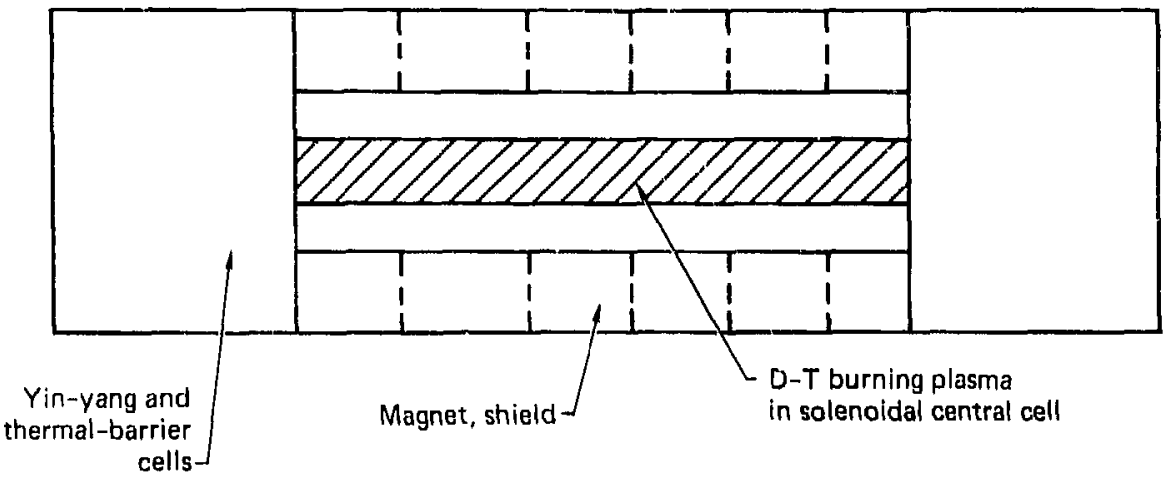

(b)
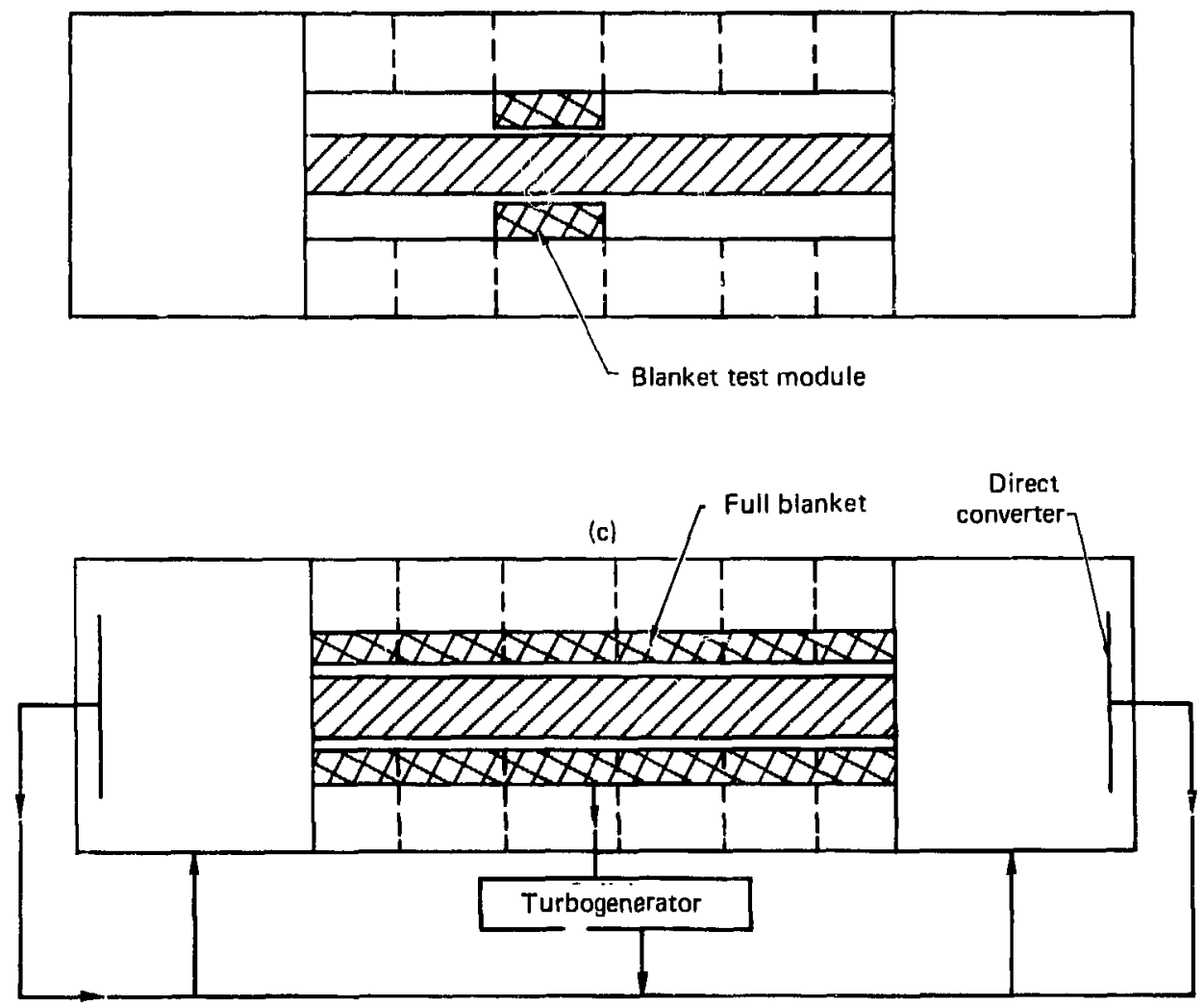

Fig. 1. Phased speration of TMVS. Initial D-T burn studies (a) are followed by test of the blanket module (b). The full blanket and power conversion apparatus are added later (c). 


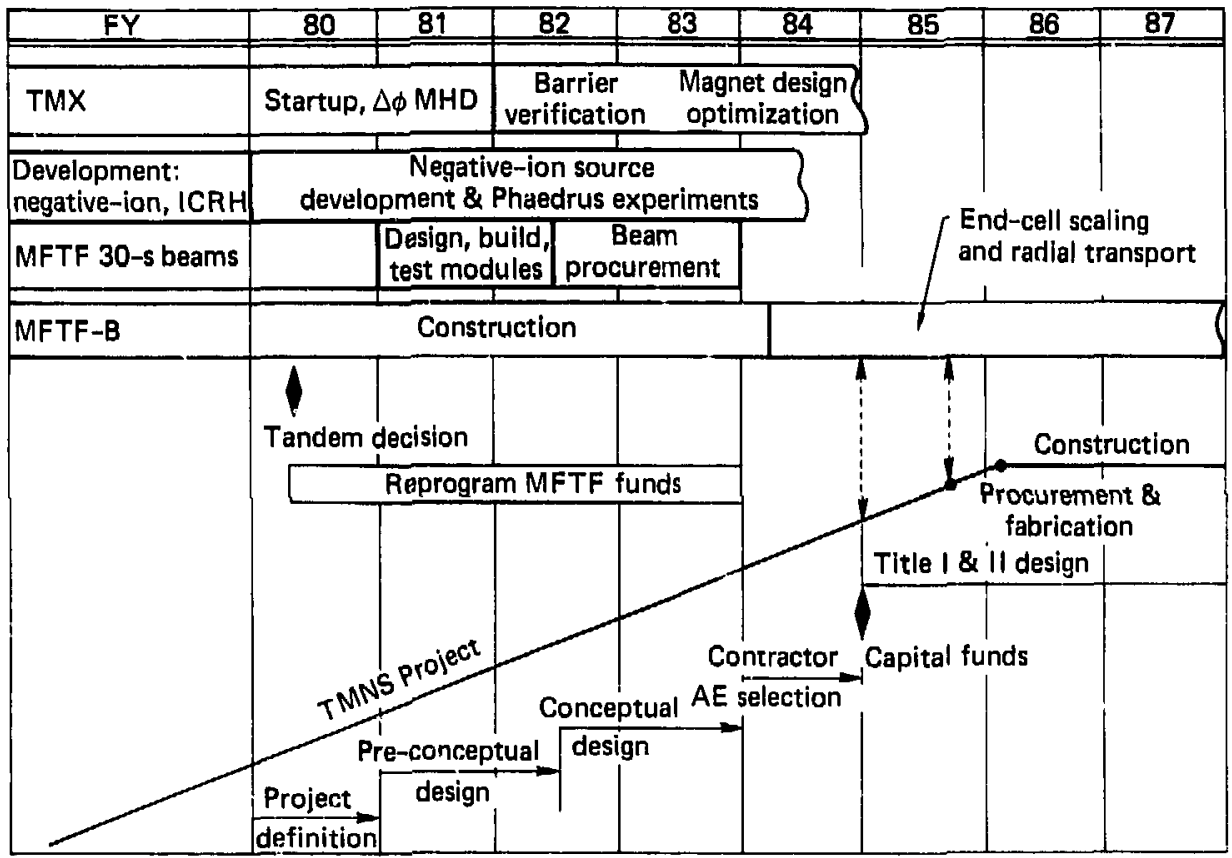

Fig. 2. Diagram showing timiag of TMNS project stages relative to elements of the mirror program, as described in The National Mirror Fusion Program Plan. 6

judging likely progress on the TMNS timescale, we have selected the following design limits for the key technologies:

- 12-T Nb${ }_{3} \mathrm{Sn}$ superconductor,

- 200-keV, negative-ion-based, steady-state neutral beams, and

- 100-GHz, 1-MW continuous wave (cw) gyrotron microwave generators.

All these technologies are reactor relevant in that they either meet or can be credibly extrapolated to meet our present concept of TMR requirements. ${ }^{3}$ Design values used for other technologies (vacuum pumping, direct converter power flux, etc.) were also selected on the basis of what we believe is demonstrable during the $1980 \mathrm{~s}$. We have not included ion heating by radiofrequency ( $r f$ ) power in the present study, although we note that this technique, under development at the University of Wisconsin for mirror application, ${ }^{6}$ could replace part of the neutral-beam heating power. other development and technology requirements for the present design are given in later sections. 
The performance guidelines for TMNS are summarized in Tehle 2, based on the rationale discussed above. As already implied, we can expect these guidelines to become firmer, clearer and less subjective on successive design iterations.

Table 2. TMNS performance guidelines.

\begin{tabular}{|c|c|}
\hline Reactor type & $\begin{array}{l}\text { Steady-state, } D-T \text { burning } \\
\text { tandem mirror }\end{array}$ \\
\hline Fusion power denaity & $\gtrsim 1 \mathrm{MW} / \mathrm{m}^{3}$ \\
\hline Wall loading & $20.4 \mathrm{MW} / \mathrm{m}^{2}$ \\
\hline Q & $\sim 5$ \\
\hline Fusion Power & 200 to $300 \mathrm{Mh}$ maximum \\
\hline Operation & $\begin{array}{l}\text { Phased, with blanket test and } \\
\text { power conversion as add-ons }\end{array}$ \\
\hline Reactor-relevant technology & $\begin{array}{l}\text { 12-T superconductor, } \\
200-\mathrm{keV} \text { neutral beams, } \\
100-\mathrm{GHz} \text { microwave power }\end{array}$ \\
\hline Others & $\begin{array}{l}\mathrm{T}_{2} \text { handling, ' }{ }_{2} \text { breeding } \\
\text { demonstration, remote maintenance } \\
\text { system, direct energy conversion }\end{array}$ \\
\hline
\end{tabular}




\section{OVERALL FACILITY DESCRIPTION}

PHYSICS AND ENGINEER ING PARAMETERS

To achieve the desired performance utilizing the relatively modest technology described in the previous section requires that the TMNS employ thermal barriers. ${ }^{7,8}$ A thermal barrier, consisting of a negative depression in the potential that thermally insulates end-cell electrons from those in the central cell, permits obtaining a high electron temperature in the end cell (and therefore a high confining potential) with reduced heating power. Electron-cyclotron resonant heating (ECRH) of electrons in the barrier region, using high-frequency microwave power, is used to optimize the electron temperature distritution. The net result is to drop the peak fields needed for a reactor from 18 to $20 \mathrm{~T}$ (for a tandem without barriers) to about $12 \mathrm{~T}$, and the maximum neutral-beam energy from over 1 MeV to a $f$ ew hundred keV. ${ }^{3,9}$ For TMNS, we have chosen an outside or "A-cell" type of barrier, similar to the geometry of MFTF-B ${ }^{2}$ and to one version of a quadrupole-stabilized TMR. ${ }^{3}$ The physics and engineering considerations based on this choice and leading to the present design are described in subsequent sections. Here, we present an overall description of the facility, the device performance parameters, and a summary of the cost estimate.

The magnet configuration and on-axis vacuum field intensity profile are shown in Fig. 3. Peak field intensities of $9 \mathrm{~T}$ on the machine axis permit a coil design with a maximum of $12 \mathrm{~T}$ at the conductor. All magrets are scaled to allow room for neutron shielding, and all magnets are superconducting and operate in steady state. The limiting flux lines shown correspond to a plasma radius in the central region of $r_{c}=0.83 \mathrm{~m}$ (see Table 3 ). The flux envelope is extended to the region of the end wall and direct converter.

The machine can be described in terms of four basic plasma regions. The central cell is the main reactor region, consisting of the long solenoid and transition coil regions between the inner mirror peaks (points $M$ in Fig. 3 ). In the ignited condition, this region is heated by reaction-product $\alpha$-particles. Both additional heating to support subignition burn and fueling are supplied by deuterium and tritium injected as neutral beams in the endcell and barrier regions. 
Table 3. Physica parameters.

\section{Parameter}

Value

Central cell

Vacuum magnetic field, $B_{c}(T)$

Density, $n_{c} 10^{19}\left(\mathrm{~m}^{-3}\right)$

9.9

Ion temperature, $T_{c}$ (keV)

30

Electron temperature, $\mathrm{T}_{\mathrm{ec}}(\mathrm{keV}) \quad 30$

Plasma radius, $r_{c}(m) \quad 0.83$

Wall radius, $r_{w}(m) \quad 1.20$

Length (mirror to mirror) (m) 61

Length, $L_{c}$ (effective) (m) 50.9

$\begin{array}{ll}B_{c} & 0.5\end{array}$

Average fusion power density $\left(\mathrm{MW} / \mathrm{m}^{3}\right) \quad 2.1$

Yin-yang end cell

$\begin{array}{ll}\text { Central vacuum field, } B_{0 p}(T) & 6 \\ \text { Peak mirror field, } B_{\mathrm{mp}}(\mathrm{T}) & 9 \\ \text { Density, } \mathrm{n}_{\mathrm{P}}\left(10^{20} \mathrm{~m}^{-3}\right) & 2.7 \\ \text { Injection energy }(\mathrm{keV}) & 150 \\ \text { Average ion energy (keV) } & 254 \\ \text { Plasma radius, } \mathrm{r}_{\mathrm{P}}(\mathrm{m}) & 0.56 \\ B_{\mathrm{P}} & 0.7\end{array}$

Thermal-barrier cell

Vacuum field at minimum, ${ }_{0 b}(T) \quad 1.8$

Peak field $B_{m b}(T)$

Passing ion density, $n_{c b}\left(10^{18} \mathrm{~m}^{-3}\right) \quad 2.2$

Total ion density, $n_{b}\left(10^{18} \mathrm{~m}^{-3}\right) \quad 8.8$

Injection energy (keV) 200

Electron energy at $B(\mathrm{keV}) \quad 590$

Electron temperature at A (keV) 77

$\begin{array}{ll}B_{b} & 0.5\end{array}$ 


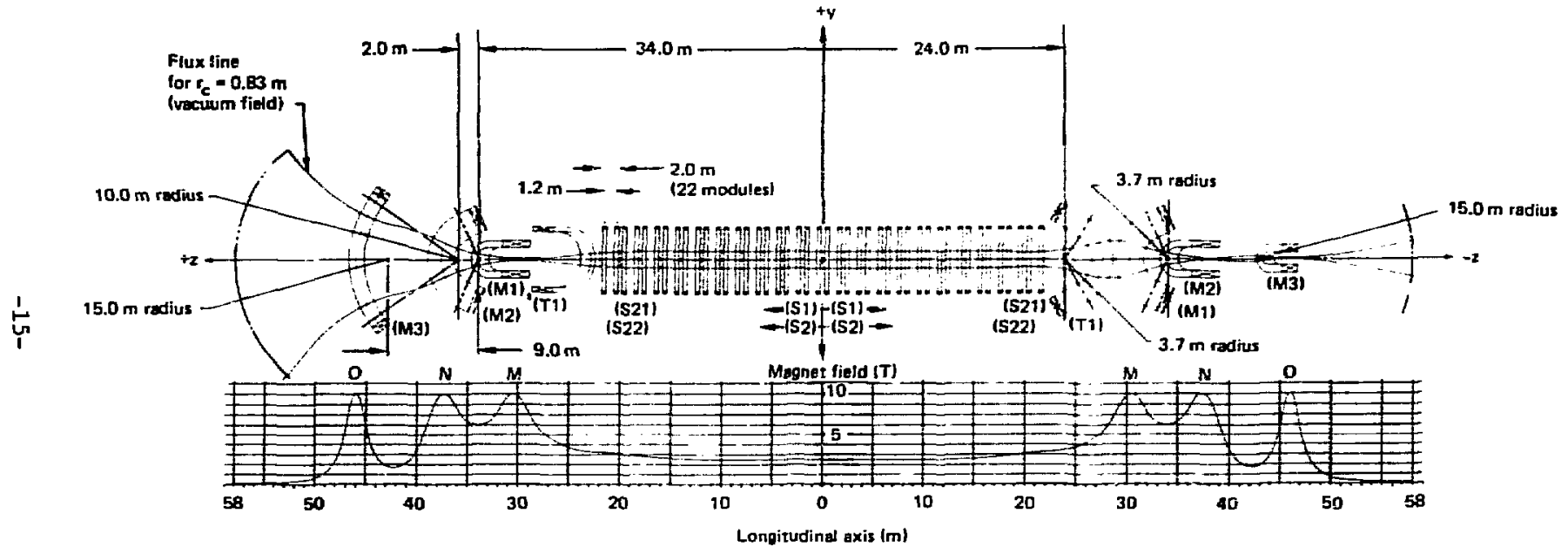

F.g. 3. Magnet configuration and resulting profile of the on-axis intensity of the vacuun field. Points $M$ are the inner mirror peaks; points $M$ and $N$ define the yin-yang cell, and points $N$ and $O$ define the barrier cell. Also shown are limiting flux lines corresponding to a centrar-cell plasma radius of $0.83 \mathrm{~m}$. 
The yin-yang erd-cell region (points $M$ to $N$, Fis. 3) provides the MHD anchor for the system; in addition, a small potential peak generated at the center of the end call helps to drop the density of central-cell particles passing to the outer or barrier region. The end-cell plasma is maintained by injection of $150-\mathrm{keV}$ neutral deuterium beams.

The barrier-cell region extends from point $N$ to the outer mirror peak at point 0 in Fig. 3 and functions to confine central-cell ions by generation of a positive potential peak. The barrier plasma is maintained by injection of 200-keV "sloshing" ions, 2 that is, ions injected so as to maintain a density at the center of the barrier that is lower than the density at the reflection points. It is also necessary to introduce ECRH at $50 \mathrm{GHz}$ to heat magnetically trapped electrons at the center of the barrier, and 100-GHz heating of electrons at the potential peak.

The fourth machine region, beyond point 0 , allows the plasma to expand to the direc: converter at the end wall, thereby reducing the power density of the emerging particle flux to a suitable level for converter operation. This region al so includes the main vacuum puming.

The main physics parameters for the three confinement regions are listed in Table 3. The key physics assumptions contained in this parameter set are that:

- Microstability of the end-cell and barrier regions will be achieved, and

- Plasma $\beta$ values, particularly $\beta_{c}$, can be reached before onset of MHD ballooning modes.

The first of these assumptions appears to have a good basis in theory; since the tandem configuration with A-cell thermal barriers automatically provides a stabilizing warm plasma component in the two regions where it is needed. For the second assumption, as already discussed in the Introduction, theoretical estimates of B-limits for ballooning do not support our reference value of $\beta_{c}=0.5$. Nevertheless, we have proceeded using the reference value in order to define a device with the desired level of performance. Further discussion of these assumptions and additional plasma parameters are given in Sec. 4 under the heading Plasma Stability. 
The potential distribution for these parameters is shown schematically in Fig. 4, with the calculated point values as indicated. (Our nomenclature matches that of Ref. 2). The value of confining potential $\phi_{c}=82.5 \mathrm{kV}$ is adequate to bring the central-cell plasma close to ignition.
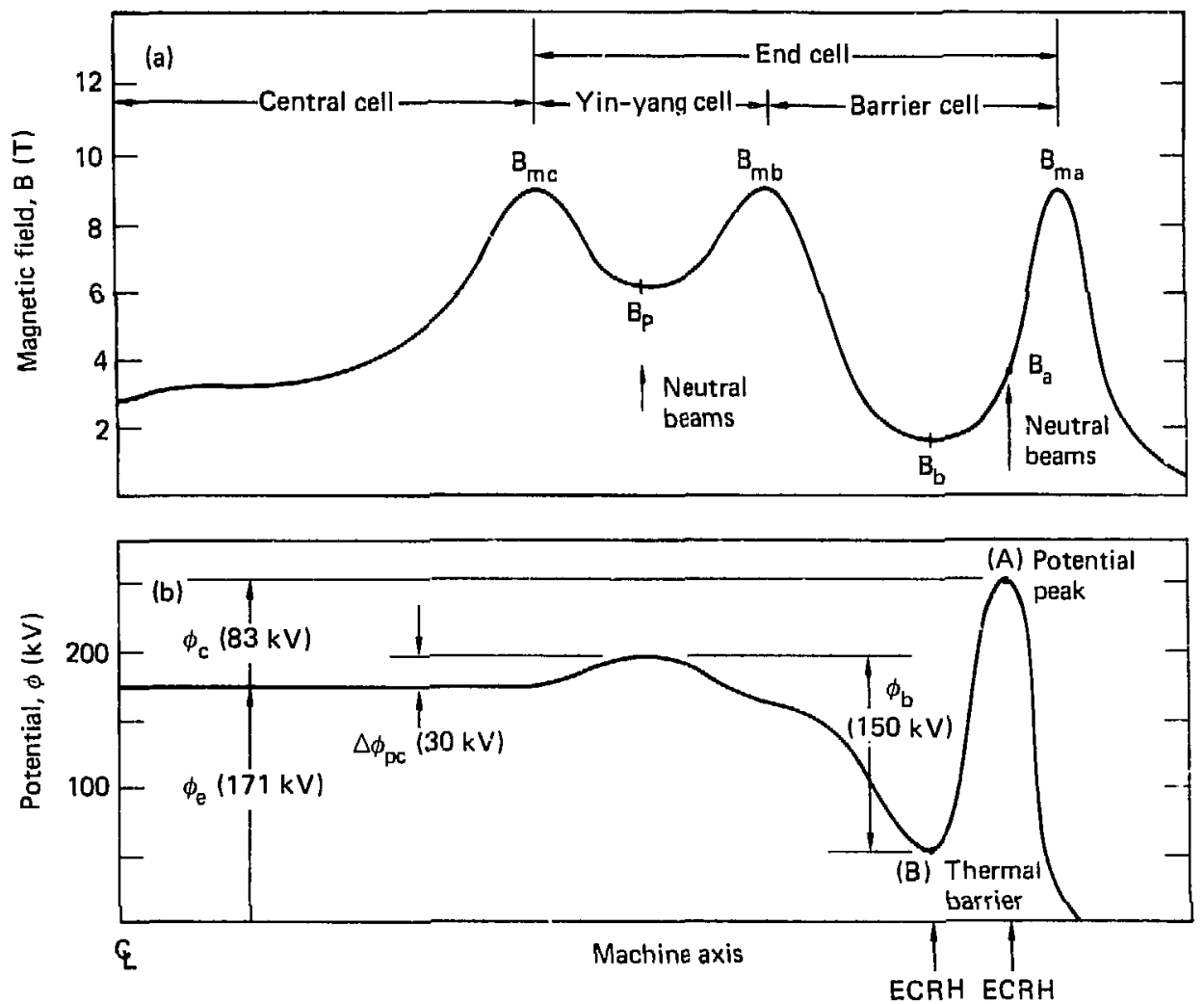

Fig. 4. Schematic representation for reference-case parameters of (a) the magnetic field $B$ and (b) potential distributions $\phi$. Calculated values are shown in parentheses. Points (A) and (B) identify the peak potential and the center of the thermal barrier. Locations of ECRH injections are also shown.

The calculated plasma power balance is listed in Table 4. The listed input powers are those absorbed by the plasma and do not account for efficiency of trapping or beam production. The fusion power output of $245 \mathrm{MW}$ includes an estimate of 13-MW fusion power in the end cells, whereas the wall loading value 
Table 4. TMNS plasma power balance.

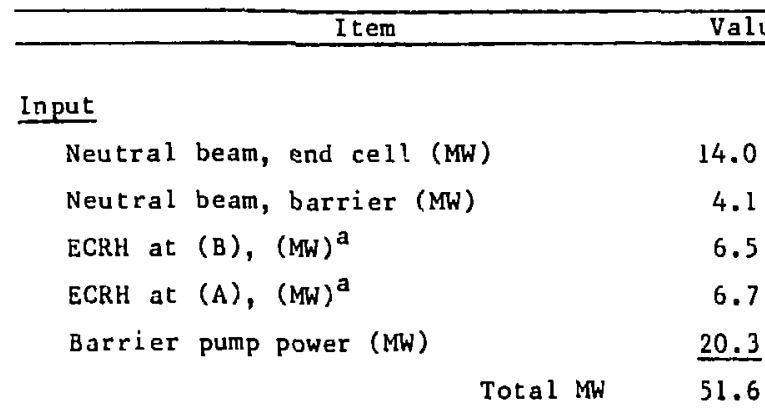

Output

Fusion power (MW)

245

Neutron wall loading, $\Gamma\left(\mathrm{MW} / \mathrm{m}^{2}\right) \quad 0.5$

Synchrotron radiation (barrier) (MW) 4.8

$\underline{Q}$

4.7

${ }^{\mathrm{a}}$ See Fig. 4 .

applies to the central ceil. (Wall loading estimates for the yin-yang end-cell regions are about $3 \mathrm{MW} / \mathrm{m}^{2}$, if half of the neutral beams into the yin-yang cell are $\mathrm{T}^{0}$, raising the possiblity of high-flux engineering tests in this area.)

Our model assumes that the density depression in the barrier region is maintained by charge-exchange pumping using neutral beams. The barrier pump power listed in Table 3 includes the beam power that goes irto removing the unwanted trapped particles and the beam that is ionized by the plasma. The inefficiencies of this method of pumping are particularly severe; in fact, the gross power requirements for the pump beams dominate the plant power balance. We have estimated the pump-beam requirements in some detail, as described in Sec. 5. The results are incorporated in our power flow diagrams for TMNS (see discussion immediately following). 
We have constructed two power-flow diagrams for TMNS. The first (Fig. 5) shows a base-case system without a requirement for power balance. The total input power is $162 \mathrm{MW}$, and the cooling load is $426 \mathrm{MW}$. The input (utility) power requirement seems reasonably modest (compare the 250-MVA, 10\% duty cycle substation for MFTF-B) and would incur an operating cost of about $\$ 7$ million per annum (at $\$ 0.05$ per $\mathrm{kWh}, 10 \%$ duty factor). The subsystem performance parameters are those that should be available in the time scale of TMNS. To allow for breakeven tritium breeding, we have included a blanket with some neutron multiplication.

Clearly in this system the power needs are dominated by the three sets of thermal-barrier pump beams (high-energy, medium-energy, and low-energy pump beams--HEPB, MEPB, and LEPB respectively), making this a most important area for performance improvement or invention.

Our scenario for implementation of TMNS says that we would start with this basic configuration and then add the components required to go toward a power balance. All hardware would be utiıized in the upgrade; however, th. load on the cooling plant would be reduced.

The second power-flow diagram (Fig. 6) shows all proposed energyrecovery systems in place. We have added direct converters to the end tanks, provided a steam turbo-electric plant, and incorporated some erergy recovery to the beam, ECRH, and auxiliary systems.

The thermal recovery efficiency ( $35 \%$ ) was salected to be conservative by modern steam plant standards to account for the variety of heat sjurces in the system. The $50 \%$ direct converter efficiency jelection is easily supported by past experiments and calculations.

The energy recovery system serving the beams, ECRH, and auxiliary systems is not clearly defined. It will be a mixture of direct recovery and thermal bottoming. We have, therefore, selected a conservative efficiency of $30 \%$.

Adding these components to the TMNS system will reduce the load on the cooling plant to $256 \mathrm{MW}$ and result in a net positive power balance with about $8 \mathrm{MW}$ available to the grid. Full rating of the large electrical power switching yard and substation may not be needed in this configuration, depending on the startup scenario selected. 


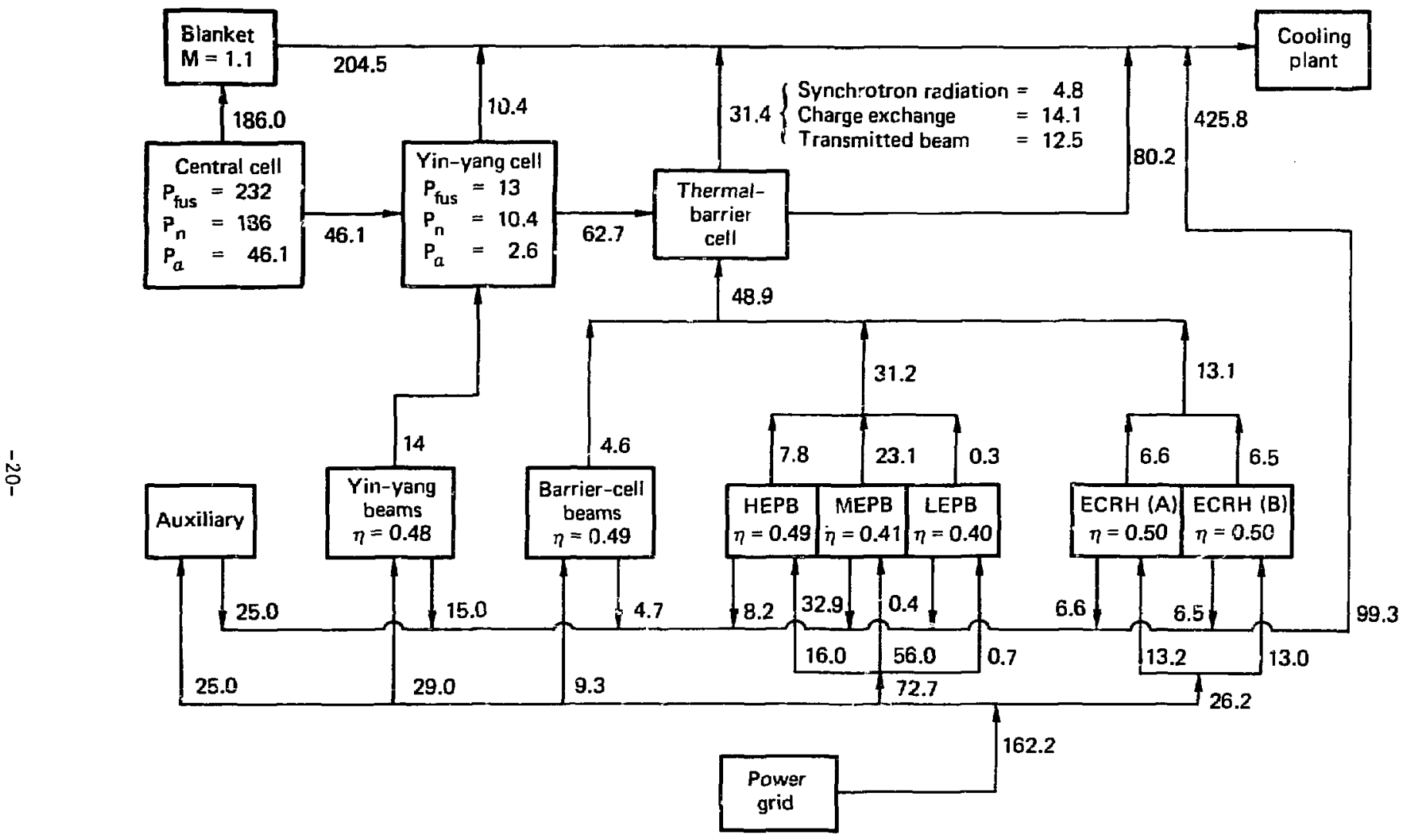

Fig. 5. Power balance for initial operation with no power conversion. All powers are in MW. Fusion power

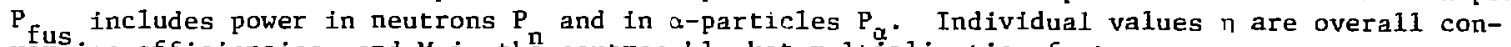
version efficiencies, and $M$ is the neutron blanket multiplication factor. 


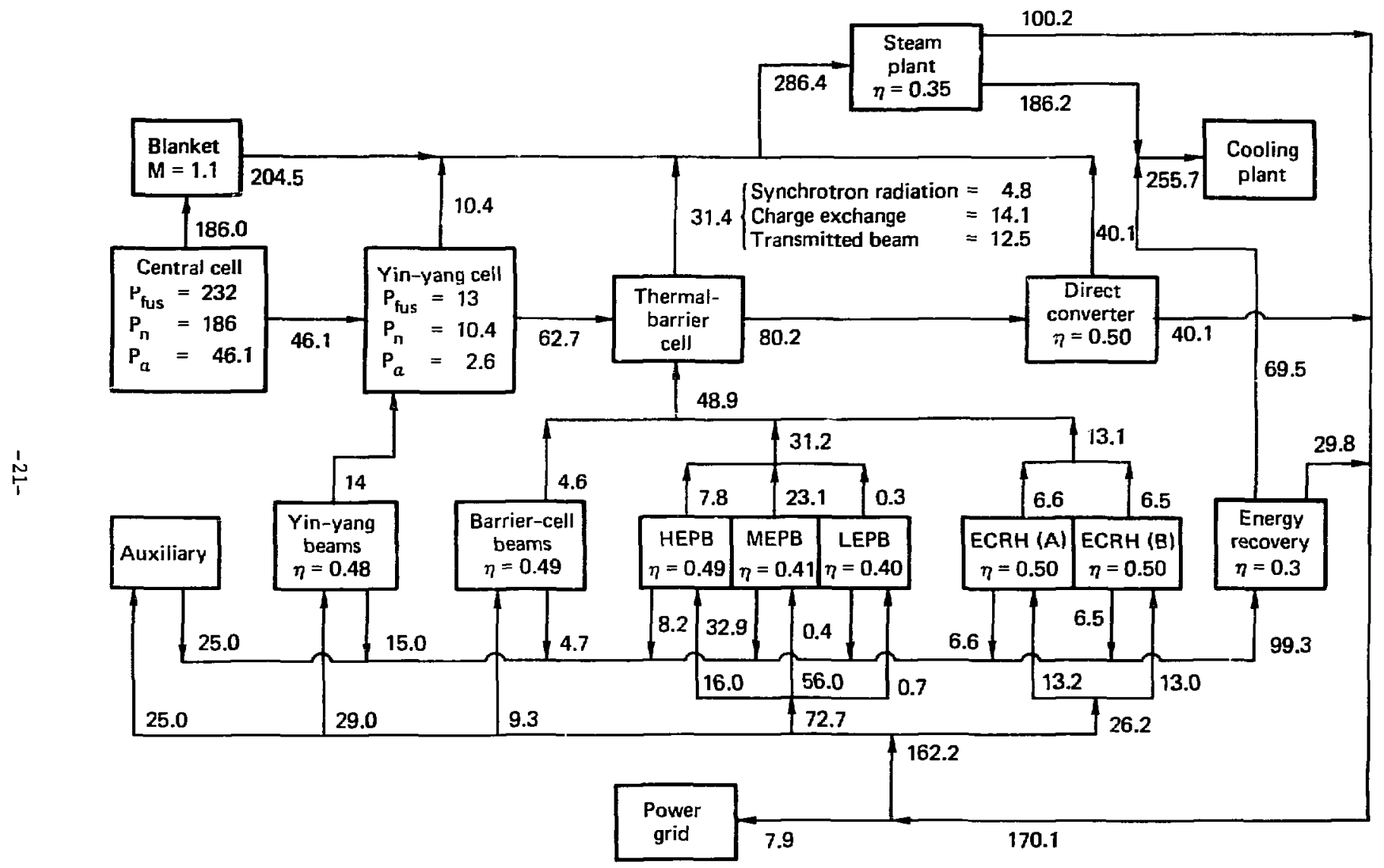

Fig. 6. Power balance with full energy recovery and conversion. Symbols are defined in caption to Fig. 5. 
The net result of the study shows that the power and cooling requirements fall within reasonable limits for TMNS and that, with the plasma parameters selected, a power balance could be achieved.

COST ESTIMATE

A sumary of cost estimates for TMNS is given in Table 5. These values, which generally represent construction and engineering costs, are rough estimates and show only magnitudes. Contingency, escalation, R\&D, and management costs are not included.

The total cost is dominated by those of the magnet system, which are $42 \%$ of the total. The magnet system costs were scaled from MFTF-B with an allowance for the added cost of $\mathrm{Nb}_{3} \mathrm{Sn}$ supercorductor, where appropriate. Unit costs were $\$ 0.035 / \mathrm{A} \cdot \mathrm{m}$ for $\mathrm{Nb}_{3} \mathrm{Sn}$ conductor bundles, $\$ 0.02 / \mathrm{A} \cdot \mathrm{m}$ for $\mathrm{Nb}-\mathrm{Ti}$ conductor bundles in the C-shaped coils, and $\$ 15 / \mathrm{kg}$ for structure. The solenoids were priced at $\$ 0.032 / A^{\prime} \mathrm{m}$, including structure, based on MFTF bids.

Vacuum vessels were estimated at $\$ 13 / \mathrm{kg}$, neutral beans at $\$ 1.50, \mathrm{~W}$ of neutral output (except for the MEPB where $\$ 2.15 / W$ was used to account ior beam purification) and ECRH at $\$ 5.00 / \mathrm{W}$ based on the PNL study ${ }^{10}$ and LLNL internal data.

Direct converters were priced at $\$ 4000 / \mathrm{m}^{2}+\$ 44 / \mathrm{kW}$ from the PNL study. For shielding, we used various unit costs: concrete at $\$ 600 / y d$, lead cement at $\$ 2 / \mathrm{kg}$, and stainless steel at $\$ 6 / \mathrm{kg}$.

The cryoplant was scaled from MFTF-B estimates based on the relative volume of conductor with a capacity allowance for neutral heating. The vacuum system was priced at $\$ 4000 / \mathrm{m}^{2}$ of cryopanel plus $\$ 3$ million for auxiliary equiprent (scaled from MFTF-B).

Power supply estimates are included under fueling and heating costs. The $\$ 35$ million for the tritium system and the $\$ 25$ million maintenance costs were taken from the ETF Interim Design Review data. 11 No estimate is included for power conversion since it is considered an add-on syatem. The controls and instrumentation costs are scaled from MFTF-B.

The source for the unit costs for Plant Facilities was the ETF Interim Design Review data. 11

We do not consider this to be a highly accurate cost estimate, but we do have confidence in the estimates for the wajor cost elements: the magnet system, fueling and heating, and shielding. 
Table 5. TMNS costs (effective November 6, 1980).a

Cost element

by work breakdown structure (WBS)

1.0 Nuclear system

.1 Magnets

.2 Vessels

.3 Fueling and heating

.4 Vacuum pumping

.5 Direct converters

.6 Shielding and blanket

2.0 Nuclear auxiliary systems

.l Cryoplant and external vacuum pumping

.2 Power supply (Included in 1.1 and 1.3 )

.3 Tritium

.4 Power conversion (not in reference case)

.5 Controls and instrumentation

.6 Maintenance

3.0 Plant Facilities

.1 Site

.2 Reactor building

.3 Ancillary otruetures

.4 Heat rejection

.5 Electrical power
Estimated cost (in thousands of $\$$ )

750,079

422,563

34,991

156,000

4,000

7,784

124,741

134,076

64,420

36,000

8,656

25,000

113,480

2,500

99,200

4,080

5,700

2,000

Grand tota1:

997,635

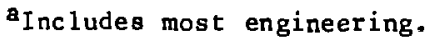


We have also broken down the cost of the TMNS nuclear core according to central cell (solenoid section only) and end cells, including transition, yinyang, and barrier-cell magnets, together with the associated heating systems. The listing in Table 6 totals to match the nuclear system cost, Table 5. The large end-cell cost provides an opportunity for saving primarily through improved (axisymetric) magnet systems, as noted in stie Introduction.

Table 6. Nuclear system cost breakdown.

\begin{tabular}{lr}
\hline & $\begin{array}{r}\text { Estima } \\
\text { (in thous }\end{array}$ \\
\hline Central cell & \\
Magnets & 57,544 \\
Vessel & 1,325 \\
Shield and blanket & 53,391
\end{tabular}

End celis

Magnets

Vessel

Fueling and heating

Shield and blanket

End regions

Vacuum pumping

Direct convertors

Vessel

Shield
112,260

$609,0 ' j 7$

365,019

30,004

156,000

58,034

28,762

4,000

7,784

3,662

13,316

Total:

750,079

The central-cell cost was further combined with the estimatrs for associated plant facilities to give an incremental cost for the central-cell of $\$ 3.2$ milition per meter of length, quoted earliar and used in the Table $i$ comparison with INTOR costs. A substantial part of this cost comes from the need for a fairly elaborate shield, really a nonbreeding blanket. (Later 
studies that include a $\mathrm{T}_{2}$ blanket design may show that it is cost-effective to proceed from the start with a breeding blanket.

By reducing the effective central-cell length from $50.9 \mathrm{~m}$ to say $25 \mathrm{~m}$, we would save $\$ 80$ million on the overall facility cost, would drop the plasma $Q$ from about 5 to about 2.5, and would eliminate any possibility of closing the power loop. On the other hand, lengthening the central cell, at the same incremental cost per meter, would increase the net electrical output that could be realized. Central-cell length really remaing an option until final design. 
$-26-$ 


\section{PHYSICS CONSIDERATIONS FOR TMNS PARAMETER SELECTION}

\section{PARAMETER SCANS}

The choice of an A-cell thermal-barrier configuration for TMNS enabled us to use for our parameter scans a computer code based on calculations for the plasma in the MFTF-B tandem ronfiguration. This code calculates equilibrium paraneters (no time dependence) by scaling from a base solution according to the model equations for $M F T F-B^{2}$; we refer the reader to Ref. 2 for a further discussion of the physics model for the A-cell thermal barrier.

The quantities input to the code calculation were:

- Magnetic fiela intensities,

- Neutral-beam energies,

- Central-cell ion and electron temperatures,

- Plasma B-values,

- Fusion power, and

- Wall loading.

Peak mirror field intensities were held constant at $9 T$, based on earlier work indicating that a coil efficiency of $75 \%$ could be achieved in a practical yiu-yang magnet design. The resulting maximum field at the conductor of $12 \mathrm{~T}$ matches our selected trinlogical limit. Mirror ratios for tye end and barrier cells were fixed at 1.5 and 5 , respectively. The $1.8 \mathrm{~T}$ ininimum field in the barrier matches a resonant frequency of $50 \mathrm{GHz}$ for ECRH. The central-cell field was varied in the calculations from 2.5 to $4 \mathrm{~T}$.

Neutral-beam energies were fixed at $150 \mathrm{keV}$ in the end cell and $200 \mathrm{keV}$ in Lne barrier; these are compatible with out technological limit at $200 \mathrm{keV}$. Beams were assumed to be deuterium, single energy. For efficiency, this implies a negative-ion-based neutral-beam source.

The central-cell ion and electron temperatures were kept equal, $T_{e c}=T_{i c}$, but were varied over the range 10 to $40 \mathrm{keV}$. At given central-cell $\beta_{c}$, this corresponds to the temperature range for the fusion power density $\left(\propto n^{2}<\sigma \gamma_{D T}\right)$, which would be optimized in combination with other machine parameters. 
The end-cell $B_{p}$ was fixed at 0.7 ; barrier $B_{b}$ was set at 0.5 ; the central-cell $B_{c}$ was varied from 0.3 to 0.5 . Further discussion of these choices in relation to MHD stability is given in a later section.

We varied the value of fusion power $P_{f u s}$ over a range from 100 to $500 \mathrm{MW}$ and neutron wall loading $\Gamma$ from 0.5 to $2 \mathrm{MW} / \mathrm{m}^{2}$, blanketing the range of interest corresponding to the performance guidelines in Table 2.

We also fixed several potential ratios used in the code. These were [refer co Fig, $4(\mathrm{~b})]_{\phi_{b}} / \mathrm{T}_{e c}=5, \phi_{c} / \mathrm{T}_{\mathrm{ec}}=2.75$, and $\phi_{\mathrm{e}} / \mathrm{T}_{\mathrm{ec}}=5.7$.

The code output gave

- Plasma radii $r_{c}$ and $r_{p}$,

- Central-cell length, $\mathrm{L}_{c^{\prime}}$

- Densities $n_{c}, n_{p}, n_{b}$,

- Various potentials,

- Average ion energy, yin-yang cell,

- Confinement parameter for the yin-yang cell (nt) ${ }^{\prime}$ '

- Neutral-beam, ECRH, and barrier-pump powers,

- Synchrotron radiation power, and

- Q.

Figures $7(a)$ and (b) illustrate the parameter scans used to arrive at our reference set of parameters. The value of $Q$ is seen to be insensitive to $T_{\text {ec }}$ between 30 and $40 \mathrm{keV}$. We chose $T_{\text {ec }}=30 \mathrm{keV}$ to help reduce the power requirements for the pump beams since the barrier potential is tied to $T_{\text {ec }}$ and determines the energy required of the pump bearus.
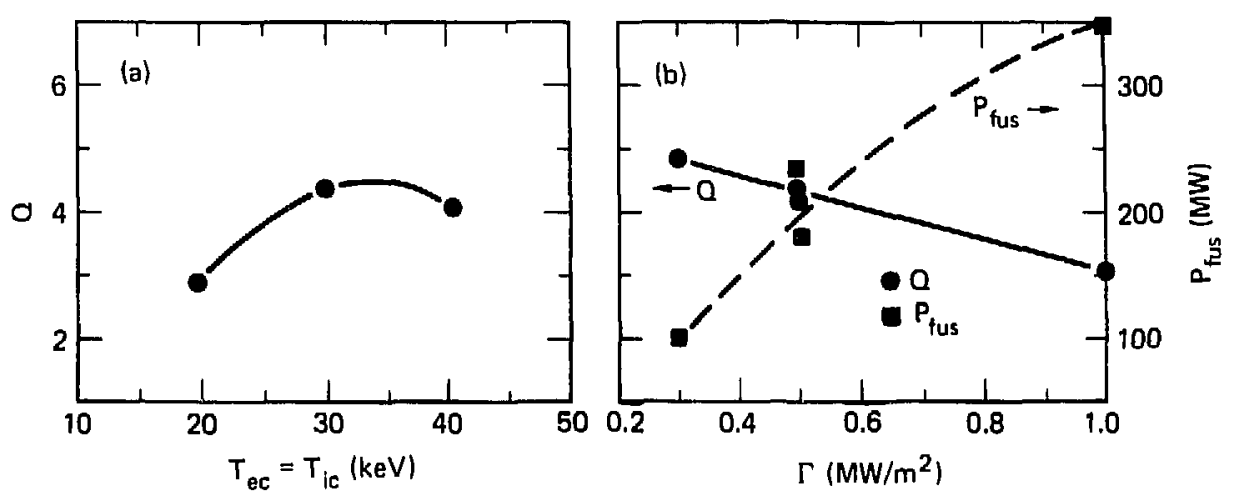

Fig. 7. Typical parameter scans: (a) variation of $Q$ with $T_{i c}=T_{e c}$ for central-cell length $L_{c}=50 \mathrm{~m}$, neutron wall loading $\Gamma=0.5$ $\mathrm{MW} / \mathrm{m}^{2}$, and fusion power Pfus $=200 \mathrm{MW}$; and (b) variation of $Q$ and $\mathrm{P}_{\text {fus with }} \Gamma$ for $\mathrm{L}_{\mathrm{c}}=50 \mathrm{~m}$ and $\mathrm{T}_{\mathrm{ec}}=\mathrm{T}_{\mathrm{ic}}=30 \mathrm{keV}$. 
The variation of $Q$ and $P_{\text {fus }}$ with $\Gamma$ leads to a rapidly increasing utility power requirement as $\Gamma$ is raised as well as to an increased machine cost. We selected a relatively low value of $\Gamma=0.5 \mathrm{MW} / \mathrm{m}^{2}$ so as to meet our performance guideline at minimun cost and utility power.

The variation of central-cell magnetic field $B_{c}$ yielded higher $Q$ at lower $B_{c} ;$ however, it also yielded increasing plasma radius and hence increasing machine cost. We chose a value of $B_{c}=2.5 \mathrm{~T}$, at the low end of our exploratory range. It is possible that an even lower field would be advantageous, and future iteration of parameters should extend this scan. (Lower $B_{c}$ may also be advantageous for MHD-ballooning stability-ree discussion titled Plasma Stability.)

The two cases calculated for $\Gamma=0.5 \mathrm{~mW} / \mathrm{m}^{2}$ [Fig. $7(\mathrm{~b})$ ] correspond to plasma of different radii, using slightly different central-cell fields. The larger-radius (higher Q) case forms the basis for our reference parameter set. The code calculation was done for a uniform effective plasma length of $50 \mathrm{~m}$. The calculation was corrected for an actual effective length of $50.9 \mathrm{~m}$. To this, we add the fusion power generated in the end cells, increasing $P_{\text {fus }}$ to $245 \mathrm{MW}$ and $Q$ to 4.7 for our reference case, Table 3.

$A$ value of $B_{c}=0.5$ is needed to achieve the level of performar!:e for the reference case. Performance at lower values of $B_{c}$ is shown in the section on plasma stability.

\section{ADIABATICITY}

The magnetic morient of the trapped particles in TMNS must be conserved to a high degree if we are to realize the long-term confinement needed. Because the plasma calculations assume that this is the case, losses due to nonadiabatic changes in magnetic moment are neglected.

Cohen et al. ${ }^{12}$ give a simple test for adiabaticity which we have applied to end and central-cell ions. This test requires, for good conservation of magnetic moment,

$$
x \equiv \Omega_{m} L_{m} / v>10,
$$

where $\Omega_{m}$ is the gyrofrequency at field minimum, $L_{m}$ is the smallest magnetic scale length, and $v$ is the particle velocity. For end-cell ions at average energy $\overline{\mathrm{E}}=254 \mathrm{keV}$, using $\mathrm{L}_{\mathrm{m}} \approx \tau_{\mathrm{p}}$ and calculating $\Omega_{\mathrm{m}}$ for a 
B-depressed central field, we obtain $X=17$. The same test for central-cell ions yields $x=42$, if we use a magnetic scale length of $1 \mathrm{~m}$, or about $1 / 6$ of the transition length. There seems to be little doubt about the adiabaticity of these two classes of particles.

Barrier ions at $200 \mathrm{keV}$ are confined at lower central field than endcell ions and moy come closer to an adiabatic confinement limit. In this case, the crude $X$-test does not give a clear sign of good confinenent. We have instead scaled the adiabatic energy limit obtained for MFTF-B, using Eq. (38) of Ref. 12. Arguing that the barrier field shapes are similar, but differing in field intensity and scale length, Eq. (38) scales the energy limit as $\left(B_{0 b} L\right)^{2}$. Since the TMNS value of $B_{0 b}$ (field at barrier minimum) is 1.8 times that of MFTF-B and the scale length (plasma length) ratio is about 2, the energy limit for TMNS is about $(3.6)^{2}$ times the $350-\mathrm{keV}$ (vacuum field) limit for MFTF-B. ${ }^{2}$ Although finite- $\beta$ may drop this by $(1-\beta)$, according to argidments by Cohen et $a 1 .,^{2}$ we predict a confinement limit well above $1 \mathrm{MeV}$ for TMNS barrier ions, thereby providing an ample margin at injection energy $E_{\text {inj }}=200 \mathrm{keV}$.

In all cases, electron orbits are smaller than ion orbits, even for ECRH-heated electrons in the barrier, and electron confinement will be highly adiabatic. The one remaining group in question consists of reaction $\alpha$-particles. We count on confinement of $\alpha$-particles for heating central-cell plasma. Using the simple $X$-test given above, we obtain $x_{x} \approx 12$, suggesting adequate adiabaticity. A more detailed estimate of $\alpha$-particle adiabaticicy is needed to verify this result.

We also note an opportunity for improving TMNS performance. The high adiabatic energy limit of $1 \mathrm{MeV}$ estimated for the barrier ions suggests that the barrier length could be reduced and still provide adequate confinement. This would reduce barrier volume and hence, heating and pumping power requirements in proportion. A refined estimate of the adiabatic energy limit is needed for this optimization.

PLASMA STABILITY

Plama atability arguments for TMN are similar to those given for MFTF-B. For the present study, we assume that microstability will be achieved 
with no anomalous losjes. We anticipate stabilization of loss-cone modes of the barrier-cell "sloshing" ions by the confinement of low-energy ions in the midplane potential depression of the barrier regions. We expect high-energy end-plug ions to be stabilized by the central-cell plasma crossing the endplug. The assumption of overall microstability will require testing by a detailed theoretical evaluation of the various possibilities for microinstability.

Our confidence in these predictions, which must be at a high level before we proceed with device fabrication, will be reinforced by the anticipated verification of theoretical predictions for microstability in TMX Upgrade experiments and, late=, from MFTF-B.

The more pressing question for our present study is that of MHD stability. Overall flute interchange stability, as determined by a pressure weigited $\int d l / B$ criterion (Ref. 2), is relatively easy to achieve. Our field design was tested against this criterion and shows stability up to $B_{c} / B_{p}=1.49$. The reference case calls for $B_{c} / B_{p}=0.71$, well within the stable range.

Stability to ballooning-interchange modes has been evaluated using procedures previously described. ${ }^{2}$ The results here indicate lack of stability for our reference case. In Fig. 8, we show a marginal stability boundary for TMNS, calculated for $\beta_{b}=0.3$. Our refereace case (Table 3) uses $\beta_{b}=0.5$, for which no stable solution was found. Evell with the lower $B_{b}$, the maximum stable $\beta_{c}$ predicted by these calculations is less than about 0.3 , compared to a $\beta_{c}=0.5$ needed to achieve the reference case performance. The rapid degradation of machine performance at reduced $B_{c}$ is shown in Fig. 9.

Although the stability evaluation for the ballooning modes is incomplete in the sense that the stabilizing finite Larmor radius (FLR) effects are not included, the prognosis for the present design is not encouraging. This deficiency points up the need for an improved end-cell configuration before we proceed with an engineering design more detailed than in the present study. The possibilities for improving the predicted ballooning $\beta_{c}$ limit include the following:

- Optimization of field design, possibly by varying mirror ratios, transition and barrier lengths, etc. The TMNS design is relatively improved over the MFTF-B design, and further optimization should be possible. 

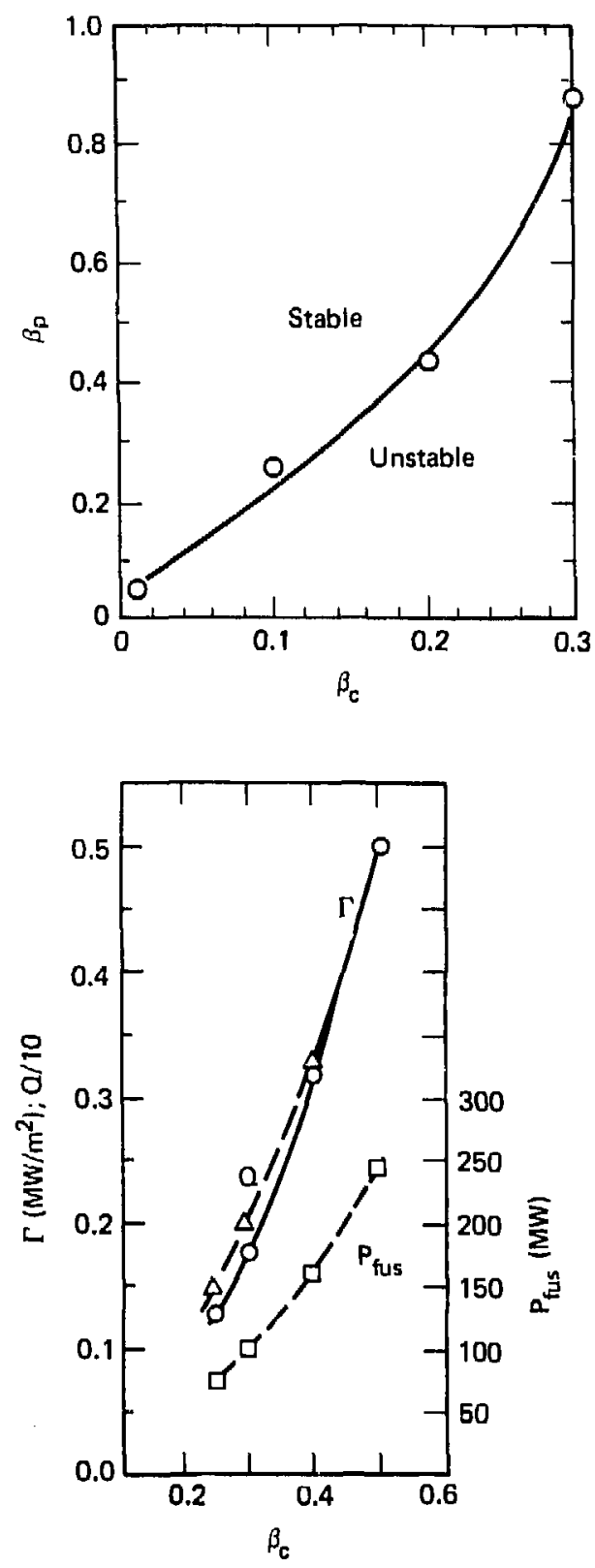

Fig. 8. Marginal stability boundary for ballooning modes in TMNS. For this calculation, $B_{b}=0.3$.
Fig. 9. Variation in machine performance with $B_{c}$ for $B_{p}=0.7$ and $B_{b}=0.5$. Note rapid degradation with reduced $B_{c}$. 
- Reduction of central-cell field. The predicted $\beta_{c}$ limit apparently improves as $\mathrm{B}_{\mathrm{c}}^{-1.6}$ (Ref. 13); therefore, a stable case may be realized at lower $B_{c}$. However, the lower plasma density results in a larger-diameter plasma and probably a more costly machine.

\section{- Completion of stability calculations to include FLR and possibly} other stabilizing effects. An experimental tie-in with theory would also be very helpful, since apparently experimental B-limits in toroidal systems are higher than predicted. A similar serendipity may hold for mirrors.

In future TMNS iterations, we may also consider changing the basic endcell geometry to one of the axisymetric configurations. These possibilities are under consideration as part of the ongoing study of advanced mirror systems at LLNL.

\section{GAS BALANCE AND VACUUM}

Estimates of neutral-beam requirements for charge-exchange pumping of the barrier regions are made in Sec. 5. These estimates allow for trapping efficiencies and for distribution of beam trapping between charge exchange and ionization. Trapping fractions for yin-yang and sloshing ions are also included. We have used these estimates from Sec. 5 to construct the particleflow chart in Fig. 10.

In the end cell, the beams are efficiently trapped. The trapped ions have a confinement $(\mathrm{nt})_{\mathrm{p}}=4.8 \times 10^{13} \mathrm{~cm}^{-3} \cdot \mathrm{s}$ and scatter to join the central-cell population, thus contributing to fueling and neating.

In the barrier cell, the trapped 200-keV sloshing ions are lost primarily by charge exchange on the several pump beams. The pump beams are poorly absorbed because of the relatively low plasma density in the barrier region. That portion of the pump beams undergoing charge exchange with trapped and passing central-cell ions in the barrier ultimately replaces those ions in the central population, with some gain in central energy. That portion of the pump beams undergoing ionization ultimately fuels the central cell. Some additional fueling occurs as a result of gas penetrating into the plasma (see below): we estimate this fueling to be about $21 \mathrm{~A}$ in the central cell, $8 \mathrm{~A}$ in the yin-yang cells, and $38 \mathrm{~A}$ in the barrier cells. Some of the gas entering the barrier plasma may be trapped there and eventual:, be removed by the pump beams. We neglect this correction. 
380 A total

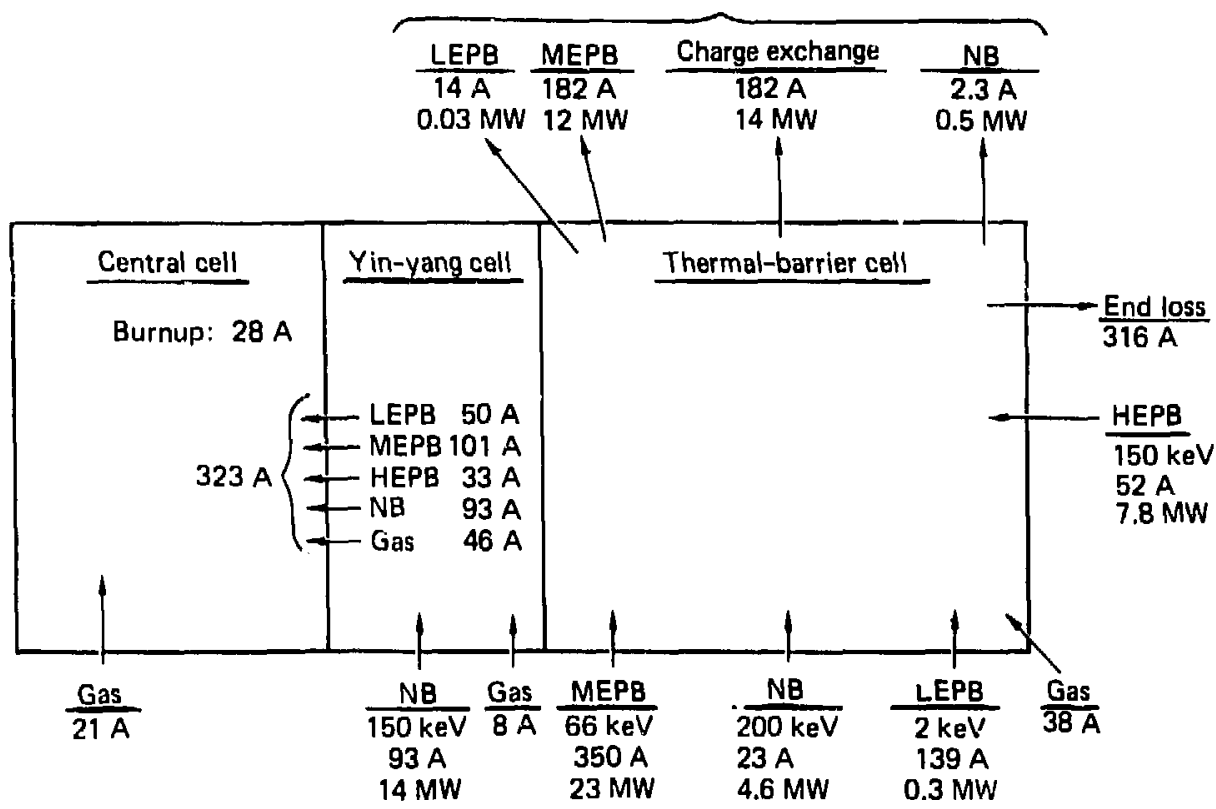

Fig. 10. Particle-flow chart for TMNS reference case. Pump beam (LEPB, MEPB, and HEPB) fractions and neutral-beam (NB) fractions entering the central cell are net (fueling) values. Flows are totals that include both ends.

An appropriate fraction of the neutral beams will be tritium for proper central-cell fueling. The estimates of Sec. 5 were made assuming all beams to be $D^{0}$. Although the method of estimating is insensitive to this choice, the generally more favorable cross sections for equal-energy $T^{0}$ beams may result in a slightly dacreased pumping beam requirement when a beam mix including tritium is used.

The fusion burnup rate is about $14 \mathrm{~A}$ of $\mathrm{T}$, hence $28 \mathrm{~A}$ total. For the flow chart in Fig. 10, we omit the details of neutron and $\alpha$-particle loss. The end losses of plasma ions are expected to dominate over radial losses, and we neglect the latter. The net end loss of $316 \mathrm{~A}$ exceeds the calculated end loss of 232 A based on the estimated Pastuhkov $(n \tau)=4 \times 10^{14} \mathrm{~cm}^{-3} \cdot \mathrm{s}$. To this extent, the central cell is overfueled, and the operating point would 
shift. For our present purposes, this is not serious; however, for future iterations it will be necessary to use an advanced tandem code (now in preparation) to obtain an accurate particle (and energy) balance and to make the fueling (and heating) self-consistent. Use of tritium beams may lower fuel input because of reduced pumping-beam requirements. If under-fueling occurs, auxiliary pellet fueling can be employed. Our present flow chart primarily examines vacuum pumping requirements and is precise enough for this purpose.

It is important to shield the plasma from excessive gas penetration, particularly in the barrier region, if we are to maintain a high-Q operation. To this end, we postulate a guard or "halo" plasma surrounding the main reacting plasma along the entire length of the confinement region. This halo plasma will be fueled primarily by gas arising in the barrier cell as a result of wall bombardment by transmitted pump beams and charge exchange, and by additional gas added in the central cell. We assume this halo plasma to have the following properties in the central cell:

- Density, $\mathrm{n}_{\mathrm{ha}}=6 \times 10^{12} \mathrm{~cm}^{-3}$

- Temperature, $\mathrm{T}_{\mathrm{ha}}=100 \mathrm{eV}$

- Radial thickness, $\Delta r=20 \mathrm{~cm}$

- Confinement, (nt) $h a=5 \times 10^{11}$

The total halo loss current is about $1000 \mathrm{~A}$, and the drive power is of order $1 \mathrm{MW}$. The halo plasma will be heated by an energy deposition from endcell ions and $\alpha$-particles that we estimate will be about $3 \mathrm{MW}$, more than adequate. These are reasonable values, somewhat like in the present TMY plasma. However, we shall need a radially dependent tandem code to show the generation of a self-consistent halo with the proper potential distribution. With a halo thickness $(n \Delta r)$ of about $10^{14} \mathrm{~cm}^{-2}$ in the central cell, penetration of incident gas will be nil. The Franck-Condon (F-C) neutrals of a few eV generated by gas dissociation in the first centimeter or so of the halo will penetrate deeper into the halo, but few will survive to reach the core plasma. However, halo ions, at about $100 \mathrm{eV}$, will charge exchange with the F-C neutrals, and a fraction of these can reach the core plasma. A crude estimate places the penetration at about $3.7 \%$ (ions into plasma per incident atom). If we fuel the halo with $400 \mathrm{~A}$ (atomic) of gas ( 40 Torr . 1/8) in the central cell and allow for an estimated $28 \%$ of the gas refluxing from the plasma, the net fueling of the plasma core is $21 \mathrm{~A}$, as indicated on Fig. 10 . 
The local vacuum surrounding the central plasma will be $2 \times 10^{-6}$ Torr, with all pumping provided by the plasma. Wall bombardment in the central cell by plasma particles is estimated at $6 \mathrm{~A}$ of $30 \mathrm{keV} \mathrm{D}$ and $\mathrm{T}, 34 \mathrm{~A}$ of $100-\mathrm{eV}$, and $140 \mathrm{~A}$ of $2-\mathrm{eV}$, the last two primarily $\mathrm{D}^{0}$. The power loading is small compared to the neutron flux of $0.5 \mathrm{MW} / \mathrm{m}^{2}$. These numbers are rough estimates; a refined Monte Carlo calculation will be required.

A similar gas shielding will occur in other plasma regions. We estimate penetration in the barrier region to be about $5 \%$, with shielding effectiveness reduced slightly because of the halo mapping. Because the resulting $38-A$ gas input to the hot plasma is small compared to the beam input, the additional plasma cooling is tolerable. Wall bombardment in the barriers includes about $26 \mathrm{MW}$ of beam and plasma particles and $4.8 \mathrm{MW}$ of synchrotron radiation.

We have constructed a gas flow chart, Fig. 11, to show the overall balance. For this estimate, we assume that each neutral-beam source introduces $10 \mathrm{~A}$ of gas through its beam duct. Other inputs are obtained from the particle flow chart in Fig. 10. Local vacuum pressures are estimated from the stated gas inputs, with $28 \%$ refluxing from the plasma. Pumping is by plasma ionization. The walls are assumed to return $100 \%$ of incident particles, and impurities and sputtering are neglected.

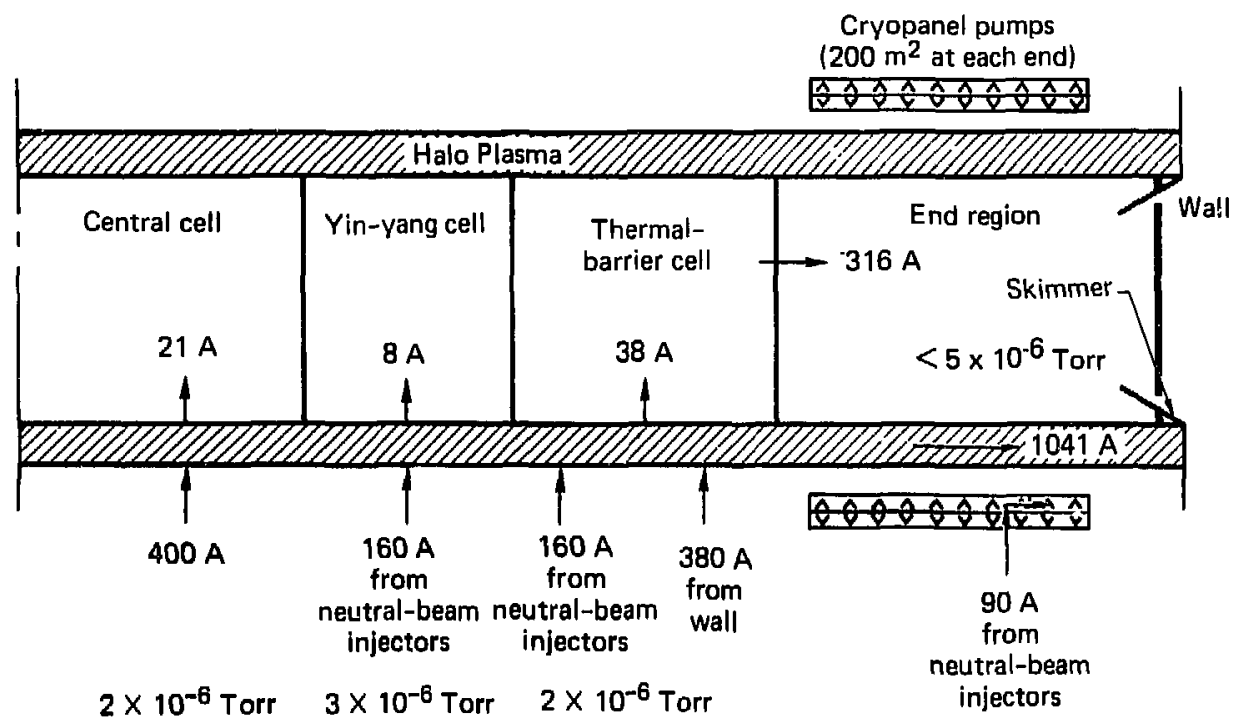

Fig. 11. Gas-flow chart based on particle flows shown in Fig. 10. Neutra1beam injectors supply 10-A gas from each module. 
Cryopanel array in the end regions are the final means of gas removal. In order to estimate the pumping requirement in this region, we use the analysis by Porter. 14 The idea is to keep the gas density low enough to avoid runaway buildup of cold-plasma density by recycling from the end wall, with corresponding power drain from the flowing plasma. To avoid the coldplasma buildup, we require [see Ref. 14, Eq. (14)]

$$
\frac{\tau_{i}}{\tau_{p}} \frac{E_{c}}{E_{h}} \frac{(\sigma v)_{h}}{(\sigma v)_{c}}>f_{h}
$$

'vere

$\tau_{i}=$ reaction time for gas in hot plasma

$\tau_{p}=$ pumping time for gas molecules

$E_{c}(h)=$ average cold (hot) ion energy

$(\sigma \mathrm{v})_{\mathrm{c}, \mathrm{h}}=$ total reaction rate for gas in cold (hot) plasma

$E_{h}=$ wall reflux fraction

In steady state, we take $f_{h}=1$. For the core plasma in the end region, the hot plasma density is so reduced by plasma expansion $\left(n_{h} \approx 7 \times 10^{6} \mathrm{~cm}^{-3}\right)$ that $\tau_{i} \approx 2 \mathrm{~s}$. With $200 \mathrm{~m}^{2}$ of cryopanel in each end region, we estimate $\tau_{p} \approx 25 \mathrm{~ms}$ and the inequality $(1)$ is dominated by the $\tau_{i} / \tau_{p}$ ratio. Even using $E_{c}=0.01 E_{h}$ (Porter estimates $E_{c} \approx 0.1 E_{h}$ for MFTF-B), the left side of (1) is 5.6 , providing an ample margin.

If we perform the same estimate for the more dense halo plasma, we cannot claim any margin of safety against the recycling buildup. A more refined estimate is needed, and also probably a rearranged pumping geometry for the haloplasma dump. We have shown a "skimmer" for the halo plasma in our engineering drawings (see Fig. 17, p. 55) to indicate the need for additional design and calculation in this area. A particularly attractive approach would be to use the rear side of a cryopanel array to pump the skimmed halo plasma, with the front surface pumping the core plasma. In this case, the vacuum could be maintained at about $1 \times 10^{-6}$ Torr in the direct-converter region. With the entire gas load pumped by the $200-\mathrm{m}^{2}$ front surface, the end-region pressure will be $<5 \times 10^{-6}$ Torr.

We have not yet devised a detailed startup scenario, but it is likely that transient pumping capability, possibly in the form of titanium gettering, will be needed for this phase. 
CONF INEMENT OF $\alpha$-PARTICLES

Reaction $\alpha$-particles are mirror-confined in the central cell while they degrade in energy by collision with central-cell plasma ions. With a vacuum mirror ratio of 3.6 , at least $85 \%$ of the $\alpha$-particles will be confined initially. Together with adequate plasma confinement, these $\alpha$-particles can provide for all the central-cell energy losses (an "ignited" central cell). Our reference case is close to this condition--it will require a more detailed enorgy balance calculation to say exactly how close. (Because additional energy input to the central cell comes from injected end-cell and barrier ions, the central plasma may be overheated. We do not anticipate the need for any direct central-cell heating. However, a startup scenario to cover the ime before heating by $\alpha$-particles occurs is not yet worked out.)

Good a-particle confinement for plasma heating requires adiabatic orbits and low radial diffusion. Devoto and ohnishi ${ }^{15}$ have looked at $\alpha$-particle drifts in tandem geometry, using an earlier version of the TMNS magnetic field. They find that stochastic diffusion due to bounce-drift resonances can be suppressed by increasing the axisymetric field in the central cell by about $20 \%$ before the quadrupole transition begins. We have included such an increase in our field design (Fig. 3 ).

Once the $\alpha$-particles have deposited their energy, their presence is no longer desirable. The problem of removing a-particle "ash" from a steadystate device like TMNS nay be approached in two ways:

- The first is suggested by the study of Ref. 15. Radial losses of a-particles will remain smail until the particles approach thermal energies. They then encer a "resonance-plateau" regime of drift orbits and may undergo rapid radial drift with subsequent loss. Additional studies to include effects of finite $B$ on orbit calculations are needed to verify these results.

- The second method for $\alpha$-particle removal was suggested in a recent TMR study. 16 This method utilizes the barrier pump beams for resonant charge exchange with thermalized $\alpha$-particles in the barrier region. If the thermalized, doubly-charged $\alpha$-particles are reduced by charge-exchange electron capture to a single charge state at the appropriate region in the barrier's potential well, they will have adequate energy to escape over the confining potential. In the present TMNS design, we were unable to locate the pump beams appropriately for this application.

Ash removal from TMNS is therefore a subject for further study and possibly invention. 


\section{PLASMA HEATING AND BARRIER PUMPING}

NEUTRAL BEAMS

Because of their importance to the overall power balance, we have evaluated the neutral-beam requirements for TMNS in some detail. These neutral beam requirements are qualitatively similar to the requirements for TMR (Ref. 3, Ch. 4 and 5) and for MFTF-B. 17 Three types of beams are required for the reference design of TMNS, which uses the A-cell version of thermal barriers. Neutral beams are required to sustain the high-density plasma in the yin-yang magnetic field, to inject sloshing ions into the thermal barrier, and to pump trapped ions out of the barrier by charge-exchange pumping. The chargeexchange beams will also provide fuel for the reacting plasma in the cenral cell.

The energy and absorbed power of each type of neutral beam are computed and optimized by a second-generation computer code consisting of a set of scaling equations normalized to the reference case of MFTF-B. The gecondgeneration code includes plasma effects on neutral-beam requirements such as the competition between ionization and charge exchange, re-ionization and re-trapping of charge-exchange products. Therefore, the computational methods for neutral-beam requirements are not precisely the same as the earlier methods, ${ }^{3,17}$ but the results are consistent.

In the earlier computations ${ }^{3,17}$ seven correction factors $F_{1}$ through $F_{7}$ were used to compute the requirements for neutral beams and for charged beams, based upon the required pumping speed I pump. In the TMNS design, we use the second-generation code to compute the current absorbed in the plasma, $I_{\text {absorbed }}=P / E_{B}$, which is the same as $I_{\text {pump }} / F_{1} F_{3}$ in the earlier computations. Here $F_{1}$ is the fraction of the neutral beam undergoing charge exchange, and $F_{3}$ is the fraction of the charge-exchange products escaping from the plasma without re-ionization. Under TMNS conditions, $\vec{F}_{3}$ is near unity; also, the penalty factor $F_{4}=1$ if the products of molecular ions are not allowed to enter the plasma.

Table 7 shows how the TMNS neutral-beam specifications are thereby derived. The attenuation factor $F_{2}$ is the fraction of the neutral beam absorbed within the barrier, and the factors $F_{5}, F_{6}$, and $F_{7}$ have been replaced for better clarity by the efficiencies of neutralization and purification. 
Table 7. TMNS neutral-beam specifications.

\begin{tabular}{|c|c|c|c|c|c|c|}
\hline & $\begin{array}{l}\text { End } \\
\text { cell }\end{array}$ & $\begin{array}{c}\text { Barrier } \\
\text { cell }\end{array}$ & HEPB & MEPB & LEPB & Total \\
\hline Power absorbed (MW) & 14 & 4.1 & 7.8 & 12.2 & 0.25 & 38.35 \\
\hline Beam energy, $E_{B}(k e V)$ & 150 & 200 & 150 & 66 & 2 & \\
\hline$I_{\text {absorbed }}=P / E_{B}(A)$ & 93 & 20.5 & 52 & 185 & 125 & 475.5 \\
\hline$I_{\text {pump }}(A)$ & - & - & 7.5 & 67.5 & 75 & 150 \\
\hline$F_{1}$ (ionization) & - & - & 0.40 & 0.36 & 0.6 & \\
\hline $\mathrm{F}_{2}$ (attenuation) & 1.0 & 0.9 & 0.36 & 0.53 & 0.9 & \\
\hline$I^{0}=I / F_{1} F_{2}(A)$ & 93 & 22.8 & 52 & 350 & 139 & 657 \\
\hline $\mathrm{I}^{0} \mathrm{E}_{\mathrm{B}}(\mathrm{MW})$ & 13.95 & 4.56 & 7.8 & 23.1 & 0.278 & 49.7 \\
\hline Beam species & $D^{-}$ & $\mathrm{D}^{-}$ & $\mathrm{D}^{-}$ & $\mathrm{D}^{+}$ & $\mathrm{D}_{2}$ & \\
\hline Neutralization efficiency & 0.6 & 0.6 & 0.6 & 0.71 & 0.9 & \\
\hline Purification efficiency & - & - & - & 0.7 & - & \\
\hline Accelerator efficiency & 0.9 & 0.9 & 0.9 & 0.9 & 0.9 & \\
\hline $\begin{array}{l}\text { Charged beam current } \\
\quad=10 / \pi \eta_{j} \text { (A) }\end{array}$ & 172 & 42 & 96 & 782 & 172 & 1264 \\
\hline Charged beam power (MW) & 26 & 8.4 & 14.4 & 52 & 0.34 & 101 \\
\hline Power supply efficiency & 0.95 & 0.95 & 0.95 & 0.95 & 0.95 & \\
\hline $\begin{array}{l}\text { Ion source power ( } 2 \mathrm{~kW} / \mathrm{A}, \mathrm{D}^{+} ; \\
\left.10 \mathrm{kH} / \mathrm{A}, \mathrm{D}^{-}\right)\end{array}$ & 1.7 & 0.4 & 1.0 & 1.6 & 0.34 & \\
\hline Total power (MW) & 29 & 9.3 & 16 & 56 & 0.72 & 111 \\
\hline
\end{tabular}


As earlier explained, 3,17 a large economy in charge-exchange pumping power is possible if two or three charge-exchange beams are injected at different beam energies. The beam energy $E_{B}$ must be sufficient that the ionized beam particles escape from the thermal barrier into the central cell; i.e.,

$$
E_{B}>\Delta \phi\left(1-R \sin ^{2} \theta\right),
$$

where $\Delta \phi$ is the potential difference shown by Fig. 4 between the yin-yang plasma potential and the barrier potential where the charge exchange occurs; $R$ is the ratio of magnetic fields at these two points, and $\theta$ is the pitch angle of the ionized pump beam. The denominator is close to unity if $\theta$ is small.

Most of the trapped ions are pumped from a region of the barrier in which the potential difference $\Delta \phi$ is small in comparison with the potential well depth $\phi_{b}$, or where $\Delta \phi$ is less than zero. In this design, we specify three pump beams injected into the barrier at low energy (LEPB), medium energy (MEPB), and high energy (HEPB). Beam injection paths are chosen so that Eq. (2) is satisfied at all points along the paths. Fokker-Planck computations indicate that about $50 \%$ of the trapped ions can be pumped by the LEPB, for which $\Delta \phi$ is less than zero. Of the remainder, about $45 \%$ can be pumped by the MEPB from a region such that $\Delta \phi \leq 0.4 \phi_{b}$; the remaining $5 \%$ must be pumped from the bottom of the potential well where $\Delta \phi \leq \phi_{b}$. These fractions are used in Table 7 to distribute the pumping load I pump among the three beams. Also, the beam energies $E_{B}$ in Table 7 are consistent with the requirement of Eq. (2) using these values of $\Delta \phi$.

The factor $F_{1}$ in Table 7 accounts for the fact that only a fraction of the pump-beam particles contribute to the effectiveness of charge-exchange pumping because of competition with other plasma collisions such as ionization and interactions with passing ions and sloshing ions. This fraction has in effect been computed by the second-generation code and has been integrated over the beam path of each pump beam. The factor $F_{2}$ is the fraction of the neutral-beam current $I^{0}$ absorbed by the plasma in the useful portion of the beam path. Consequently, the requirement for injected neutral-beam current is $I^{0}=I_{\text {pump }} / F_{1} F_{2} . \quad F_{2}$ will be almost unity for the LEPB because we have the freedom to choose the beam energy $E_{B}$ to optimize the penetration of this low-energy beam. 
The three high-energy beams ( 150 to $200 \mathrm{keV}$ ) will be derived from $\mathrm{D}^{-}$, wh. reas the MEPB and LEPB will be derived from $D^{+}$or possibly $D_{2}^{+}$for the LEPB. The reasons for these choices are the very poor neutralization efficiencies for high-energy $D^{+}$and the relatively low overall beam current densities $\left(5 \mathrm{~mA} / \mathrm{cm}^{2}\right.$ ) expected for $\mathrm{D}^{-}$ion sources. The low $\mathrm{D}^{-}$current density is adequate for the moderate current requirements of the three high-energy beams, but is inadequate for the high-current requirements of the MEPB and LEPB.

In the 1979 TMR design study, ${ }^{3}$ we explained that contamination with positive molecular ions is not tolerable for charge-exchange pump beams because of the half-energy and third-energy products of molecular ions that become trapped in the thermal barriers. Consequently, it is necessary to separate the $D_{1}^{+}$from the molecular ions $\left(\mathrm{D}_{2}^{+}\right.$and $\mathrm{D}_{3}^{+}$) of the MEPB before the beam is neutralized. Purification of the $D_{1}^{+}$beam is possible by magnetic separation or by $r f$ acceleration. In this design, we specify a purification magnet between the MEPB ion source and the neutralizer. The price that we must pay for the purification of the MEPB is the loss of molecular ions (assumed to be $10 \%$ of the charged beam) and the loss of about $20 \%$ of the $\mathrm{D}_{1}^{+}$ by premature charge exchange within the purification magnet and in the preceeding drift region where the pressure of background gas will be about $3 \times 10^{-4}$ Torr. Consequently, in Table 7 we show a purification efficiency of 0.7 for the MEPB.

The remainder of Table 7 shows the effects of the accelerator efficiency (0.9) and power supply efficiency (0.95), and the power consumed by the ion sources (2 $\mathrm{kW} / \mathrm{A}$ for a $\mathrm{D}^{+}$ion source; $10 \mathrm{~kW} / \mathrm{A}$ for a $\mathrm{D}^{-}$ion source). The accelerator efficiency takes into account the losses due to premature charge exchange, collimator losses, and re-ionization of the neutral beam,

The result is that the total input power for the five types of neutral beams will be $111 \mathrm{MW}$.

Attainment of the assumed efficiencies will require several near-term developments during the 10-year time scale of TMNS design and construction. 18 The $\pi$ ut iuportant required developments are continuously operated cryogenic pumpirg, adequate pumping to avoid beam loss, reliable beam optics, $D^{-}$ion sources operating at an overall current density of $5 \mathrm{~mA} / \mathrm{cm}^{2}$, and magnetic shielding capable of excluding fringing fields up to $0.2 \mathrm{~T}$ from the large volumes occupied by the injectors and their neutralizers. The power supply efficiency will be improved by avoiding the regulation of the high voltage, and by development of solid-state switching devices that operate at low 
voltage when conducting. Deregulatio:l of the high voltage will require regulation of the ion source to compensate for fluctuations of the high voltage. 19 We believe each of these developments is attainable by near-term technology, and have avoided unnecessary assumptions involving more advanced technology.

Magnetic shielding of the large-volume injector assemblies is a nontrivial requirement. Table 8 shows the maximum value of the fringing magnetic field for which shielding must be designed for the five types of injectors.

Table 8. Maximum values of fringing magnetic field at the locations of injectors and neutralizers.

\begin{tabular}{lc}
\hline \multicolumn{1}{c}{ Location } & $\begin{array}{c}\text { Fringing magnetic field } \\
(\mathrm{T})\end{array}$ \\
\hline End-cell injectors & 0.06 \\
Barrier-cell injectors & 0.12 \\
HEPB & 0.05 \\
MEPB & 0.22 \\
LEPB & 0.06 \\
\hline
\end{tabular}

The shielding techniques to be considered are layers of ferromagnetic materials, bucking coils, and/or superconductors. If necessary, the MEPB injectors could be moved farther from the outer barrier coil to reduce the maximum shielding requirement.

Extrapolation from the ferromagnetic shielding design for the injectors of MFTF-B 20 indicates that iron shielding at least $20 \mathrm{~cm}$ thick would be required for the MEPB's to avoid saturation. We believe that superconducting shielding extrapolated from the experience acquired with the Baseball II injector ${ }^{6}$ would be more practical. Fringing fielda up to $0.15 \mathrm{~T}$ were excluded from a cylindrical volume $33 \mathrm{~cm}$ in diameter. To simplify the problems of supports and connections, the superconducting shielding should be engineered jointly with the cryogenic pumping system.

Figures 12 and 13 show injector modules for TMNS based upon negative ions (Fig. 12) and upon pasitive ions (Fig. 13). The positive-ion module for the 


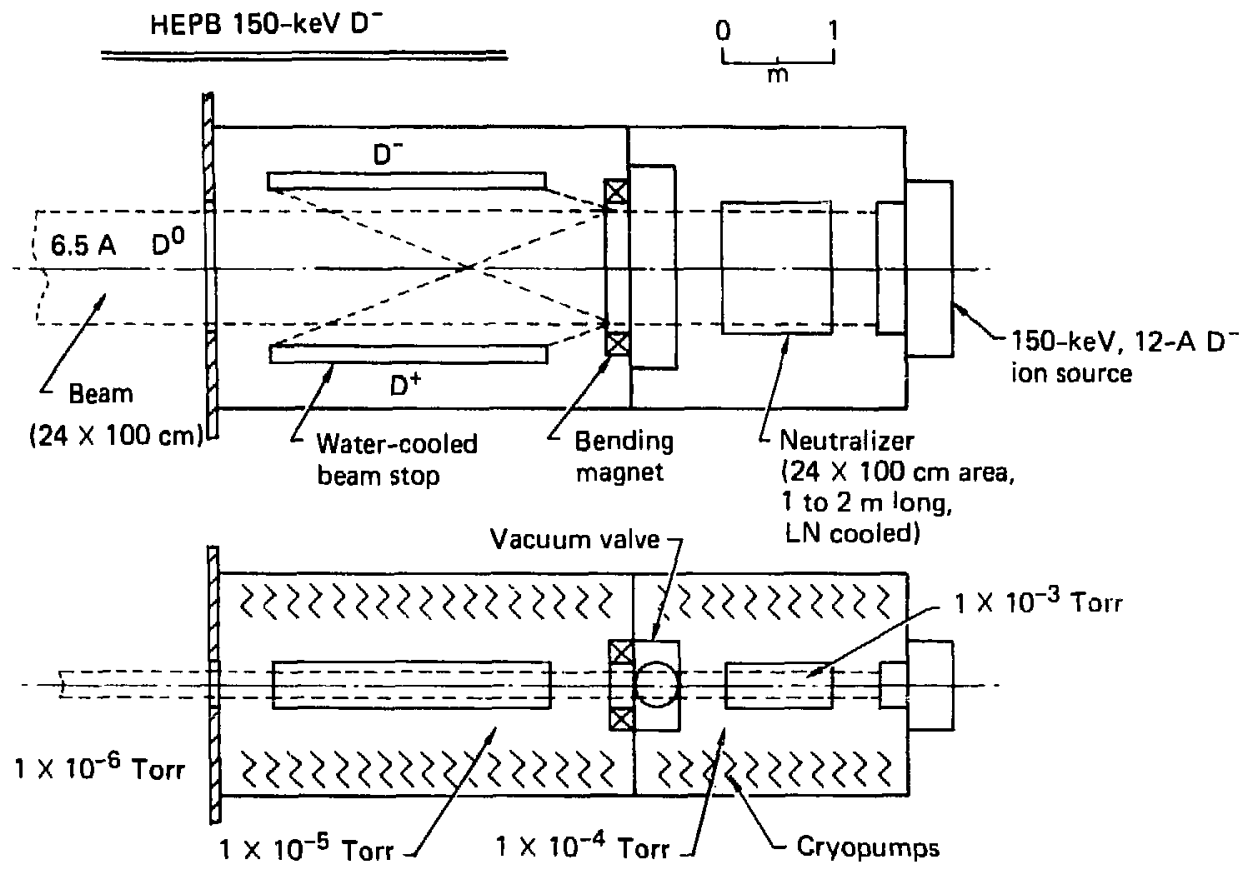

Fig. 12. An injector module suitable for the 150-keV HEPB of TMNS. The ion source, emitting $12 \mathrm{~A}$ of $\mathrm{D}^{-}$in a $24-$ by $100-\mathrm{cm}$ area, is compatible with the development goals of existing negative-ion programs. The neutralizer, bending magnet, beam stops, and gas-punping system are shown to scale. 


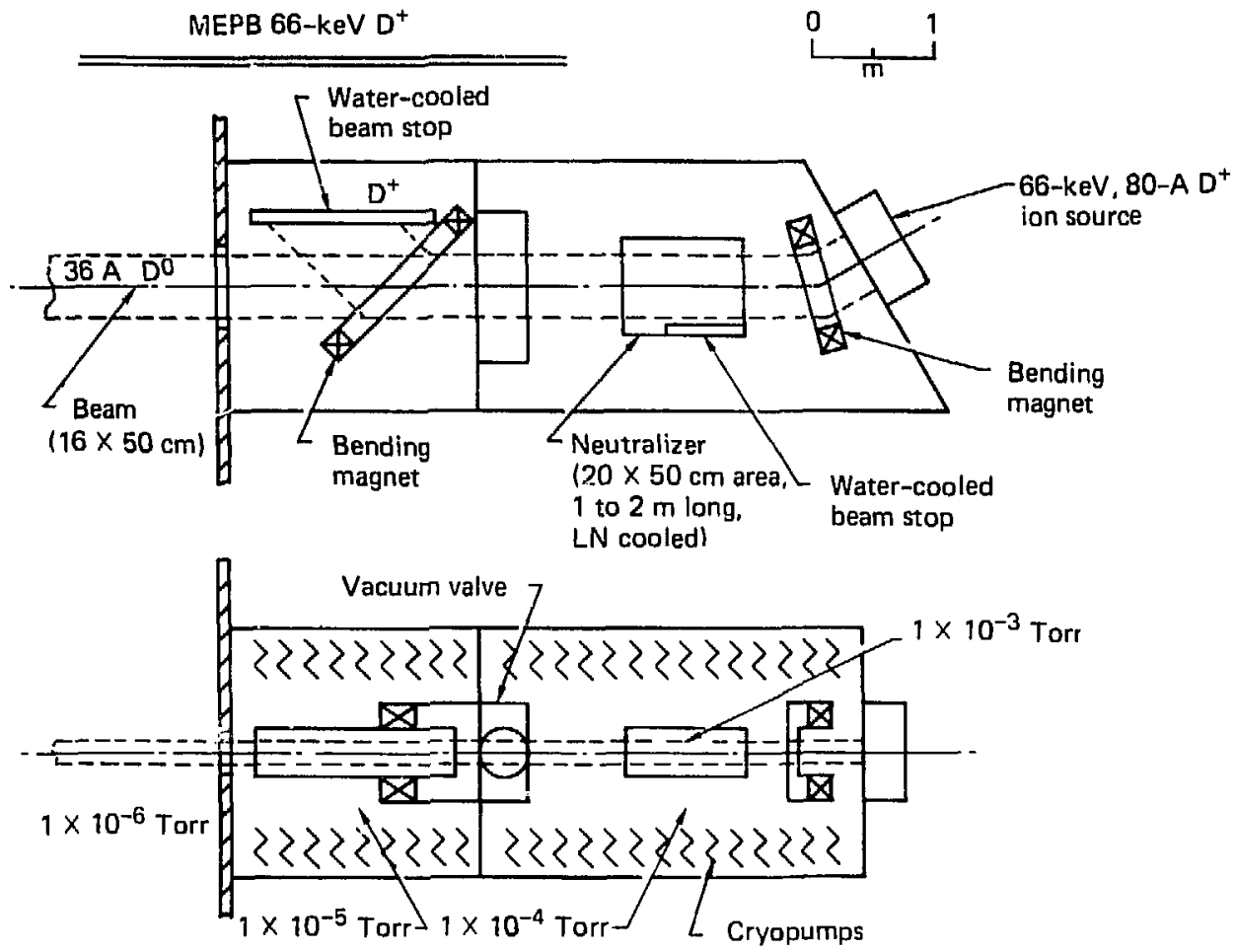

Fig. 13. An injector module suitable for the purified $6 \dot{b}-\mathrm{keV}$ MEPB of TMNS. Note the purification magnet between the ion source and the neutralizer. The primary beam must be $D^{+}$rather than $D^{-}$for two reasons: because a relatively high beam density is required, and because the 10-year construction schedule does not allow time for major new developments. 
MEPB is based upon a $66-\mathrm{keV}, 80-\mathrm{A}$ ion source with a bending magnet before the neutralizer for separating the $D_{1}^{+}$from the molecular ions. The negative-ion module for the HEPB is based upon a 150-keV, 12-A $\mathrm{D}^{-}$source compatible with sources under development in several negative-ion programs.

In both cases, a three-stage gas pumping system is required to maintain pressures of about $10^{-4}$ Torr before and after the neutralizer; $10^{-5}$ Torr is required in the vicinity of the charged beam stop; and $10^{-6}$ Torr is required in the injection path from the injector to the TMNS plasma. These pressures are required to avoid large beam losses by collisions with the background gas. In both cases, the neutralizer consists of a rectangular duct 1 to $2 \mathrm{~m}$ long with gas added to the midplane so that the maximum pressure is $10^{-3}$ Torr; and so that the thickness of the neutralizing gas is $3 \times 10^{15}$ molecules/ $\mathrm{cm}^{2}$ for the $150-\mathrm{keV} \mathrm{D}^{-}$and $7 \times 10^{15} \mathrm{molecules} / \mathrm{cm}^{2}$ Eor the $66-\mathrm{keV} \mathrm{D^{+ }}$. In contrast with conventional positive-ion systems, both modules require extra cryopanels between the ion source and the neutralizer to reduce the gas pressure to $1 \times 10^{-4}$ Torr in this region. The cryopanel design includes a provision for periodically pumping away the condensed gas without its being necessary to shut down the injection system.

Both systems include beam stops for disposal of the residual charged beam emerging from the neutralizer. Bending magnets may be required for this purpose; in certain locations, the fringing field of TMNS will be sufficient for charged-beam disposal. Vacuum valves are required to isolate each injector for maintenance.

Figure 14 shows how arrays of such modules may be installed at each end of TMNS to provide the currents shown by Table 17 in the Fueling and Heating discussion (p. 71). Here we have allowed for at least one spare module in each array. The assumed gas efficiencies are $35 \%$ for positive ions and $10 \%$ for negative ions. Beam densities and gas efficiencies are consistent with our expectations for 1990 or before. Because of this 10-year time schedule for TMNS, we are trying to avoid advanced concepts such as photodetachment, high-density $D^{-}$beams, $r f$ acceleration, or beam energy recovery.

Table 17 also shows how the number of each type of injector modules was computed from the beam requirements of Table 7 and the module designs shown by Figs. 12 and 13. These computations are consistent with the module layout of Fig. 14. The gas pumping specifications and the areas of each cryopump are al so computed self-consistently. 


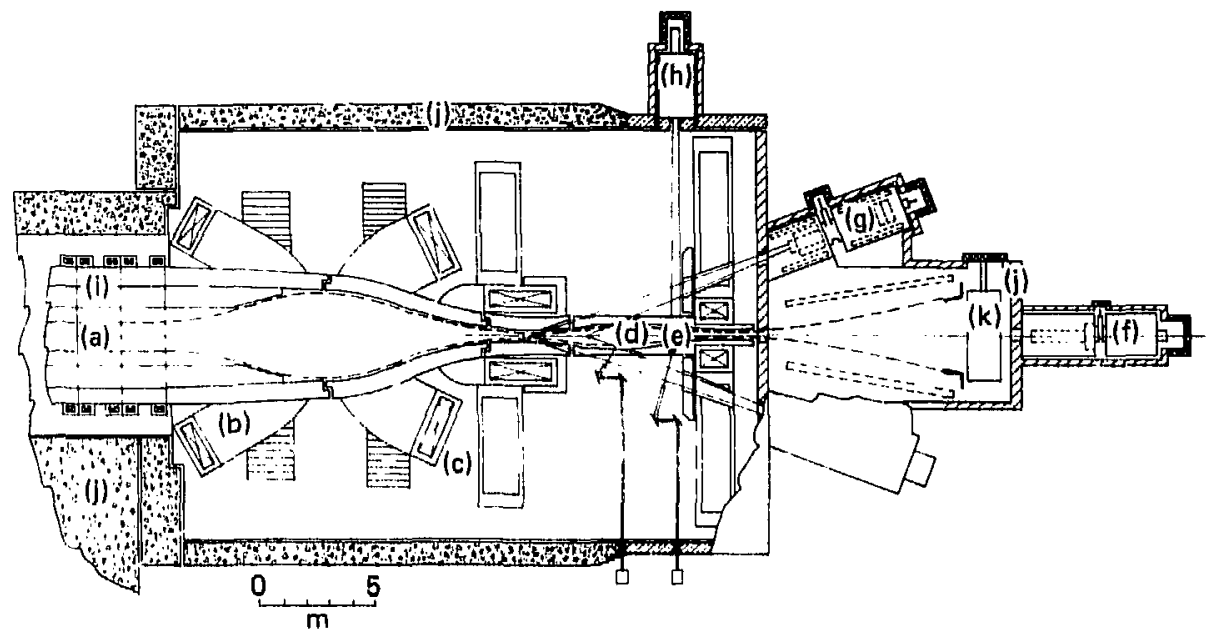

Fig. 14. Elevation of one end of TMNS showing the following components: (a) central cell; (b) transition coil and structure; (c) yin-yang coil and atructure (d) thermal barrier; (e) barrier cell with barrier coil and structure; (f) a $D^{-}$HEPB (there will be six modules at each end); $(g)$ a $D^{+}$MEPB (there will be four modules at each end, top and bottom; and ( $h$ ) a $D^{+}$LEPB (there will be three modules at each end). Also, shown are ( $i$ ) the neutron blanket, ( $j$ ) radiation shields, and ( $k$ ) the plasma direct converter.

ELECTRON CYCLOTRON RESONANT HEATING (ECRH)

It has been explained ${ }^{8}$ how the performance of tandem mirrors can be improved by two types of electron heating. The most obvious improvement is the increase in the peak plasma potential in the thermal-barrier cell, where the hot electrons are electrostatically contained by the positive ambipolar potential. Also, the potential well in the thermal barrier can be deepened by heating the electrons enough that they become collisionless and are therefore confined magnetically rather than electrostatically. To meet these two purposes, two heating systems are required. Of the various possible techniques for heating electrons, we prefer ECRH, because this technique heats the electrons directly, without ion interactions, and because a large body of experimental evidence is available to prove its effectiveness. 
The ECRH power requirements for the reference case of TMNS have been computed by the second-generation code as $6.66 \mathrm{MW}$ into the potential-peak region of the barrier cell and $6.50 \mathrm{MW}$ into the thermal barriers [points (A) and (B), respectively, in Fig. 4]. The frequency requirements are determined by the magnetic fieid and electron densities at these two points. The condition for resonance and for accessibility is

$$
f=f_{c e}>f_{p e} \text {, }
$$

where $f$ is the microwave frequency, $f_{F}=A B / 2 \pi m_{e}$ is the electron cyclotron frequency, and $f_{p e}=\left(n e^{2} / m_{e} \varepsilon_{0}\right)\left\{f_{2} / 2 \pi\right.$ is the electron plasma frequency.

Table 9 shows how these requirements are used to specify the ECRH power absorbed by the plasma and the microwave frequency required. By making further assumptions of overall efficiency, power density, and power per unit, we obtain the performance requirements of the gyrotrons, waveguides, and windows. The condition for accessibility of the resonance is satisfied, since $f_{c e}$ is larger than $f_{p e}$ in both cases.

Table 9. ECRH requirements for the reference case of TMNS. [Points (A) and (B) may be found on Fig. 4.]

\begin{tabular}{|c|c|c|c|}
\hline & $\begin{array}{c}\text { Potential peak } \\
{[\text { point (A)j }}\end{array}$ & $\begin{array}{c}\text { Center of barrier } \\
\text { [point (B)] }\end{array}$ & Total \\
\hline $\begin{array}{l}\text { Power absorbed by plasma, } \\
\text { both ends of TMNS (MW) }\end{array}$ & 6.56 & 6.50 & 13.16 \\
\hline$B_{\text {vac }}(\bar{r})$ & 3.6 & 1.8 & \\
\hline$f=f_{c e}=28 B_{v a c}(G H z)$ & 100 & 50 & \\
\hline$n_{e \max }\left(10^{13} \mathrm{~cm}^{-3}\right)$ & $\sim 2$ & $\sim 1$ & \\
\hline$f_{p e}=8.97 \times 10^{-6} n_{e}^{1 / 2}(\mathrm{GHz})$ & 56.8 & 28.4 & \\
\hline
\end{tabular}


The performance requirements indicated in Table 9 are believed to be within the reach of near-term technology. In our TMR design of 1979 (Ref. 4, Ch. 6), we discussed a similar set of ECRH requirements and showed how they can be fulfilled by extensions of technology already under development. During the past few months, these expectations have been strengthened in the following ways:

- Improved rf windows have recently made possible the steady-state operation of comnercially available, $28-\mathrm{GHz}$ gyrotrons at power levels up to $212 \mathrm{~kW}$. The improved windows consist of two slabs of dielectric (alumina or beryllia) cooled by a liquid dielectric flowing between them. Since the window losses are proportional to frequency, it is possible to design for average power densities of $\mathrm{K} / \mathrm{f}$, where $\mathrm{K}$ has been experimentally proven to be at least $187 \mathrm{~kW} \cdot \mathrm{GHz} / \mathrm{cm}^{2}$, and where new designs are based upon values of $\mathrm{K}=400 \mathrm{~kW} \cdot \mathrm{GHz} / \mathrm{cm}^{2}$.

- Development of gyrotrons with steady-state outputs of $1 \mathrm{MW}$ each is a reasonable expectation during the next few years, according to the opinions of several scientists working in this field. ${ }^{21}$ Pulsed gyrotrons have already been reported at 1-MW operation. ${ }^{22}$ This implies a window diameter of $18 \mathrm{~cm}$ for a frequency of $100 \mathrm{GHz}$. The $0.3-\mathrm{cm}$ microwaves must be transmitted at high mode numbers in the $18-\mathrm{cm}$ waveguide.

- Gyrotron efficiencies can theoretically be improved either by tapering the magnetic field in the resonant cavity or by tapering the cavity itself. 23 The Naval Research Laboratory is predicting an enhanced efficiency of $60 \%$; a gyrotron with an output of $147 \mathrm{~kW}$ at $47 \%$ efficiency has already been commercially tested. We believe that the other losses (waveguide, windows, plasma absorption, etc.) will be small under TMNS conditions, and we are therefore assuming an overall efficiency of $50 \%$.

A recent experiment in the ISX-B Tokamak 24 is noteworthy because a high-power gyrotron $(80-\mathrm{kW}, 35-\mathrm{GHz})$ has injected microwaves into a plasma under conditions such that significant ECRH absorption occurred for a single transit. The electron temperature increased from $850 \mathrm{eV}$ to $1250 \mathrm{eV}$, in agreement with calculations. For the first time, it was demonstrated that the electron temperature in a tokamak scales linearly with ECRH power.

Four ECRH assemblies are required to heat each of the two thermal barriers and the two potential-peak regions. Each assembly will consist of 
only four gyrotrons, each of which is assumed to inject 1-MW into the plasma at $50 \%$ overall efficiency. This includes $20 \%$ extra capacity. Each gyrotron has an input power of $2 \mathrm{MW}$, which is the power of an 80-keV, 25-A electron beam. The total connected input power is $32 \mathrm{MW}$ for the 16 gyrotrons. 


\section{ENGINEERING DESIGN}

TMNS is a tandem-mirror machine employing quadrupole end cells with thermal barriers. The engineering task is to convert the physics requirements for field configuration, fueling, heating, and vacuum environment into an integrated system that can be built with near-term technology. The most significant technological constraint imposed on the physics parameters is the 12-T conductor field limit for $\mathrm{Nb}_{3} \mathrm{Sn}$ superconductor, which in turn limits the peak centerline vacuum magnetic field to $9 \mathrm{~T}$.

This section describes the engineering design. The discussion is organized in accordance with the work breakdown structure (WBS) shown in Table 10. In this structure, the nuclear system comprises the components within the reactor vault, the nuclear auxiliary systems are those directly servicing the reactor, and the plant facilities include the "conventional facilities."

Table 10. TMNS work breakdown structure (WBS).

\begin{tabular}{ll}
1.0 & Nuclear system \\
.1 & Magnets \\
.2 & Vessels \\
.3 & Fueling and heating \\
.4 & Vacuum pumping \\
.5 & Direct converters \\
.6 & Shielding and blanket \\
& \\
2.0 & Nuclear auxiliary systems \\
.1 & Cryoplant \\
.2 & Power supply \\
.3 & Tritium \\
.4 & Power conversion \\
.5 & Controls and instrumentation \\
.6 & Maintenance \\
& \\
3.0 & Plant facilities \\
.1 & Site \\
.2 & Reactor building \\
.3 & Ancillary structures \\
.4 & Heat rejection \\
.5 & Electrical power \\
4.0 & Project management \\
.1 & Project office \\
.2 & System integration \\
.3 & Safety \\
.4 & Quality assurance \\
\hline
\end{tabular}


The limited level of effort available for this study forced us to concentrate our work on the most critical design issues. We have related our work to other studies where appropriate, and have pointed out areas for further study or in need of R\&D effort.

NUCLEAR SYSTEM

Because the nuclear system is the most complex and costly of the major systems, it received the major emphasis in this study. As seen in Fig. 15, the nuclear system consists of three principal units: the two end cells (each containing a yin-yang cell and a thermal-barrier cell) and the central cell. The end-cells are mirror images that are rotated $90^{\circ}$ to each other around the z-axis.

Starting at the end of the machine and wor:ing inward, the first item we encounter is the high-energy pump beam (HEPB) system that fires through openings in the direct converters into the thermal-barrier cell. The direct converters are arranged to intercept the leakage plasma at the end wall. The main cryopump panels are parallel to the plasma fan. Straddling the pumping chamber are the arrays of medium-energy pump beams (MEPB). These fire through openings in the barrier-cell magnet structure into the barrier cell. The lowenergy pump beams (LEPB) are aimed at right angles to the machine center plane just inside the barrier-cell magnet. Two sets of ECRH wave guides also terminate in this region. The barrier-cell magnet forms the barrier well and the mirror that provide the stoppering function for the plasma.

In-board of the barrier-cell magnets is located the yin-yang coil pair. These two coils form the minimum-B field that stabilizes the plasma. Not visible in Fig. 15, but shown in Fig. 16, are the beam lines which are at $45^{\circ}$ to the transverse axis of the yin-yang magnets.

In-board of the end cell is the transition magnet that recircularizes the plasma flux tube as it enters the central cell. The central cell is surrounded by the circular solenoidal coils that form the essentially flat field profile for containing the large central-cell plasma.

The entire interior of the machine is lined with a cooled shield. The central cell also has space for a tritium-breeding blanket. The outside of the machine is covered with shielding to absorb any neutrons not captured internally and to shield the vault from gamma rays emitted from neutron-activated internal structures. 


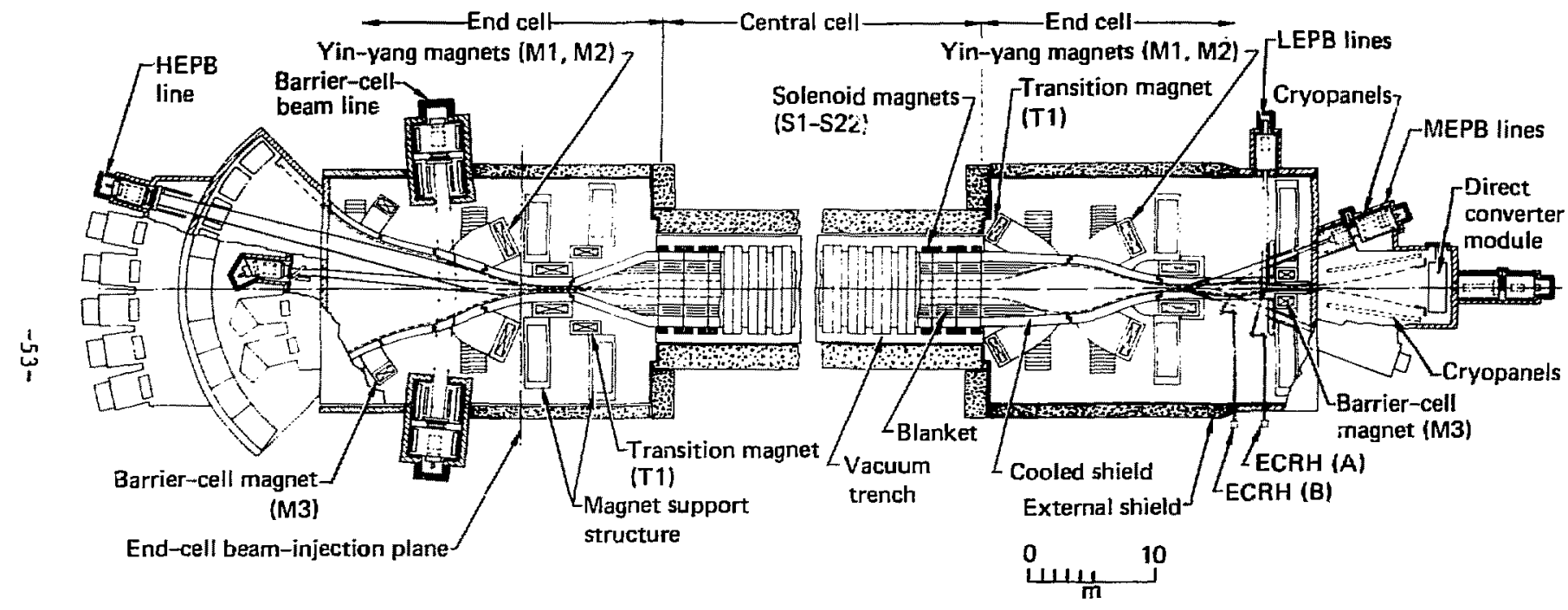

Fig. 15. The nuclear system of TMNS. Magnet identification numbers are shown in parentheses, e.g., yin-yang magnets (M1, M2). The ECRH injection points (A) and (B) are identified on Fig. 4. 

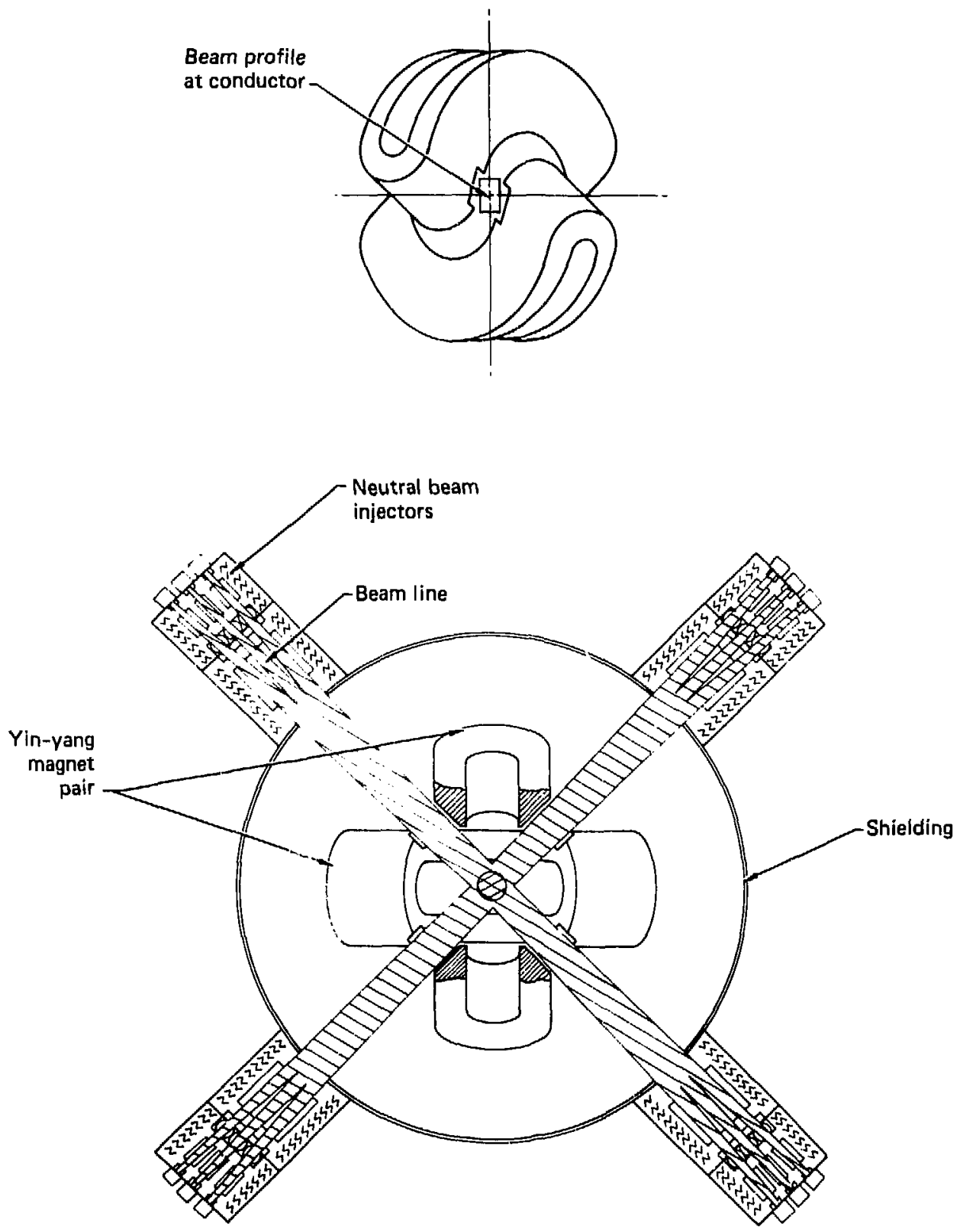

Fig. 16. Neutral-beam trajectory into the yin-yang pair in the end cell. The insert shows the beam profile at the conductor. Note the beveling of the conductor pack to allow passage of the beams. 
Magnet Systerm

Requirements and Performance: Overall Requirements. The magnet system for TMNS has been developed to a point suitable for overall machine layours, structural analysis, conductor assessment, and neutral-beam integration. The overall length of the machine is nominally $116 \mathrm{~m}$, with $68 \mathrm{~m}$ between the yinyang cells. The effective machine length of the central cell is $50.9 \mathrm{~m}$.

Mirror peak magnetic fields of $9 \mathrm{~T}$ on-axis will require the use of $\mathrm{Nb}_{3} \mathrm{Sn}$ superconductor for operation at $12 \mathrm{~T}$. Ni-Ti superconductor will be used where the field at tha conductor is less than $8 \mathrm{~T}$. The vacuum magnetic Field plot, $B(z)$, and coil locations are shown on Fig. 3. Figures 17 and 18 8 nuw how the coils are located in an 18-m-diam shielded vacuum tank at each end of the machine. The coil case and support structure will be fabricated from type $304 \mathrm{LN}$ atainless steel and cooled to $4.5 \mathrm{~K}$.

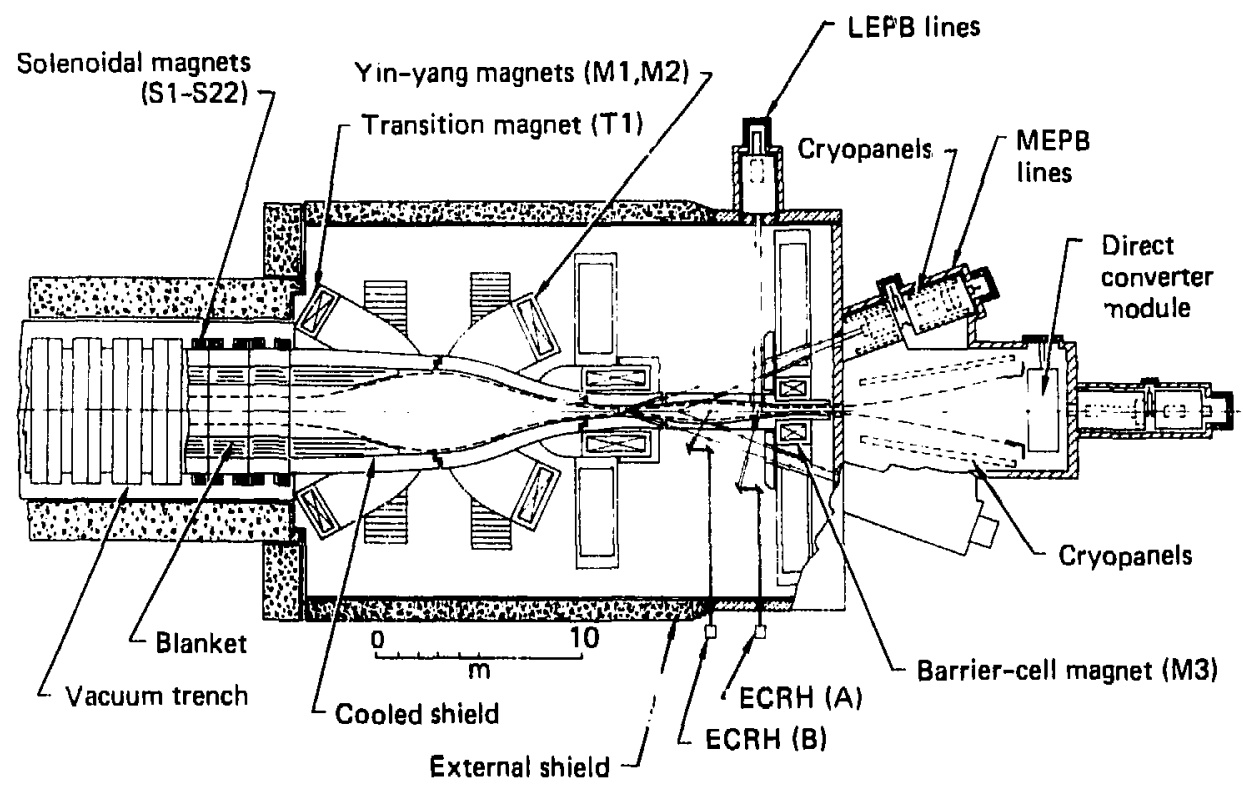

Fig. 17. Enlarged view of the end-cell region of the TMNS nuclear syatem depicted in Fig. 15, showing plasma fan and HEPB and barrier-cell beam lines. 


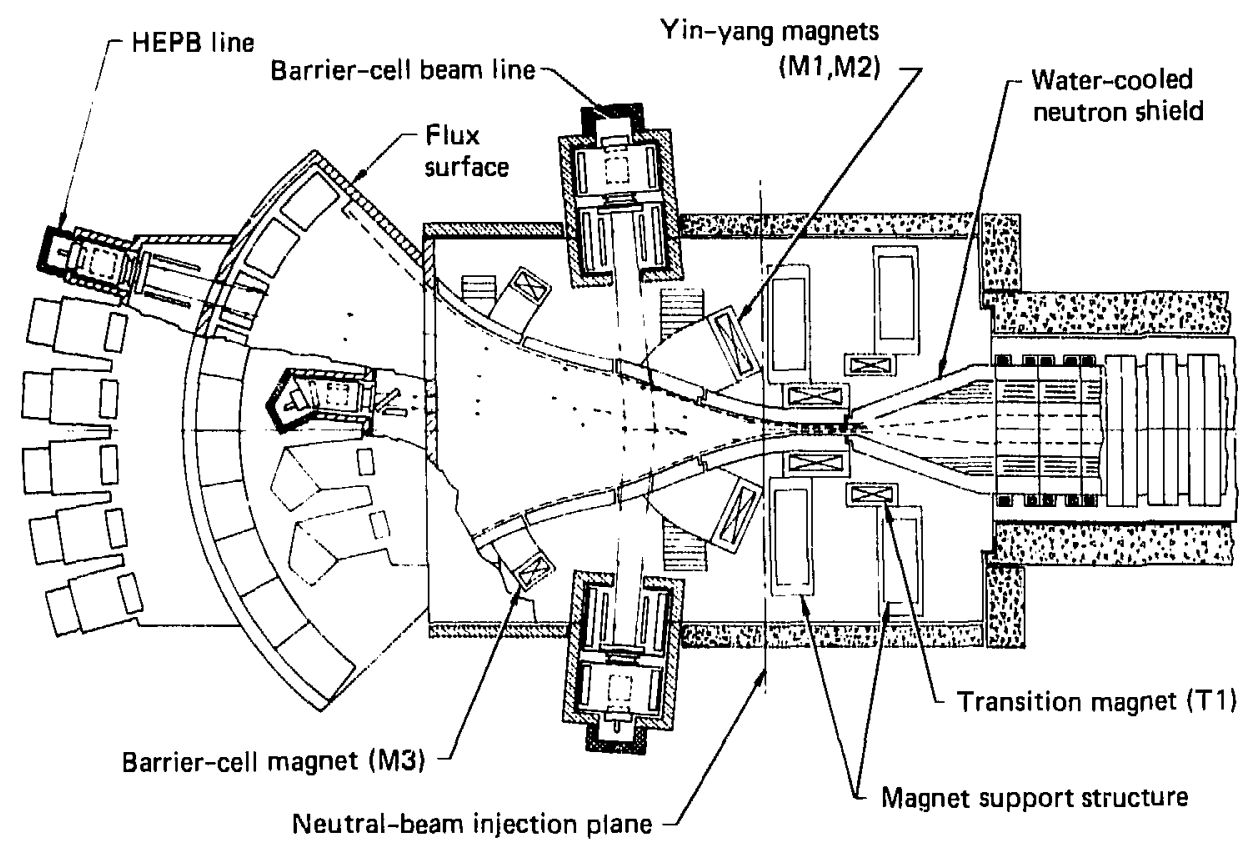

Fig. 18. Enlarged view of the end-cell region of the TMNS nuclear system in Fig. 15 showing the location of the MEPB and LEPB lines.

Because the neutral beams are directed through or near the coil structures, numerous water-cooled liners will be required to protect the cold structures. The inner water-cooled neutron shield will require special shapes to protect the coils from neutron radiation damage and from heating caused by neutron-induced gamma radiation.

In designing the magnet system we made the following assumptions regarding the configuration:

- The magnet system consists of solenoidal and quadrupole elements to produce:

A uniform-field central-cell region;

Minimum-B end-cell regions; and

Barrier-cell regions.

- The quadrupole fields are produced with C-shaped magnets with a yinyang pair for the end-cell regions. 
- The design field levels and scale lengths are:

$\begin{array}{ll}\text { Central-cell uniform field, } & { }_{\mathrm{B}_{c}:} 2.5 \mathrm{~T} \\ \text { Yin-yang cell mirror, } & { }_{\mathrm{Bp}}: 9 \mathrm{~T} \\ \text { Yin-yang cell minimum, } & { }_{\mathrm{B}}: 6 \mathrm{~T} \\ \text { Barrier well, } & \mathrm{B}_{\mathrm{Ob}}: 1.8 \mathrm{~T} \\ \text { Barrier mirror, } & \mathrm{B}_{\mathrm{mb}}: 9 \mathrm{~T} \\ \text { Yin-yang cell plasma radius, } & \mathrm{r}_{\mathrm{p}}: 0.56 \mathrm{~m} \\ \text { Central-cell plasma radius, } & \mathrm{r}_{\mathrm{c}}: 0.83 \mathrm{~m} \\ \text { Central-cell length (effective) } & \mathrm{L}_{\mathrm{c}}: 50.9 \mathrm{~m}\end{array}$

Our design was subject to the following engineering constraints:

- The coil designs will utilize $\mathrm{Nb}_{3} \mathrm{Sn}$ technology where necessary, with a field limit of $12 \mathrm{~T}$, and $\mathrm{Nb}-\mathrm{Ti}$ technology where suitable, with a field limit of $8 \mathrm{~T}$.

- The coil designs will accomodate the space required for neutron shielding between the plasma and coils.

- The current density in the high-field coils will be held at about $2 \times 10^{7} \mathrm{~A} \cdot \mathrm{m}^{-2}$.

- The long cooldown and warmup times required ( 1 to 2 weeks) necessitate an exterior vacuum jacket around each coil structure to permit the machine vacuum vessel to come up to air independently of magnet operation.

Design Description. The overall magnet configuration is depicted in Fig. 19. Parametric values are summarized in Table 11 and operating currents in Table 12.

Central Cell (S1 through S22). The solenoid layout in the central cell is based on a 2-m-long module length, with two coils per module. Twenty-two modules are used, resulting in a solenoidal length of $44 \mathrm{~m}$ and an effective central-cell length of $50.9 \mathrm{~m}$. The mean diameter of each coil is $6.5 \mathrm{~m}$ to accommodate a $0.83-m^{-m}$ radius plasma, a $2-m$ radiation sinield, and $0 . j-m$ thermal shield and vacuum enclosure.

Yin-Yang Cello (M1 and M2). A yin-yang pair is utilized for the minimum-B end-cell region. Given the desired field level, mirror ratio, and current dengity, the coil size is limited by space requirements at the mirror throat, which limits the size of the minor radius. 


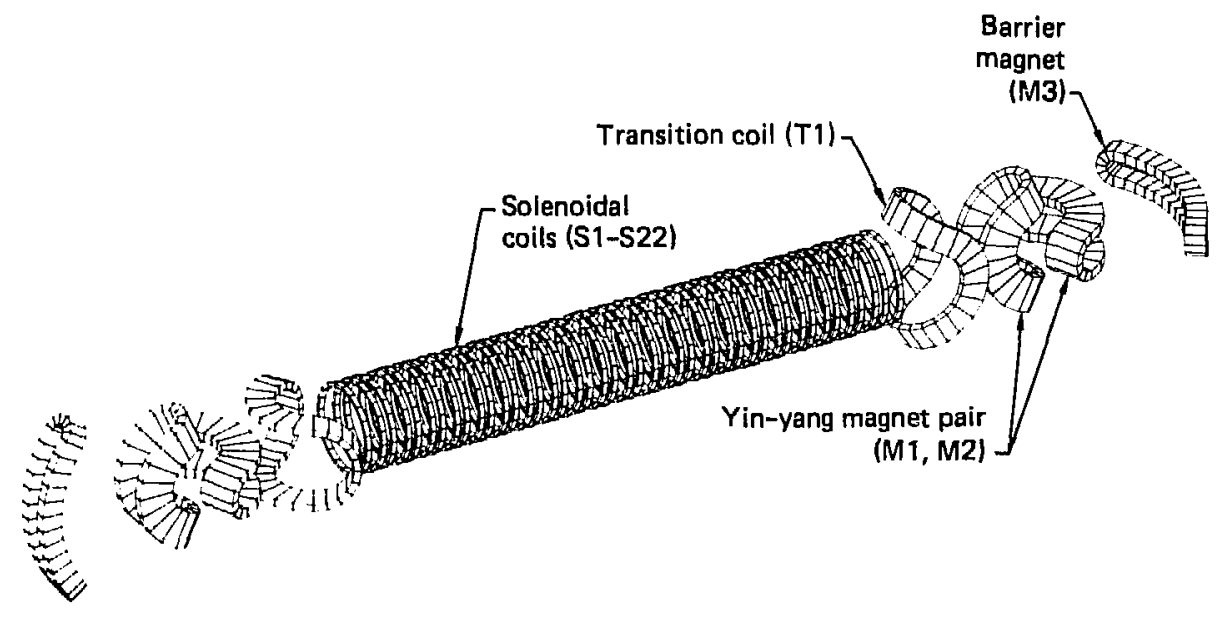

Fig. 19. Computer drawing of the TMNS magnet configuration. 
Table 11. Magnet system physical parameters ( 52 coils total).

\begin{tabular}{|c|c|c|c|c|c|c|c|}
\hline \multirow{2}{*}{$\begin{array}{c}\text { Coil } \\
\text { ident. }\end{array}$} & \multirow[b]{2}{*}{$\begin{array}{l}\text { Coil } \\
\text { type }\end{array}$} & \multirow[b]{2}{*}{$\begin{array}{l}\text { No. } \\
\text { required }\end{array}$} & \multicolumn{5}{|c|}{ Parameters } \\
\hline & & & $\begin{array}{l}\text { M- } \\
\text { (m) }\end{array}$ & $\begin{array}{l}\text { Minor } \\
\text { radius } \\
\text { (m) }\end{array}$ & $\begin{array}{l}\text { Sweep } \\
\text { angle } \\
\text { (deg.) }\end{array}$ & $\begin{array}{l}\text { Bund le cross } \\
\text { selection } \\
(m \times \mathrm{m})\end{array}$ & $\begin{array}{l}\text { Tura } \\
\text { length } \\
\text { (m) }\end{array}$ \\
\hline Barrier (M3) & C & 2 & 10.00 & 1.00 & 35 & $1.54 \times 0.80$ & 30.72 \\
\hline Yin-yang $(M 1, M 2)$ & c & 4 & 3.70 & 1.50 & 65 & $2.72 \times 0.68$ & 26.21 \\
\hline Transition (T1) & c & 2 & 3.70 & 3.00 & 60 & $2.00 \times 0.50$ & 34.35 \\
\hline Central cell ( $\mathrm{Sl}$ through $\mathrm{S} 22$ ) & Solenoid & 44 & (me: & $\begin{array}{l}0 \\
i a m)\end{array}$ & & $0.40 \times 0.24$ & 20.42 \\
\hline
\end{tabular}


Table 12. Magnet system operating currents.

\begin{tabular}{lcc}
\hline $\begin{array}{c}\text { Coil } \\
\text { ident. }\end{array}$ & $\begin{array}{l}\text { Ampere } \\
\text { turns } \\
\text { (MA) }\end{array}$ & $\begin{array}{c}\text { Current } \\
\text { density } \\
\left(10^{7} \mathrm{~A} \cdot \mathrm{m}^{-2}\right)\end{array}$ \\
\hline S1 through 520 & 1.97 & 2.05 \\
S21 & 2.64 & 2.75 \\
S22 & 2.30 & 2.40 \\
T1 & 25.00 & 2.50 \\
M1 & 32.37 & 1.75 \\
M2 & 37.73 & 2.04 \\
M3 & 24.89 & 2.02 \\
\hline
\end{tabular}

For the present TMNs coil design (Fig. 20), we assume the following space allowance (working outward Erom the center line of the machine to the conductor):

$\begin{array}{lc}\text { Plasma half thickness } & 10 \mathrm{~cm} \\ \text { Vacuum space } & 5 \\ \text { First wall } & 5 \\ \text { Neutron shielding } & 60 \\ \text { Vacuum wall } & 4 \\ \text { Stiffener } & 5 \\ \text { Vacuum space } & 2.5 \\ \text { Magnet vacuum wall } & 2 \\ \text { Vacuum space } & 1 \\ \text { Liquid-nitrogen baffle } & 1.5 \\ \text { Vacuum space } & 1 \\ \text { Case } & 13 \\ \text { Bladder } & 5 \\ \text { Jacket } & 4 \\ \text { Insulation } & 1 \\ & \\ \text { Total distance from axis } & \\ \text { to conductor: } & 120 \mathrm{~cm}\end{array}$




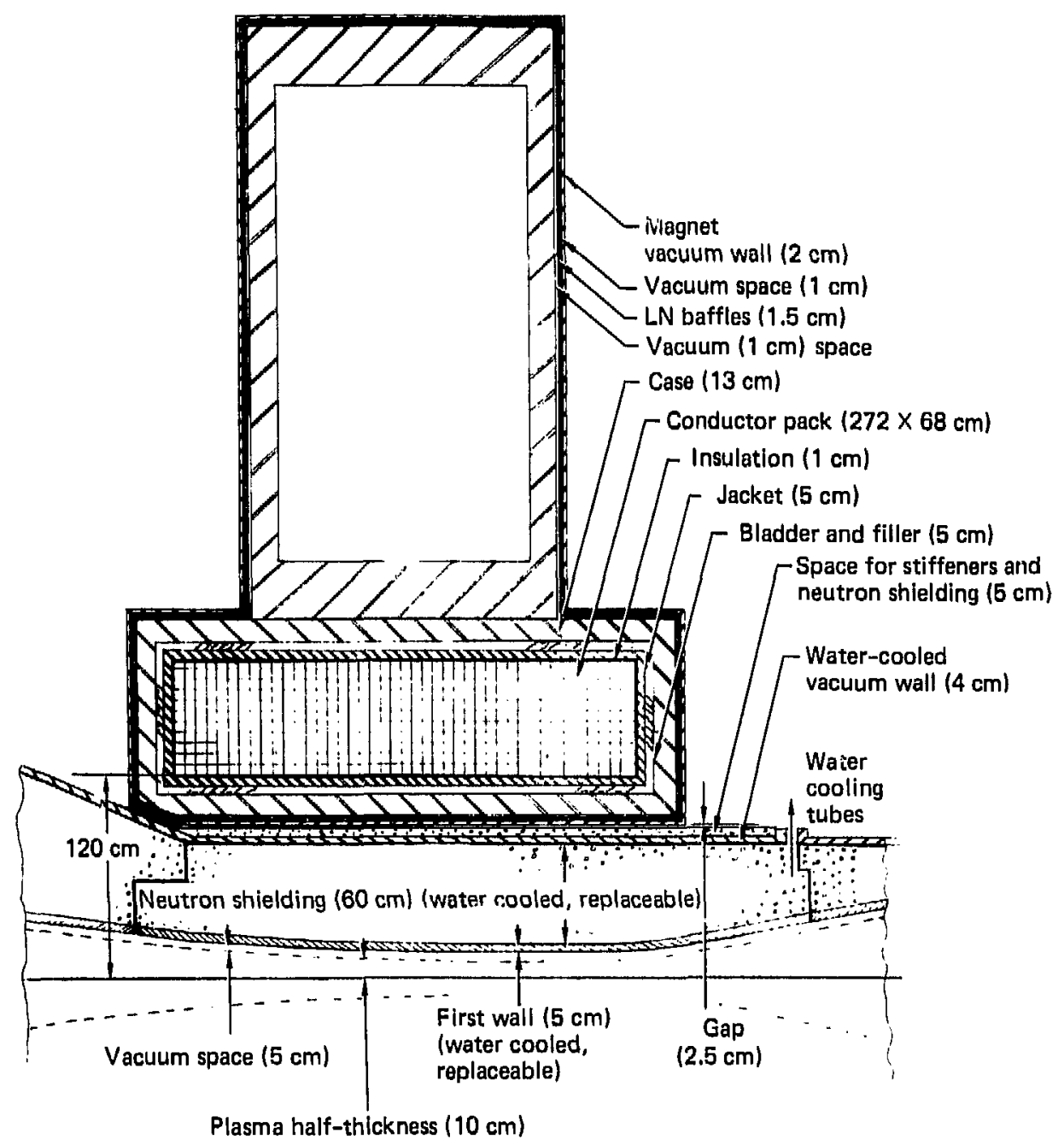

Scale: $1 \mathrm{~cm}=10 \mathrm{~cm}$

Fig. 20. Cross section at the mirror throat of the yin-yang magnets ( $M I$ and $M 2$ in Fig. 15). 
This results in a minor mean radius of $1.5 \mathrm{~m}$; to achieve a mirror ratio of 1.5:1, the major radius is $3.7 \mathrm{~m}$. The sweep angle is made as small as possible to reduce the elipticity of the flux surface, both for the transition and the barrier regions. A $65^{\circ}$ (half-angle) sweep is sufficient to maintain a minimum-B condition at the nominal plasma surface. The aspect ratio for the conductor pack is now somewhat arbitrary; it is related to the current density and maximum conductor field, and needs refinement in future design iterations. The rectangular conductor pack will probably be beveled on one edge to permit the passage of neutral beams and to provide space for the water-cooled neutron shield. Figures 16 and 21 show the neutral-beam trajectory into the yin-yang pair.

Transition Coil (T1). A single C-shaped magnet is utilized in the transition region. To maintain a smooth field profile, the minor radius is quite large $(3.0 \mathrm{~m})$. A reduction in the size of this coil can be achieved only by digtributing the current axially, which would require two or more transition coils.

Barrier Cell (M3). The barrier-cell mirror field is produced with a $\mathrm{c}$-shaped magnet having a major radius of $10 \mathrm{~m}$ and a minor radius of $1 \mathrm{~m}$. The current space budget between the center line and the surface of the coil is:

$\begin{array}{lc}\text { Plasma/pump beam } & 10 \mathrm{~cm} \\ \text { First-wall liner } & 5 \\ \text { Neutron shielding } & 10 \\ \text { Vacuum space } & 5 \\ \text { Coil thermal shield } & 10 \\ \text { Coil structure } & 20 \\ \begin{array}{l}\text { Distance from axis } \\ \text { to conductor }\end{array} & 60 \mathrm{~cm}\end{array}$

The axial position of this coil is very dependent on the minor radius. To achieve a 5:1 mirror ratio from barrier peak to barrier minimum, the present coil dimensions require the center of the coil be at $z=22 \mathrm{~m}$. 


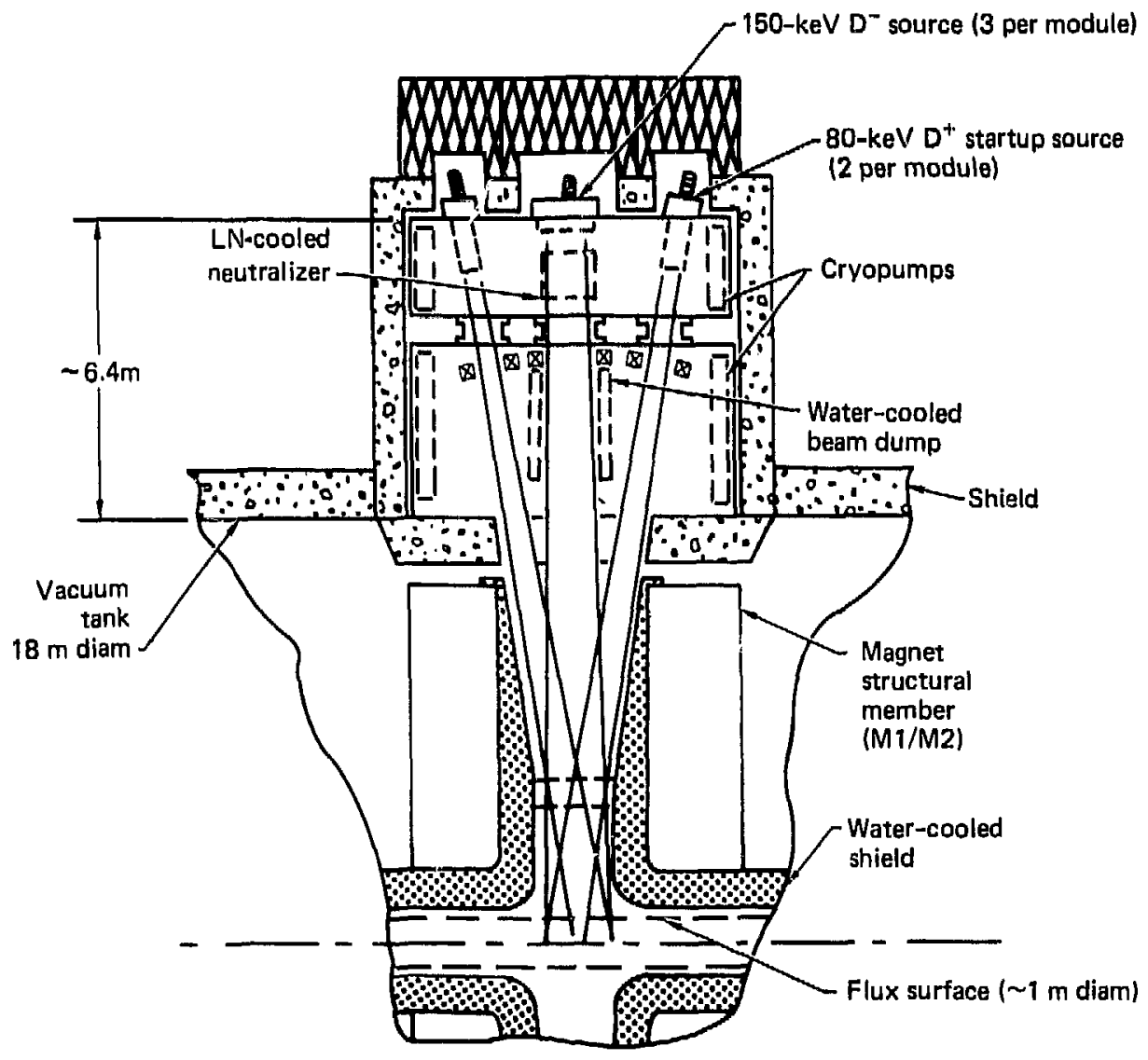

Fig. 21. Detailed cross section of one of the neutral-beam injectors in Fig. 16 (including the $80-\mathrm{kV}$ starter beams) and showing the beam array for injection into the yin-yang cell. 
C-Coil Structure. The magnetic forces on the magnet coils will be supported by a welded case and a LHe-cooled external structure. The EFrI fieldForce computer code was used to calculate the lobe-spreading forces (Table 13) on the c-coils using the parameters listed in Table 11.

Table 13. Lobe-spreading forces on C-coils.

\begin{tabular}{ll}
\hline Coil & $\begin{array}{c}\text { Lobe spreading Force, } \\
\mathrm{GN}\left(10^{6} \mathrm{~b}\right)\end{array}$ \\
\hline M3 & $1.05(235)$ \\
M2 & $1.57(350)$ \\
M1 & $1.34(300)$ \\
T1 & $0.66(148)$ \\
\hline
\end{tabular}

We used a simplified design approach to determine the approximate dimensions of the coil case and the external support structure. We

- Assumed that type 304 LN stainless steel, which has a yield stress of $771 \mathrm{MPa}(111,800 \mathrm{psi})$ at $4.5 \mathrm{~K}$, would be used in both the case and the external structure,

- Limited the combined tensile and compression stress generated in any structure to $552 \mathrm{MPa}(80,000 \mathrm{psi})$ with the deflections not to exceed $19.1 \mathrm{~mm}$ $(0.75 \mathrm{in.})$, and

- Limited the case wall, which resists a very large conductor pressure, to a 203-mm (8-in.) maximum thickness for reasons of fabrication.

The lobe-spreading force is carried by a box-beam tensile member structure as shown in Fig. 22. The tensile member consists of a number of flat plates which are secured to the box beam at the ends but are free to elongate and bend individually when the box beam is subjected to the load. When this design is compared to a support structure designed like a window frame, we see that the overall diameter of the vacuum vessel to house the magnet structure could be reduced from $24 \mathrm{~m}$ to $18 \mathrm{~m}$.

The weights of the coils and structure based on a box-beam tensile member structure are 1 isted in Table 14.

Inter-Coil structure. During normal operating conditions, the magnetic forces between coils are large, and LHe-cooled intercoil support structures are required. Approximate values of the intercoil forces are shown in Table 15. 


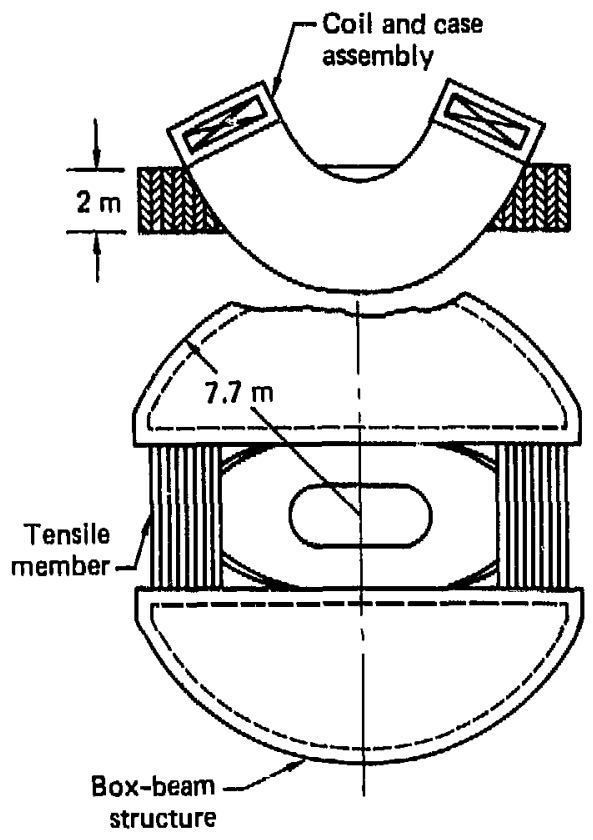

Fig. 22. External support structure for one of the magnets in the yin-yang pair (magnet MI).

Table 14. Weights of coils and structure.

\begin{tabular}{lccccc}
\hline & \multicolumn{5}{c}{ Coil ident. } \\
\cline { 2 - 5 } \multicolumn{1}{c}{ Component } & $\mathrm{Mg}\left(10^{3} \mathrm{Mb}\right)$ & $\mathrm{Mg}\left(10^{3} \mathrm{lb}\right)$ & $\mathrm{Mg}\left(10^{3} 1 \mathrm{~b}\right)$ & $\mathrm{Mg}\left(10^{3} 1 \mathrm{~b}\right)$ \\
\hline \multirow{2}{*}{$\begin{array}{c}\text { Conductor } \\
\text { Coil Case }\end{array}$} & $179(394)$ & $229(504)$ & $229(504)$ & $162(357)$ \\
External structure & $182(413)$ & $232(511)$ & $232(511)$ & $224(493)$ \\
& $1101(2427)$ & $1477(3257)$ & $1477(3257)$ & $1454(3161)$ \\
& $1467(3234)$ & $1938(4272)$ & $1938(4272)$ & $1819(4011)$ \\
\hline
\end{tabular}


Table 15. Intercoil forces.

\begin{tabular}{cr}
\hline Coil ident. & Axial force, $10^{4} 1 \mathrm{~b}$ \\
\hline M3 & -10.0 \\
M2 & -76.5 \\
M1 & 19.8 \\
T1 & 23.4 \\
S7 & -8.3 \\
S6 & -5.0 \\
S5 & 7.0 \\
S4 & 3.5 \\
S3 & 5.3 \\
S2 & -4.2 \\
S1 & 4.6 \\
\hline
\end{tabular}

An intercoil atructure consisting of four cooled support members betwees: each magnet is illustrated in Fig. 23. These members have been located to clear neutral-beam trajectories and to permit assembly and dissassembly of the inner water-cooled neutron shield.

Comparison to MFTF-B. The magnet layout for TMNS is very similar to that for MFTF-B except that the maximum conductor magnetic field has been increased from $7.7 \mathrm{~T}$ to $12 \mathrm{~T}$. To obtain a comparison between the two systems, the physical characteristics of one yin-yang coil for each system are listed in Iable 16 .

R\&D Work. The fabrication of the coils will require significant development because it is beyond present technology. Potentially required R\&D projects include the following:

- Development of the $\mathrm{No}_{3} \mathrm{Sn}$ conductor and conductor pack. Extremely high forces and stress levels will be encountered. We must develop organic materials for use at high compression loads and in a neutron radiation environment.

- Development of new fabrication techniques and facilities for coil assemblies twice the size and 10 times the weight of MFTF-B coils.

- Development of coil assembly support structures to permit high shrinkage rates due to Lhe temperatures, to resist forces between magnet coil, to provide protection againat seismic forces, and to maintain a vacuum seal between removable central-cell modules. 
(a)
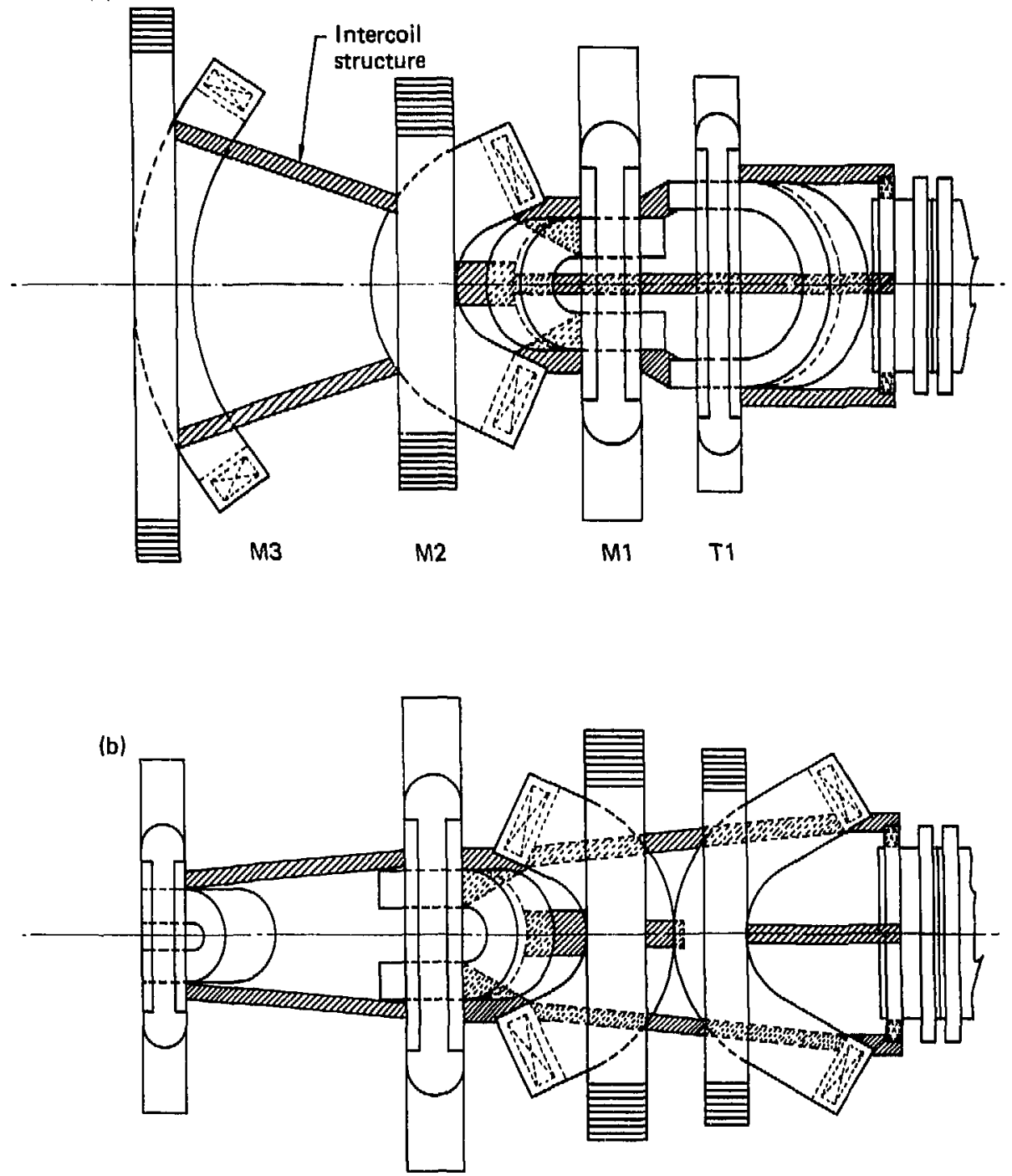

Fig. 23. The intercoil support structure: (a) plan view, and (b) elevation. 
Table 16. Comparison between MFTF-B and TMNS magnets.

\begin{tabular}{|c|c|c|}
\hline & MFTF-B & TMNS (M2) \\
\hline Maximum conductor field $(\mathrm{T})$ & $\leq 7.7$ & $\leq 12$ \\
\hline Lobe spreading force $\left(10^{3} \mathrm{lb}\right)$ & 22 & 350 \\
\hline $\begin{array}{ll}\text { Conductor } & \text { Volume }\left(\mathrm{m}^{3}\right) \\
\text { bundle } & \text { Weight }\left(10^{3} \mathrm{lb}\right)\end{array}$ & $60^{5.8}$ & $\begin{array}{r}49 \\
504\end{array}$ \\
\hline Coil case weight $\left(10^{3} 1 \mathrm{~b}\right)$ & 255 & 511 \\
\hline Conductor and case weight $\left(10^{3}(\mathrm{~b})\right.$ & 315 & 1011 \\
\hline Exterior coil support structure $\left(10^{3} \mathrm{lb}\right)$ & - & 3257 \\
\hline Total magnet weight $\left(10^{3} \mathrm{lb}\right)$ & 315 & 4268 \\
\hline $\begin{array}{l}\text { Wiameter of vessel required to } \\
\text { contain magnet structure (m) }\end{array}$ & 10.6 & 18 \\
\hline
\end{tabular}

\section{Vessel System}

Requirements and Performance: Overall Requirements. Large vacuum vessels are required at each end of the machine to contain the end-cell magnets and to huuse the gridelemencs for the direct converters. These vessels will be all rype 304 stainless steel with external radiation shielding that may be used for additional structural strength. All-metal, double-sealed, differentially pumped flanges will ensure a vacuum-tight seal after long exposures to neutron radiation. Since the neutral beams will be operated in a continuous mode, large cryopanel areas are required to handle the gas load and to maintain a vacuum of $1 \times 10^{-6}$ Torr. Most of the cryopanels will be mounted in the direct converter vessels. The neutral-beam domes will be double-chambered and equipped with apertures and cryopanels to reduce the gas flow into the large vessels,

Because of the large size of the vessels and the eventual buildup of neutron-induced gamma radiation, we must provide access for maintenance. 
End-Cell Vessel. The vacuum vessel for each of the end cells is cylindrical (18 $\mathrm{m}$ diam. by $26 \mathrm{~m}$ long) and houses the transition, yin-yang pair, and barrier-cell magnets. It is connected to the $2-m$ central-cell modules and the vacuum trench on one side and to the direct converter vessel on the other side. Domes for all of the neutral beams, except the HEPB's, will be mounted on this vessel. The vessel must support the weight of the magnets and the additional forces encountered when the magnet is cooled down and energized. It must also support 1 - to $2-m$-thick neutron shielding and atmospheric pressure forces. Preliminary calculations indicate that a vessel with a 5-cm-thick wall and reinforcing ribs would wirhstand atmospheric pressure only, not the weight of the shielding. Fucire desigis tiould include the shielding as a structural member of the vessel.

Direct Converter Vessel. The vacuum vesse! iof each set of direct converter modules is fan-shaped (27 $\mathrm{m}$ wide at its largest dimension) in one plane and has nearly parallel flat surfaces ( 6 m apart) in the other. The neutron-gamma shielding ( $0.5 \mathrm{~m}$ thick) is used to stiffen the large, flat, vacuum walls. This vessel houses the direct converter grid modules and approximately $200 \mathrm{~m}^{2}$ of cryopanels. The six HEPB's will be mounted to the end of this vessel.

Future End-Cell Vessel Configuration Study. An alternative to the external end-cell vessel would be an internal one that is much smaller but more complex in shape. Access to the magnets would be more direct since the coils and structure are mounted externally to the vacuum vessel. However, the maintenance of this system after buildup of neutron-induced gama radiation needs further study.

\section{Fueling and Heating}

Many neutral beams are required to start, fuel, and heat the plasma. Figures 15 and 17 show the positions of the various neutral beams in relation to the end-cell magnets. The beams pass near or through magnet structures and must travel 13 to $31 \mathrm{~m}$, depending upon the source location. Also shown schematically are the ECRH units to heat the barrier electrons: five are required for each end. 
The neutral-beam sources will operate in a high-level radiacion environment and must be shielded to permit personiel access for maintenance. bucause all sources require perlodic servicing, replacement must be possible with a minimum exposure of personnel to radiation.

The sources must deliver a continuous, relatively pure hydrogen beam that is more uniform in energy than is possible with today's sources. Special $D^{-}$and $D^{+}$sources (see Figs. 12 and 13 ) with LN-cooled neutralizers and bend magnets with beam dumps are required. Two vacuun vessels for each source are mounted in series and cryopumped continuously to remove the excess gas. In general, the two vacuum vessels will be maintained at $1 \times 10^{-4}$ Torr and $1 \times 10^{-5}$ Torr pressure and will be outfitted with apertures to limit gas flow to the lower pressure region. The LN cooled neutralizer will be maintained at $1 \times 10^{-3}$ Torr pressure by a regulated $D_{2}$ gas flow at ita center.

Table 17 ists all continuously operated neutral-beam sources used for fueling and heating. The eight $80-\mathrm{keV}, 80-\mathrm{A} \mathrm{D}^{+}$neutral beams used for startup are not listed.

The number of souices in each module is determined by the machine requirements, the number of spares desired, the output of a source, and the optimum number and placement of modules on the machine. We estimated the required gas loeds and cryopumping areas by assuming efficiencies for beam transport and neutralization.

Design of the $\mathrm{D}^{-}$Source Module. To improve the performance of the ion source, we lower the pressure in the extractor portion of the source by mounting it in the vacuum vessel (see Fig. 13). The l-m-long neutralizer chamber is LN cooled to increase the molecular density and thereby to optimize neutralization of the $D^{-}$beam. A continuous $D_{2}$ gas supply at the center of the neutralizer produces a pressure gradient that provides the molecular density required for optimum neutralization. To obtain maximum vacuum conductance at each end for removal of excess neutralizer gas, the neutralizer is located at the center of the vacuum vessel. A cryopanel system that pumps gas continuously is used to maintain a $1 \times 10^{-4}$ Torr vacuum. An isolation vacuum valve at the exit of the neutralizer vacuun vessel permits removal of the source while the reactor vessel is still under vacuum. 
Table 17. Neutral-beam sources (for one end of machine only).

\begin{tabular}{|c|c|c|c|c|c|}
\hline & Yin-yang cell & $\begin{array}{l}\text { Bartier } \\
\text { cell }\end{array}$ & HEPB & MEPB & LEPB \\
\hline Species & $D^{-}$ & $\mathrm{D}^{-}$ & $\mathrm{D}^{-}$ & $\mathrm{D}^{+}$ & $D^{+}$ \\
\hline Beam energy (keV) & 150 & 200 & 150 & 66 & 2 \\
\hline I/sonzce (total beam) (A) & 12 & 12 & 12 & 80 & 80 \\
\hline$I^{0} /$ source $(A)$ & 6.5 & 6.5 & 6.5 & 36 & 65 \\
\hline No, of sources/module & 3 & 2 & 1 & 1 & 1 \\
\hline No. of modules & 4 & 2 & 6 & 8 & 3 \\
\hline I0 total possible (A) & 78 & 26 & 39 & 288 & 195 \\
\hline${ }^{0}$ total required & 47 & 12 & 26 & 175 & 70 \\
\hline I $^{0}$ spare sources & 4 & 2 & 2 & 3 & 1 \\
\hline $\begin{array}{l}\text { Gas supplied to source } \\
\text { module (Torr.1/s) }\end{array}$ & 34 & 23 & 11 & 30 & 41 \\
\hline $\begin{array}{l}\text { Gas supplied to neutralizer } \\
\text { module (Torr. } 1 / \mathrm{s} \text { ) }\end{array}$ & 27 & 18 & 9 & 9 & 0 \\
\hline $\begin{array}{l}\text { Total gas supplied } \\
\text { module (Torr-l/s) }\end{array}$ & 61 & 41 & 20 & 39 & 41 \\
\hline $\begin{array}{l}\text { Pressure in neutralizer } \\
\text { vessel }\left(10^{-4} \text { Torr }\right)\end{array}$ & 1 & 1 & 1 & 1 & : \\
\hline $\begin{array}{l}\text { Gas Load: neutralizer vessel } \\
\text { module (Torr. } 1 / \mathrm{s} \text { ) }\end{array}$ & $\sim 44$ & $\sim 29$ & $\sim 14$ & $\sim 30$ & $\sim 24$ \\
\hline $\begin{array}{l}\text { Area of neutralizer cryopumps } \\
\text { module }\left(\mathrm{m}^{2}\right)\end{array}$ & 6 & 4 & 2 & 4 & 4 \\
\hline $\begin{array}{l}\text { Pressure in vessel adjacent to } \\
\text { neutralizer }\left(10^{-5} \text { Torr }\right)\end{array}$ & 1 & 1 & 1 & 1 & 1 \\
\hline $\begin{array}{l}\text { Gas load in vessel adjacent to } \\
\text { neutralizer module (Torr } \cdot 1 / 8 \text { ) }\end{array}$ & $\sim 14$ & $\sim 10$ & $\sim 5$ & $\sim 5$ & $\sim 2$ \\
\hline $\begin{array}{l}\text { Area of cryopumps, vessel ad jacent } \\
\text { to neutralizer ( } \mathrm{m}^{2} / \text { module) }\end{array}$ & 20 & 14 & 7 & 7 & 3 \\
\hline
\end{tabular}


In the adjacent, lower-pressure vessel, bend magnets with water-cooled beam dumps remove the $\mathrm{D}^{+}$and $\mathrm{D}^{-}$components of the beam, and a continuously operated cryopanel system maintains a pressure of $1 \times 10^{-5}$ Torr. An aperture reduces gas flow into the reactor vessel, which is maintained at $1 \times 10^{-6}$ Torr.

Design of the $\mathrm{D}^{+}$source module. Except for the added problem of obtaining pure $\mathrm{D}^{+}$before neutralization, the modules for the $\mathrm{D}^{-}$and $\mathrm{D}^{+}$sources are nearly the same. In the latter (Fig. 13), an additional magnat and beam stop placed between the neutralizer chamber and the ion source remove the $\mathrm{D}_{2}^{+}$ and $\mathrm{D}_{3}^{+}$from the beam.

The $\mathrm{D}^{+}$sources will be very similar to present-day sources except for the following: the extractor grid structure must be water cooled for continuous operation, and the extractor grid must be mounted as closely as possible to the $1 \times 10^{-4}$ Torr vacuum vessel.

Yin-Yang Neutral-Beam Modules. Four modules, each containing three 150-kev, 12-A $D^{-}$sources, inject neutral beams into the center of the yin-yang pair (see Figs. 17 and 18): four of these twelve sources are spares. These sources will be exposed to the highest neutron flux of any of the sources in the machine and will require the largest amount of shielding. Two $80-k e v \mathrm{D}^{+}$ $i$ on sources are provided in each module for startup of the plasma. Providing space for the beams to pass between the yin-yang coils and yet providing adequate neutron shielding around the coils is significant.

Barrier-Cell Neutral-Beam Modules. Two modules, each containing two 200-keV 12-A $D^{-}$sources, inject neutral beams into each barrier cell to produce a thermal barrier (see Fig. 17). So that the beams will clear the coil structure and neutron shielding, the modules are mounted at an angle and as close to the plasma as possible.

Pump Beams. As described in Sec. 5, nzutral beams are used to remove by charge exchange those ions that become trapped in the barrier region. For economy of beam power, three sets of beams at different energies are used for this function, namely, high-, medium-, and low-energy pump beams. 
High-Energy Pump Beams (HEPB). Six HEPB modules with one 150-keV, 12-A $D^{-}$source in each are required at each end of the machine (see Figs. 17 and 18). The modules are mounted on the direct converter vacuum vessel. The grid structure of the direct converter module must be modified to permit passage of the neutral beams from the HEPB.

Medium-Energy Pump Beam (MEPB). Eight MEPB modules with one 80-keV, 80-A $0^{+}$ source in each are required at each end of the machine (see Figs. 17 and 18). The optimum beân trajectory from the source to the plasma necessitateo that openings be provided through the outer structure of the barrier-cell coil. Some difficulty may be encountered in steering the beam because the $\nu^{+}$ions must pass through the bending magnet before being neutralized.

Low-tinergy Pump Beam (LEPB). Three LEPB modules with one 2-keV, $80-\mathrm{A} \mathrm{D}_{2}$ source each are required for pumping and charge exchange in the barrier-cell (see Figure 18). Construction of the sources and the neutralizer is similar to that in present-day sources, except that the grid structure must be water cooled for continuous operation. A cryopanel system for continuous pumping must also be provided to maintain a $1 \times 10^{-4}$ Torr and $1 \times 10^{-5}$ Torr vacuum, respectively, in the adjacent beam-line vessels.

\section{Vacuum Pumping}

A continuous cryopumping system is one of the important R\&D items required for TMNS or for any steady-state, large mirror device. The vacuum pumping system must maintain suitable background pressures in the vacuum vessels during startup, run, and shutdown. The principal species to be pumped are deuterium, tritium, and helium, along with small amounts of contaminants. The amount of $D$ and $T$ is dependent on the neutral-beam input plus any additional fuel added by pellets or gas. Because it is a combustion product, the amount of he is directly determined by the fusic: power.

In a mirror machine, the very good vacuum pump formed by the plasma sweeps all losses out the ends of the system; therefore, in TMNS all mainvessel pumping is done in it:? nd vessels. The gas load to the main vacuum chamber pumping system cones irom two sources: the hot plasma streaming out the plasma fan, and the cold-plasma "halo" on the surface of the hot plasma. 
The hot plasma first intercepts the end wall (or direct converter), is thermalized and theu diffuses to the pumps (Fig. 15). The "halo" plasma is skimmed off the hot plasma and pumped away.

From particle-balance calculations, the end-loss gas loads are $314 \mathrm{~A}$ (atomic) from the hot plasma and 1131 A (atomic) from the halo plasma and neutral-beam injectors. These convert to a gas load of $140 \mathrm{Torr} \cdot 1 / \mathrm{s}$.

To maintain proper pressure upstream in the barrier cell, yin-yang cell, and central cell, the end vessel must be at $5 \times 10^{-6}$ Torr or less, which at the given gas load requires a pump speed of $2.8 \times 10^{7} \mathrm{l} / \mathrm{s}$. The only practical continuous pumping method for this gas load and pressure combination is cryopumping with LHe-cooled cryopumps. A standard LHc-cooled cryopump will not pump He, but by employing argon cryotrapping on a portion of the pumps, the He load can be satisfactorily handled.

If we assume a unit pump speed for cryopanels of $8 \mathrm{l} / \mathrm{s} \cdot \mathrm{cm}^{2}$, the required pumping area is $350 \mathrm{~m}^{2}$ ( $175 \mathrm{~m}^{2}$ at each end of the syst.m). By providing $250 \mathrm{~m}^{2}$ of panel (at each end), allowance is made for a degassing cycle.

A cryopanel is schematically shown in Fjg. 24. The LHe surface may be degassed during machine operation by closing the louvers and then slightly warming the LHe panels. The pumped gas is driven off and repumped on the degassing pump (see Fig. 25). The number of modules that can be attached to a single degasaing pump will be determined by the ratio of running time to recycle time. The running time is a function of safety limits for flamability and tritium retention, not pumping life. The flammability limit can be estabished by some objective criterion such as a worat credible air leak not exceeding the lower flammability limit of hydrogen. The tritium safety limit will be a function of more complex criteria yet to be established.

The output of the vacuum pumping system will go to the tritium system.

\section{Direct Converters}

In a mirror machine, there is a continuous flow of charged particles out the ends. The total power involved is roughly equal to the input beam and ECRH power plus the energy carried by the fusion-produced $\alpha$-particles. The escaping particles are accelerated to an energy equal to the ambipolar potential of the barrier; for TMNS, this is about $250 \mathrm{keV}$. 


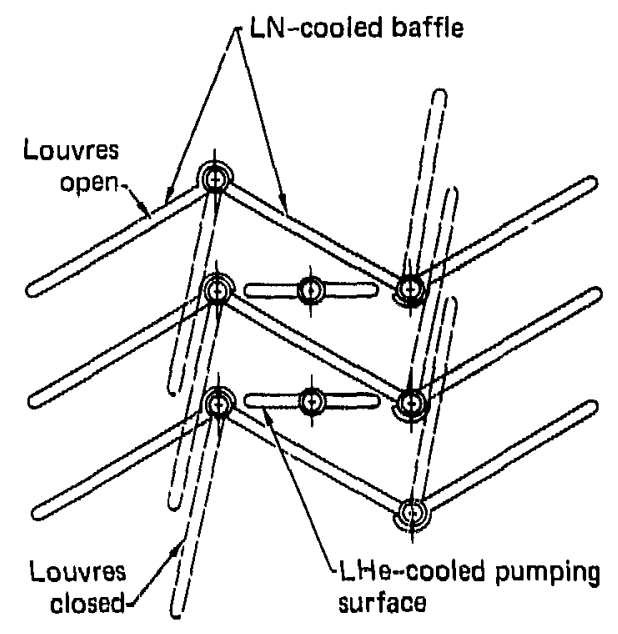

Fig. 24. A cryopumping panel used as part of the continuous cryopumping system devired for TMNS.

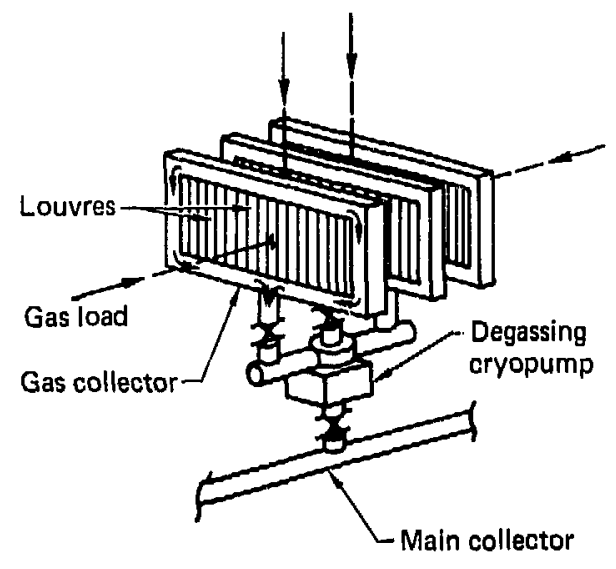

Fig. 25. A degassing pump used for repumping gas driven off the cryopanels. 
The overall system efficiency can be improved by collecting most of the charged-particle energy directly as electricity by slowing the ions in a decelerator or direct converter. The remaining energy goes to a thermal collector, where it may either be converted to electricity or discharged to the atmos phere.

Direct converters are proposed for TMNS not as a necessity for operation but as a means of improving performance and verifying the design for reactor application, where their use will have a signilicant impact on economics.

The TMNS direct converters are munted in the end vessels, Fig. 15, where they intercept all the energetic particles leaking out the ends. The direct convertor is shown conceptually on Fig. 26. The incoming electrons are repelled by the negative grid; the ions are decelerated and collected on the back plate.

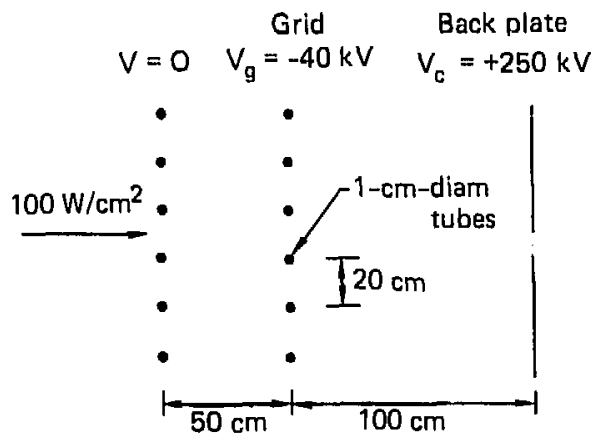

Fig. 26. Conceptual representation of the plasma direct converter.

The converters for TMNS, Fig. 27, are composed of modular units arranged across the end vessels. Because of the relatively small dimensions of the plasma fan, the grid wires span its entire thickness. This improves efficiency since there need be no dead spaces where insulators and manifolds are located. It also allows the use of water-cooled grid wires of reasonable diameter and pressure drop.

The power density on the direct converter is about $100 \mathrm{~W} / \mathrm{cm}^{2}$. This then becomes one of the sizing parameters for the end vessels. The other sizing parameter is the space needed for cryopumps. In the case of TMNS, these two requirements are well balanced.

The sizing and mounting of each direct converter module are based on considerations that are discussed under Maintenance. 


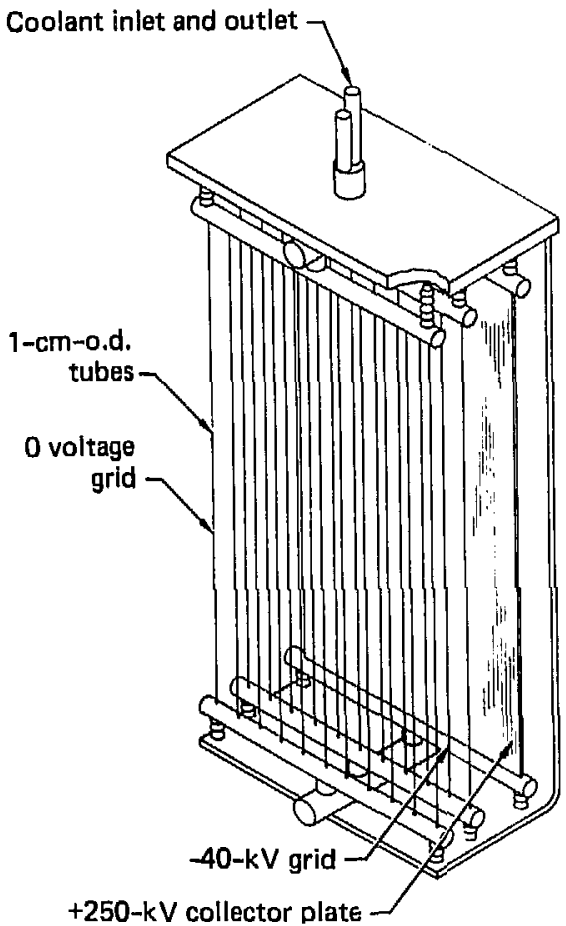

Fig. 27. Modular unit of the plasma direct converter.

\section{Central-Cell Blanket and Shield}

The reference-case TMNS design does not incorporate a blanket for power production or tritium breeding. Because the high rate of tritium consumption $(\sim 1.5 \mathrm{~g} / \mathrm{h})$ thus represents an operating cost of about $\$ 15,000 / \mathrm{h}$, it may be desirable to start breeding part or all of the required tritiun early in the life of the machine.

Although thermal energy extracted and converted to electricity would also reduce the operating cost, the added capital cost of a turbo-electric planc would reduce these savings. However, the testing of reactor grade $\mathrm{T}_{2}$-breeding blankets at high temperatures and neutron flux is one of the tasks for the system. In order to assure ourselves that we can test reactor-grade blanket modules, we have examined two candidate aystems from the standpoint of design integration. These are described below. 
The blanket surrounds the plasma and converts the kinetic energy of the neutrons to useful thermal heat. It also produces tritiun for future fuel use. The blanket extends through the central cell to the edge of the yin-yang coils at each end (see Fig. 15). In the central cell, 22 modules, 2 m long and replaceable, contain the blanket, shield, and solenoid coils. (A detailed description of the central-cell modules and assembly in a vacuum trench can be found in Ref. 3.) A cross section of the stainless-steel blanket pods and the shield is shown in Fig. 28. The pods are filled with granular lithium oxide $\left(\mathrm{Li}_{2} \mathrm{O}\right)$ for breeding tritium. High-pressure helium cools the blanket and removes the tritium. The module shield is primarily lead concrete $\left(\rho=10 \mathrm{~g} / \mathrm{cm}^{3}\right)$ and water cooled.

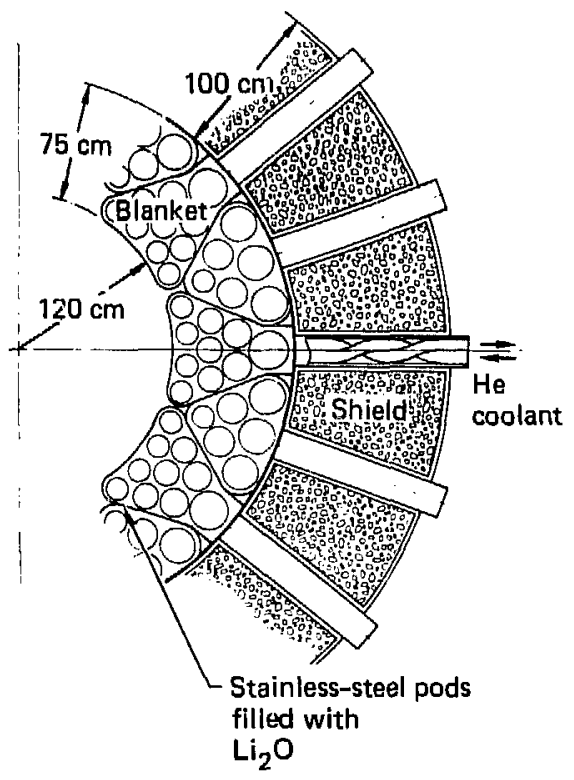

Fig. 28. Cross section through a blanket and shield module. Each. module is $2 \mathrm{~m}$ long. Tritium is bred in the blanket, which is composed of stainless-steel pods filled with granular $\mathrm{Li}_{2} \mathrm{O}$. High-pressure helium cools the blanket and removes the tritium. The shield is watercooled lead concrete.

An alternate module design for the central cell, one using steam for cooling and helium to remove the tritium in the blanket, is described in a later section.

\section{End-Ce11 Shields}

The shield configuration (Fig. 15) of the reactor is based on the premise that personnel can enter the reactor building after long-term operation to per- 
form maintenance tasks. A recent activation analysis ${ }^{25}$ of a similar mirrorfusion device (using a yin-yang pair) that was not shielded indicates that at $1 \mathrm{~m}$, the dose rate was greater than $100 \mathrm{rem} / \mathrm{h}$. The dose rate was based on a 1-year reactor operation with a 2-day cooldown period. We have not performed a detailed analysis of the TMNS shield; however, we assume that the equivalent of a 3-m-thick ordinary concrete reactor shield (with an allowance for attenuation by distance) would be required. A water-cooled, high-density composite shield $(0.7-\mathrm{m}$-thick) would be required in the inner plasma region to protect the coils from neutron damage and to reduce the heat load on the coils' cryogenic system. To permit replacement after lorg-term use, the inner shield would be fabricated in removable sections. Replacement of the highly-activated inner shield will be very difficuit because the sections are heavy and the area cannot be reached by the remote handling equipment. This problem requires more study.

The material used in the outer vessel shield will be selected on the basis of one or all of the following:

- Cost of shield.

- Space efficiency. Higher-cost, compact shielding for neutrons and gamma rays may be required for reactor components such as ion sources that are maintained regularly.

- Structural strength. The shield may be used as a structural component to support the forces exerted upon the large vacuum vessels.

A detailed computer study of the shield will be made after the geometry of the reactor has been firmly established. The large number of ports in the inner shield for neutral beams and the requirement for a low heat load on the superconducting magnet coils necessitate very close analyses of the potential problems. It is also apparent that maintenance of reactor components on either a regular or a nonregular basis presents a sizable problem. The outer shielding will be bulky and/or heavy. Regular maintenance requires that shielded, remote-handling devices be used to remove and replace shields over reactor components. Failure of reactor components not scheduled for regular maintenance will present a very difficult problem because of high radiation fields and inaccessability for repair. 
Figure 29 illustrates a design concept for a 9-m-long module which might prove to be less costly and easier to maintain than the 2-m-long module described earlier. The blanket consists of a circular array of 9-m-long pipes that are manifolded and removable from the module as a unit. The blanket is mounted inside the vacuum vessel; the coil and its shield are mounted outside. Commercially available water-film casters (60 units with a 40-ton capacity each) are used in a remotely operated device to move the module into the remote maintenance cells.

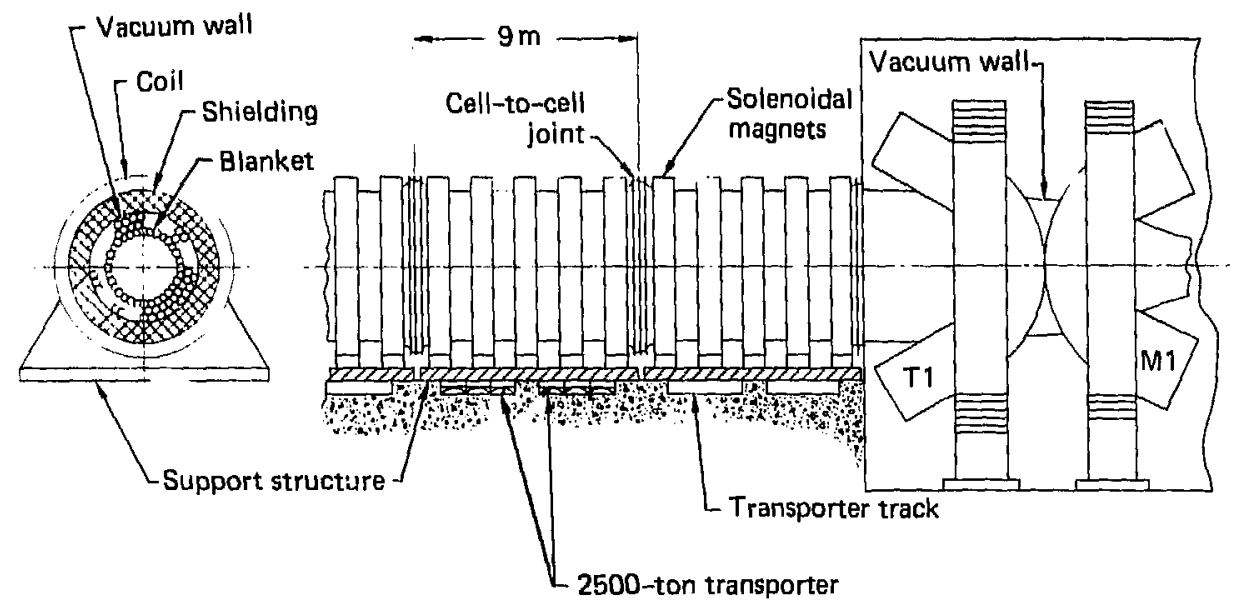

Fig. 29. Alternate design for a blanket and shield module. Each of these modules is $9 \mathrm{~m}$ long. As explained in the text, this module might be less costly and easier to maintain than the design described in Ref. 3 and shown in Fig. 14.

Figure 30 depicts a possible floor plan for the reactor and the shielded cells.

A aimplified flow schematic of the reactor heat-removal and tritiumrecovery system is shown in Fig. 31. The primary coolant is steam, which is fed directly into the turbine-generator unit. Pressurized gaseous He transfers lieat from the steam to the canister containing the $\mathrm{Li}_{2}{ }^{\mathrm{O}}$. It also serves as 


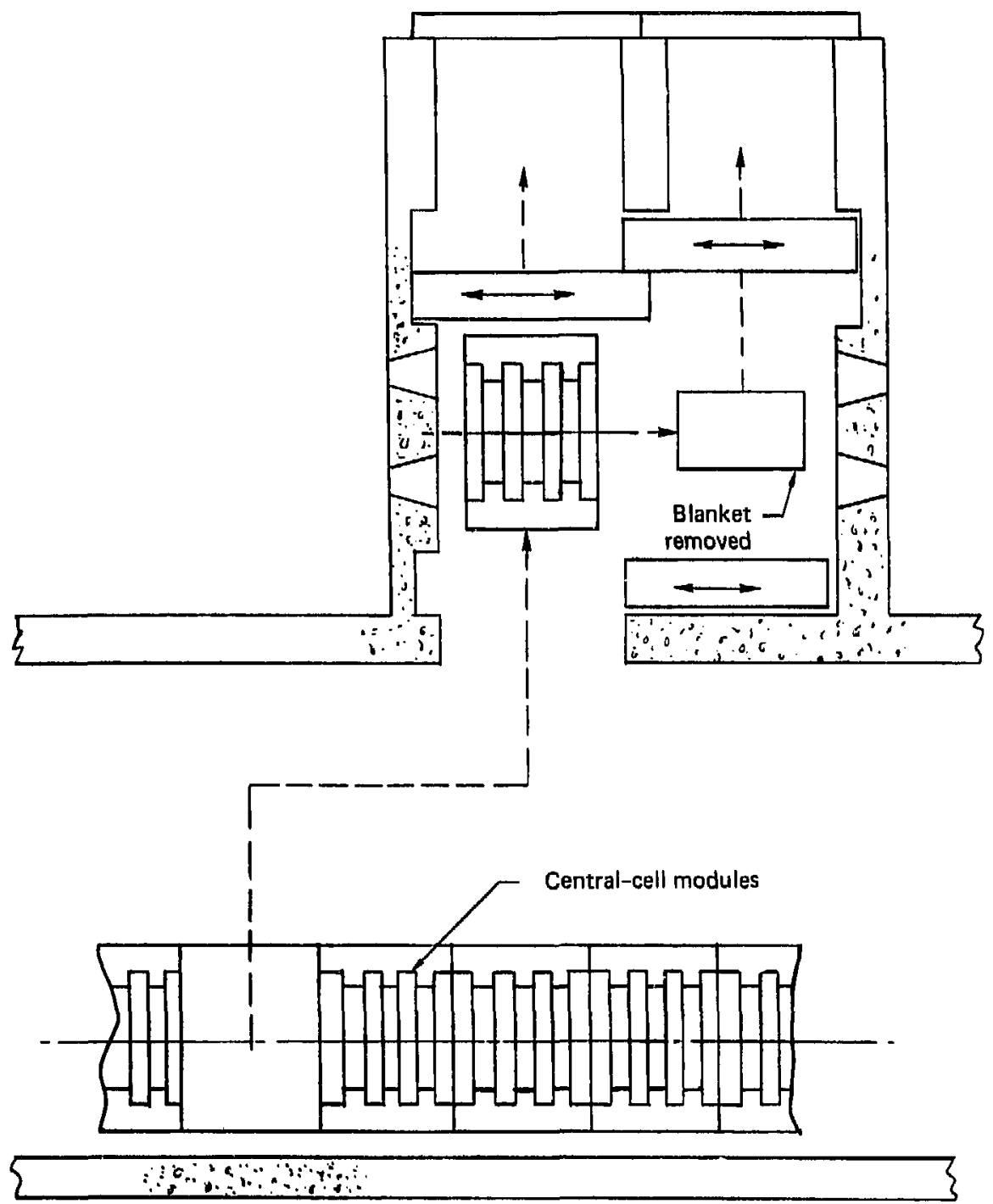

Fig. 30. Plan view of posaible arrangement of facilities for performing remote maintenance on the $9-m-10 n g$ blanket and shield modules. 


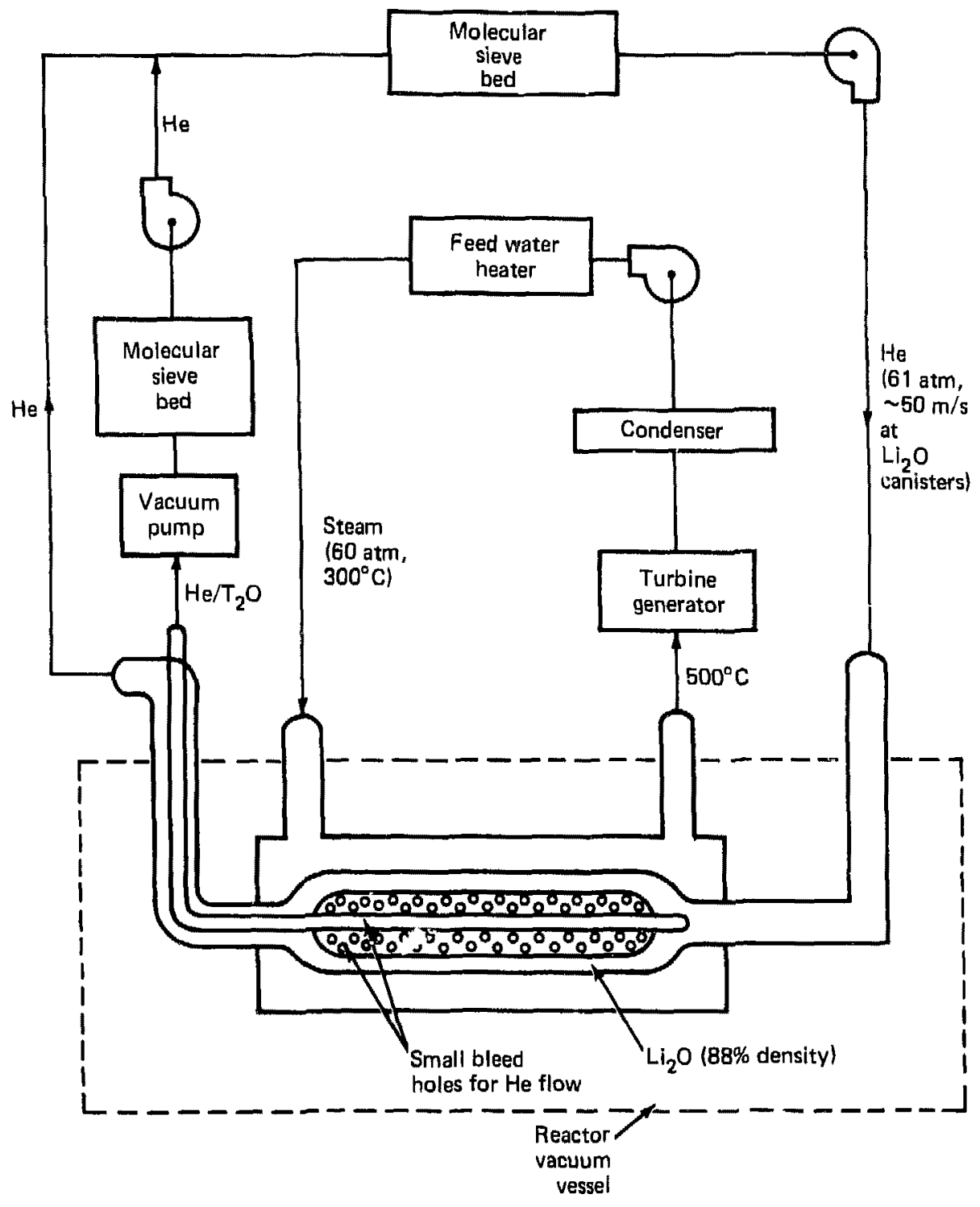

Fig. 31. Flow diagram showing the heat-removal and tritium-recovery system for the 9 -m-long blanket and shield module. The helium coolant is pressurized at $61 \mathrm{~atm}$ and has a velocity of about $50 \mathrm{~m} / \mathrm{s}$ at the $\mathrm{Li}_{2} \mathrm{O}$ cannisters. The density of the $\mathrm{Li}_{2} \mathrm{O}$ is $88 \%$. 
a permeation barrier between the steam and the tritium bred in the $\mathrm{Li}_{2} \mathrm{O}$. The tritium inventory in the blanket is kept low by a small flow of helium (containing a small percentage of oxygen) through the $\mathrm{Li}_{2} \mathrm{O}$ to a tube at the center of the canister. The location of this tube inside the pressurized-helium return line prevents the tritium from diffusing into the steam system or the reactor building environment. The tritium oxide is removed and the helium purified in molecular sieve beds.

Figure 32 shows a $\mathrm{Li}_{2} \mathrm{O}-\mathrm{filled}$ canister with the pressurized-helium jacket in an 8-in. steam tube. Figure 33 shows a cross section of an 8-in. steam tube with seven $\mathrm{Li}_{2} \mathrm{O}-\mathrm{fill}$ ed canister assemblies. Figure 34 shows a 1-m-thick blanket assembly using 8-in. and 10-3/4-in, o.d. steam-tube units. Diffusion of tritium from the plasma into the steam coolant needs to be estimated, based on a partial pressure of $\mathrm{T}_{2}$ in the plasma region of $1.5 \times 10^{-6}$ Torr. Previous studies, such as that of Mintz et al. ${ }^{26}$ will be helpful in making this estimate.

This alternate concept has the following advantages:

- Uniformity in packing and loading the $\mathrm{Li}_{2} \mathrm{O}$ into the canisters.

- Long, easily obtained tubes and pipes are used for a high-pressure, high-temperature application instead of fabrication of special pressure vessels.

- Defective $\mathrm{Li}_{2} \mathrm{O}$ canisters can be easily replaced.

- The tritium purge system can be easily constructed and tested.

- Tritium diffusion to the primary coolant and the reactor environment is eliminated by an outer, high-pressure, helium-filled tube.

- Fewer tube connections are required because steam instead of helium is used as the primary coolant.

This concept requires more analysis in areas such as thermodynamics, fluid flow, and neutronics, but is presented as a possible alternate to the present 2-m-long reactor module. 


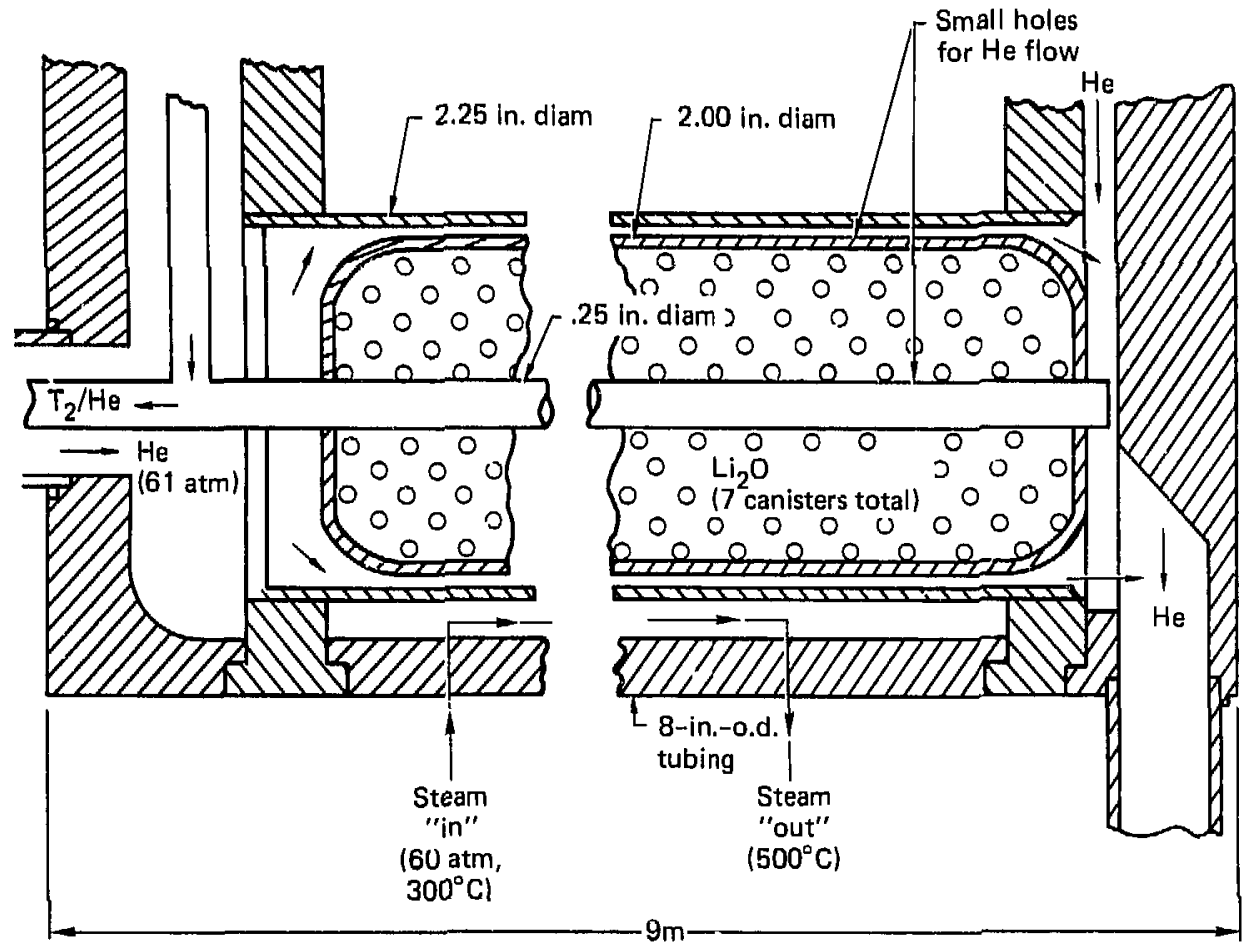

Fig. 32. Cross section of a $\mathrm{Li}_{2} \mathrm{O}$-filled cannister and presaurized-He jacket within an 8-in.-diam steam tube. In and out pipes for the steam are not shown. 

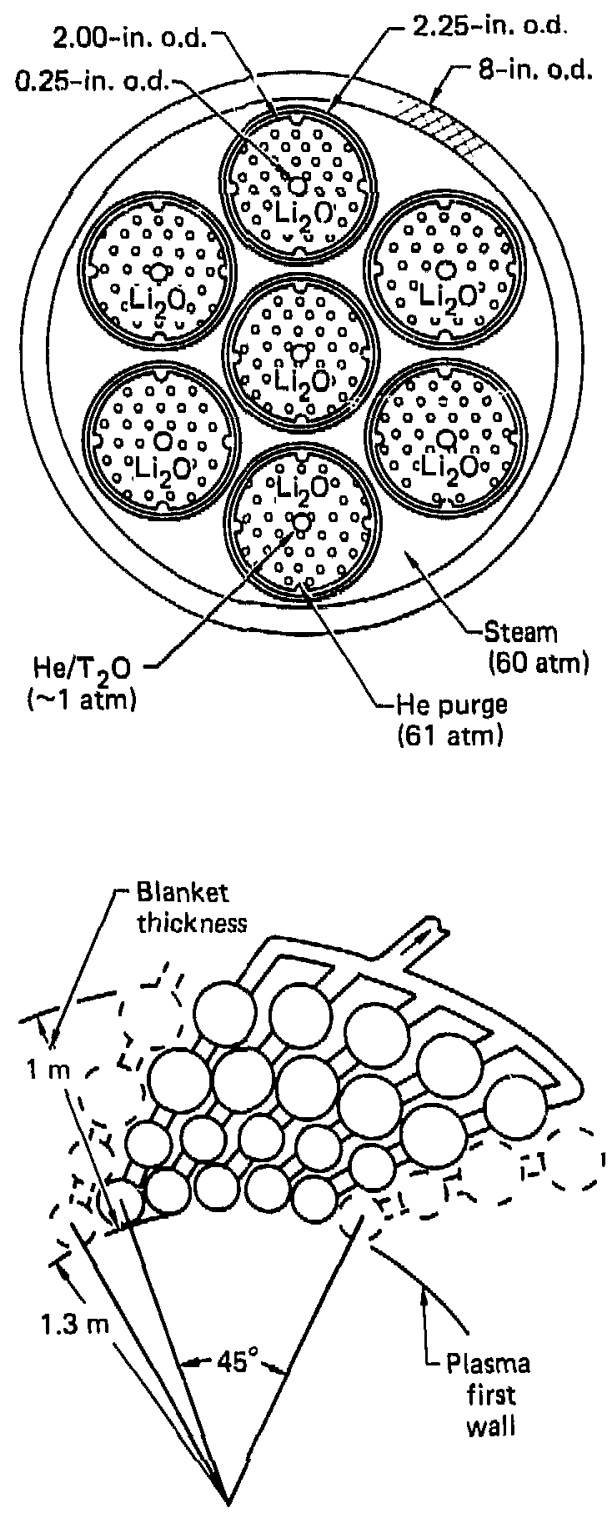

Fig. 33. Cross section of an 8-in.diam steam tube containing seven Li ${ }_{2} \mathrm{G}$-filled, 8-in.-0.d. canisters.
Fig. 34. Cross section of 1-m-thick blanket assembly showing placement of steam-tube units. Larger rubes are 10-3/4 in. o.d., smaller are 8 in. 
The nuclear auxiliary systems are those that are directly needed to make the nuclear system function. A list of these systems is show in Table 18. Most of these systems have been scaled directly from MFTF-B; this is adequate for the purposes of a conceptual design. The tritium and maintenance systems, however, are unique to a D-T device like TMNS, and pertinent data are less available.

Table 18. TMNS nuclear auxiliary system (level 2 WBS).

$\begin{aligned} 2.0 & \text { Nuclear auxiliary system } \\ 2.1 .0 & \text { Cryoplant } \\ .1 & \text { Liquid helium } \\ .2 & \text { Liquid nitrogen } \\ 2.2 .0 & \text { Power supply } \\ .1 & \text { Neutral beams } \\ .2 & \text { ECRH } \\ .3 & \text { Magnets } \\ .4 & \text { Direct convertor } \\ .5 & \text { Other power supplies } \\ & \\ 2.3 .0 & \text { Tritium } \\ .1 & \text { Purification and separation } \\ .2 & \text { Cleanup } \\ .3 & \text { Blanket product } \\ .4 & \text { Handing } \\ 2.4 .0 & \text { Power conversion } \\ .1 & \text { Heat exchangers } \\ .2 & \text { Turbo-electric plant } \\ .3 & \text { Circulators } \\ 2.5 .0 & \text { Controls and instrumentation } \\ .1 & \text { Controls } \\ .2 & \text { Instrumentation } \\ 2.6 .0 & \text { Maintenance } \\ .1 & \text { Special purpose remote tooling } \\ .2 & \text { General purpose remote tooling } \\ .3 & \text { Contact maintenance tooling } \\ & \\ & \end{aligned}$


The function of the cryoplant is to provide liquid and gaseous cryogens to systems where they are required; LN and LHe are produced and distributed. Both liquids and vapors are returned to the cryoplant.

The two major users of cryogens are the magnet system and the vacuum pumping system. Both employ liquid-filled Dewars for cooling; the boiled-off gas is returned for reliquefaction. Liquid nitrogen is principally used to cool baffles that thermally isolate the surfaces at LHe temperature and, in the case of the cryopunips, to condense or pre-cool system gas loads.

We assume that the cryoplant is a scale-up of the MFTF-B system with no new technology required. The details of that system are described in the MFTF-B Proposal. 1

The cryogenic needs of TMNS we assessed by scaling from the loads of MFTF-B, using the surface area of the coils and cryopanels as scaling factors, and allowing for neutron and gamma-ray heating. The surface-area ratio between TMNS and MFTF-B is 4.4. For our estimates, we used a factor of 5, which brings the total LHe cryoplant capacity of TMNS to $48.4 \mathrm{~kW}$. Obviously, this is not a rigorous analysis. However it is accurate enough to suit the purposes of this study, where our goal is to estimate the cost and power needs of the system.

Using a liquefaction power requirement of $400 \mathrm{~W} / \mathrm{W}$ of LHe cooling, we find that the total power to the cryoplant is approximately $19 \mathrm{MW}$. Because this is a significant fraction of the reactor power, the design must be carefully done if the system is to approach an engineering power balance. If, in fact, $0.1 \%$ of the fusion power were absorbed at LHe temperature in any fusion reactor, it would be impossible to achieve a power balance.

\section{Power Supply}

The power supply system includes the power supplies and their local controls for driving the neutral-beam, magnet, and ECRH systems.

Epace has been allocated to house these systems, and their costs have been included in the estimate. No specific design work has been done since these systems are being developed by other programs and should be available to TMNS after modest improvements. 
The neutral-beam power supplies will be developed as part of the longpulse and negative-ion work now being done or proposed. The ECRH supplies are under development, and such systems will be used on TMX Upgrade and MFTF-B. The magnet power supplies will be nearly identical to those for MFTF-B.

\section{Tritium System}

The tritium system provides fuel to the neutral-beam system and to any auxiliary pellet and gas-feed systems, processes all output from the vacuum system, and provides safe atorage for the tritium inventory. It also provides the environmental cleanup system for the reactor building, in both the normal and accidental-release modes.

The principal load to the system comes from the vacuum pumps. The total system throughput is $1090 \mathrm{Torr} \cdot 1 / \mathrm{s}$, of which about $90 \mathrm{Torr} \cdot 1 / \mathrm{s}$ is tritium an.: the remainder is deuterium. There is also a small amount of helium $(2.45$ Torr $\cdot 1 / \mathrm{s})$, a product of the fusion reaction. The mass flow is then about $2.3 \mathrm{~kg} /$ day of tritium and $22 \mathrm{~kg} /$ day of deuterium.

The large flow of deuterium comes partly from the excess gas needed by the neutral-beam injectors. This gas will be almost pure $\mathrm{D}_{2}$, but will be contaminated with $\mathrm{T}_{2}$ diffusing back through the beam apertures. The gas feed to the halo plasma in the central cell also contributes to the $D_{2}$ gas flow.

We presume that at some time during the life of TMNS tritium-breeding blankets will be employed to breed some or all of the tritium consumed in the system. At $245 \mathrm{MW}$ of $\mathrm{D}-\mathrm{T}$ fusion power, the tritium consumption rate is $1.56 \mathrm{~g} / \mathrm{h}$, which at present prices represents an operating expense of $\$ 15,600 / \mathrm{h}$.

The tritium system will perform the following tasks:

- Fuel cleanup,

- Extraction of tritium from the blanket coolant,

- Isotope separatiun,

- Fuel storage and delivery,

- Gas analysis and accountability,

- Effluent processing,

- Ventilation-air cleanup, and

- Monitoring and personnel safety. 
These functions and their interrelationships are shown schematically in Fig. 35. Schematics of the fuel cleanup, blanket-coolant tritium extraction, isotope separation, and effluent processing systems are shown in Figs. 36 through 39.

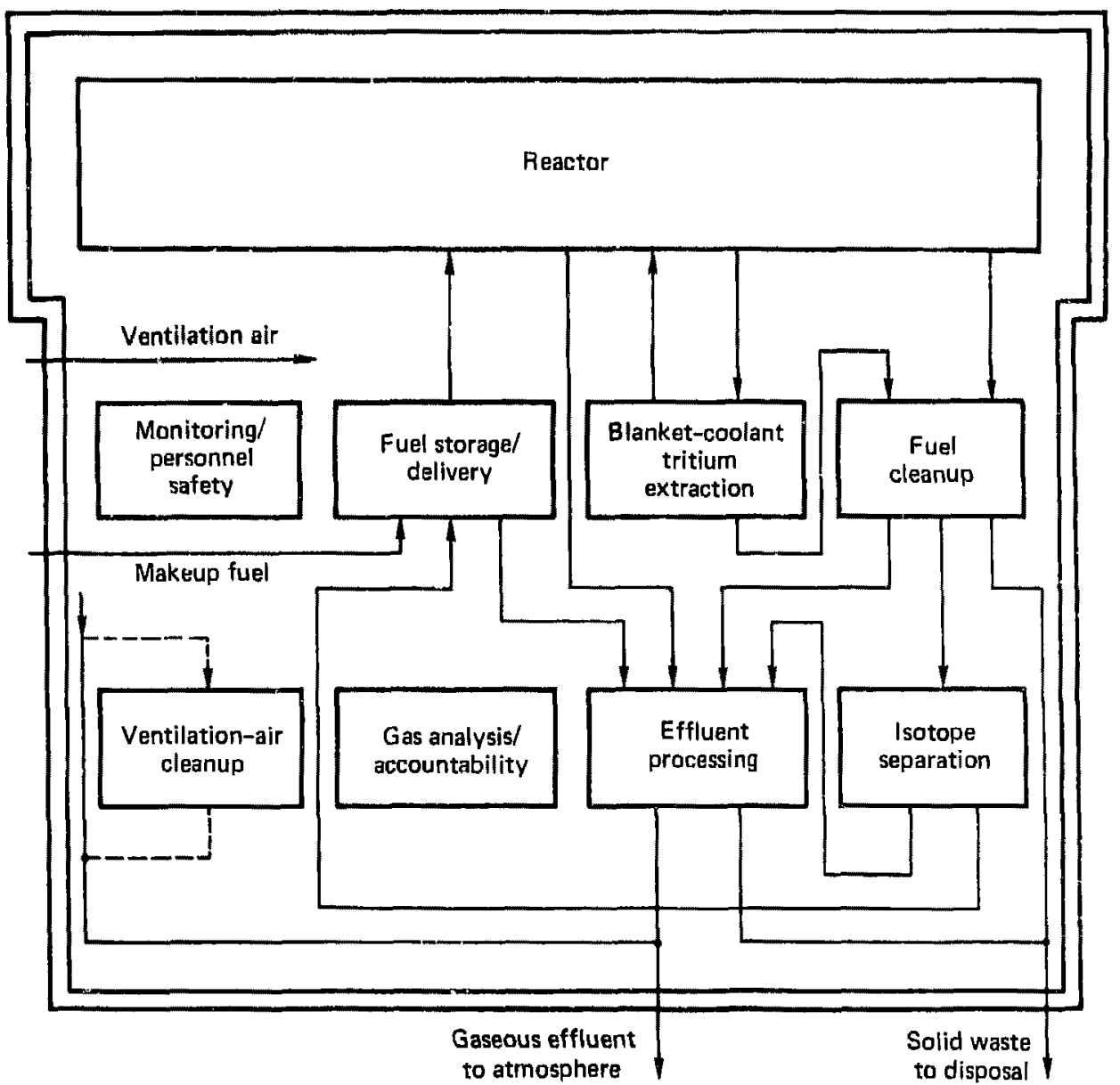

Fig. 35. The TMNS tritium system. The diagram shows the various functions of the syatem and their interrelationships. Individual functions are described in detail in the next four illustrations. 
Palladium diffusers (Pd-25 wt\% Ag)

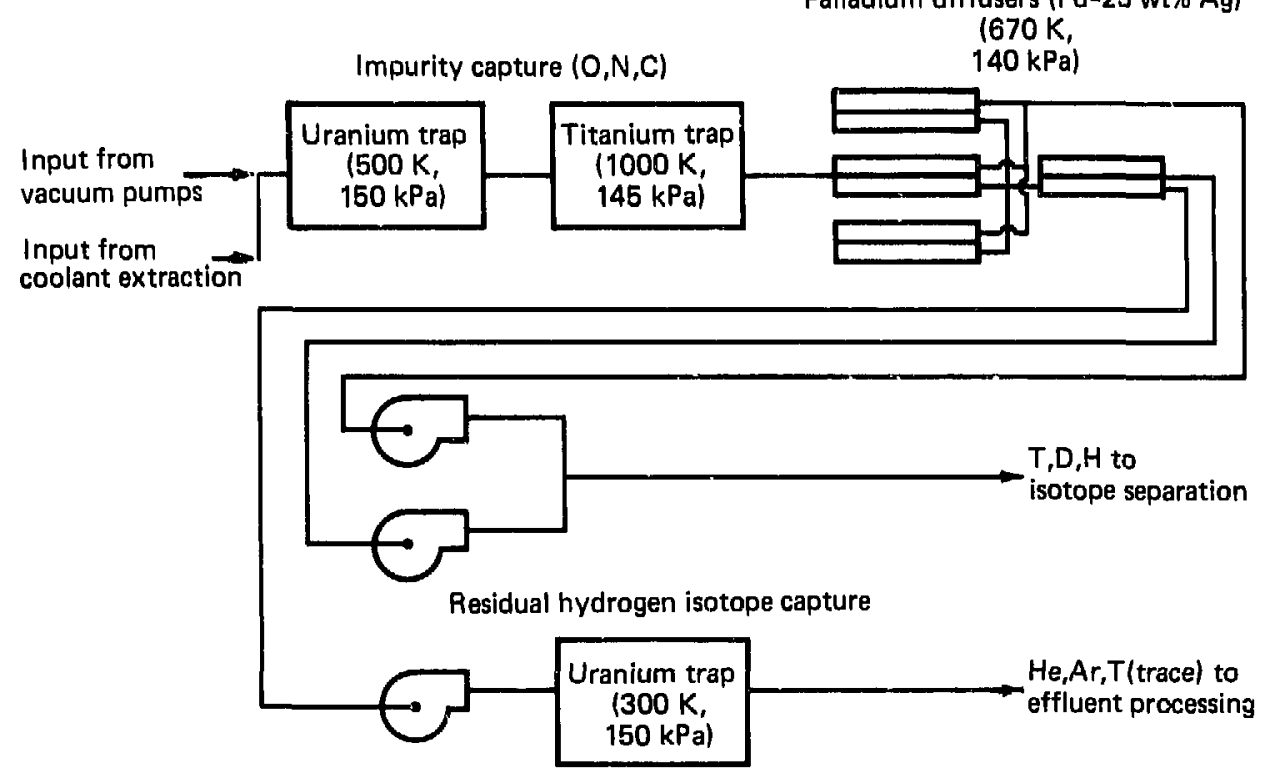

Fig. 36. The fuel-cleanup system, 
He coolant from breeding module

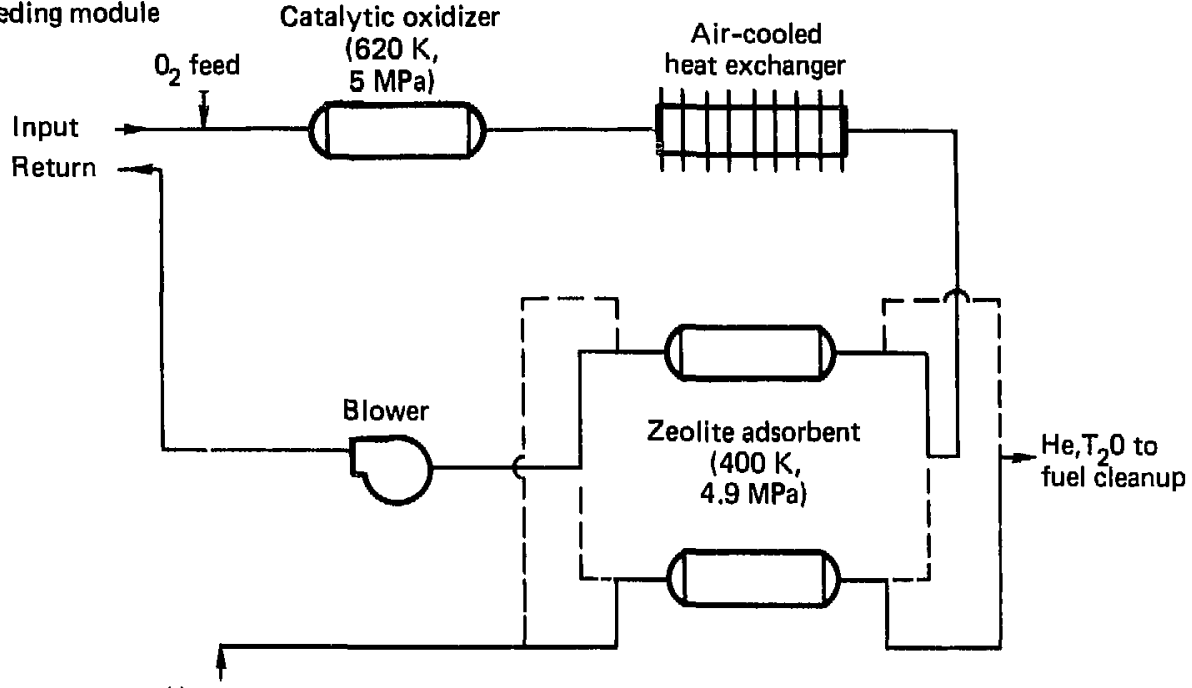

He purge

Fig. 37. The blanket-coolant, tritium-extraction system.

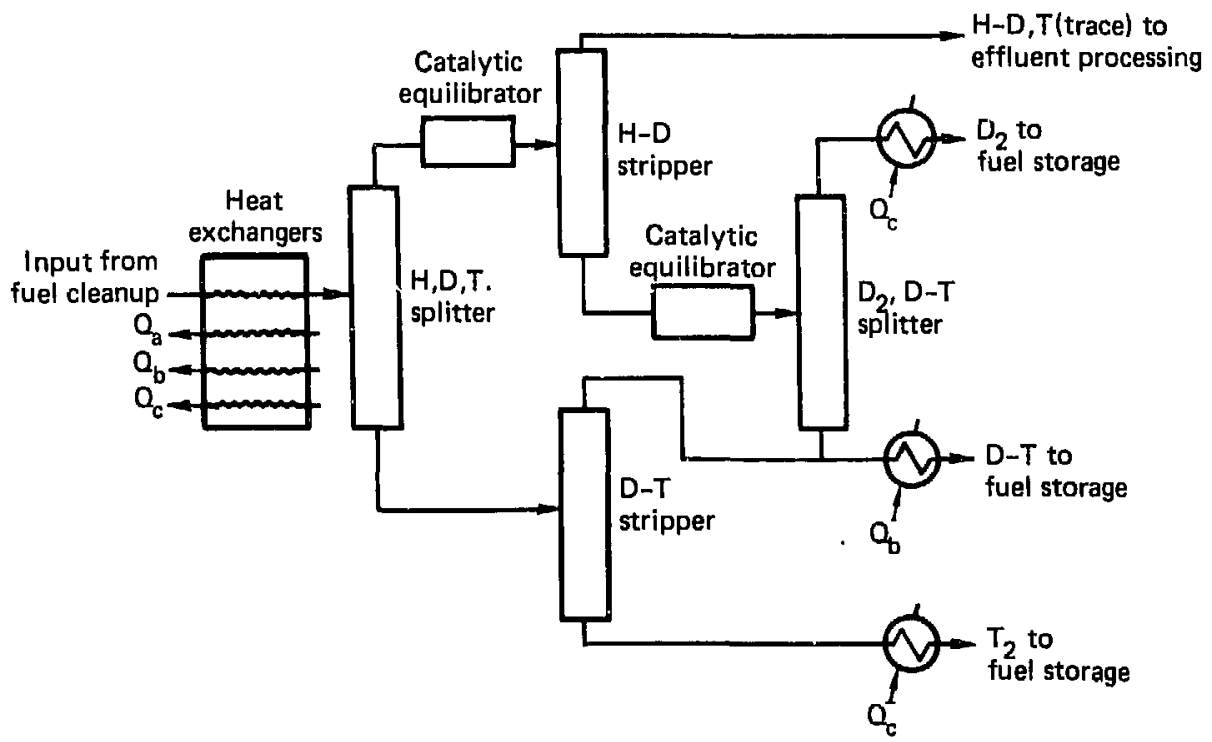

Fig. 38. The isotope-separation system. The cryogenic distillation columns (the splitter and strippers) operate at 20 to $26 \mathrm{~K}, 101 \mathrm{kPA}$; the equilibrators operate at $300 \mathrm{~K}, 101 \mathrm{kPA}$. 


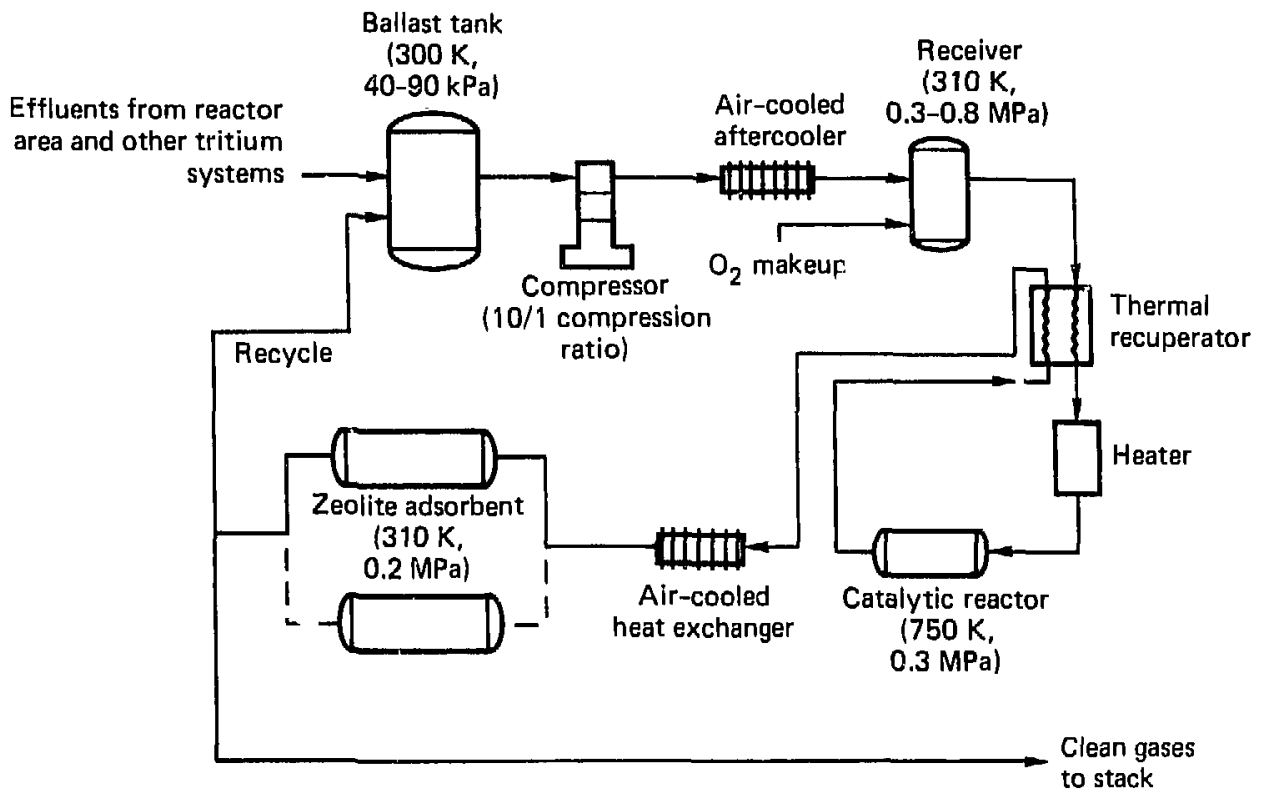

Fig. 39. The effluent-processing system.

For the purpose of this study, we presume that the necessary design data for systems of this size have been produced by the Tritium Systems Test Assembly (TSTA) at Los Alamos National Laboratory. 27

Because the safety requirements for such systems affect all major nuclear systems, they will be needed well in advance of system design.

\section{Thermal Power Conversion}

Power conversion equipment in the context of this discussion includes those components used to transfer heat from the primary cooling loops to the heat rejection system. In the TMNS reference case, these merely consist of the heat exchangers that transfer heat from the shields, dumps, blsnkets, etc. to the low-temperature coolant of the cooling-tower system. The heat exchangers could be contaminated by tritium if it should leak into any of the many coolant lines of the nuclear system. Therefore, to protect the cooling- 
tower system from contamination, the heat exchangers must be designed to prevent tritium permeation through the tube walls. The primary heat exchangers are located in a sealed space as part of the safety system.

In the reference-case mode, the power conversion system must handle $426 \mathrm{MW}$ without direct conversion, and $386 \mathrm{MW}$ with direct conversion. If a thermal power plant were added to the TMNS system, it would get its input steam from heat exchangers in this same location. The turbo-generator would be located in the power plant building at some distance from the reactor building, as seen in Fig. 4l, p. 100 .

No specific power-plant type or configuration has been selected for TMNS. This decision would be made in conjunction with the selection of blanket type and coolant parameters.

The thermal power plant capacity for a fully developed TMNS would be about $100 \mathrm{MW}$ electric, as indicated in the power-flow diagram (Fig. 6).

\section{Controls and Instrumentation}

The controls and operating instrumentation for TMNS will be almost identical with those for MFTF-B. TMNS will have more subsystems for beams and magnets, but the control philosophy will be the same. A complete description of the MFTF-B control system may be seen in Ref. 1.

\section{Maintenance}

Maintenance Philosophy. Our ability to successfully maintain the components of a fusion reactor that are exposed to tritium contamination and neutron activation may be the critical issue in the economic deployment of fusion technology. Although TMNS is not required to be "economic," its success will also be highly dependent on oux ability to repair and replace components in a highly hostile environment. Indeec, two of the programmatic tasks for TNiNS are to demonstrate the highly reliable operation of subsystems in this environment and to show that they can be maintained at reasonable cost.

There are two principal problems in fusion systems that force the use of remote maintenance techniques: tritium contamination and neutron activation. Tritium is radioactive and highly toxic. It is best dealt with by removing it from the system requiring work. Under normal operating conditions, when the 
tritium is confined to the vacuum, tritium, and fueling system, it is readily removed. Under abnormal conditions, tritium may escape into the reactor building; extensive atmospheric cleanup would then be required.

The 14-MeV neutrons produced in a D-T reactor are captured in the internal structures of the system. Many of the captured neutrons result in the production of radioactive isotopes that are strong gamma-ray sources. These gamma rays are absorbed within the reactor as long as its internal shield remains intact. When some part of the system is opened for maintenance, gama rays beam out into the vault. The public is protected, because these rays are attenuated by the vault walls, roof, and floor; however, any maintenance being done when the shielding is not intact must be done in the remote mode.

To approach the maintenance problem in a rational way, we first must develop a philosophy and then apply that philosophy in generating system requirements. Our philosophy for TMNS is as follows:

- Maximize contact operations. We would maximize contact operations so as to minimize the time required to make critical connects, disconnects, etc., since a complex operation can require 5 to 20 times the schedule time if done by remote means. On TMNS, we propose to man-rate the vaults and sealed spaces whenever the system is off, the tritium is removed, and the magnetic fields are at or below acceptable levels. To further this approach, the reactor vault has been divided into three sections (Fig. 41). It will, therefore, be possible to do contact maintenance in one section while remote operations are required in another.

- Provide special tooling for scheduled maintenance or repair. Special tooling for scheduled maintenance both lets us speed up some operations that could be done in the contact mode and makes remote operations more reliable and efficient.

- Have available a broad range of general-purpose tooling and facilities to handle unanticipated failures. General-purpose remote tooling is necessary for both general machine repair and maintenance of the remote special-purpose tools. TMNS is a very large machine, and it will require that remote tooling have a very long reach so that it can operate in any part of the shielded and sealed space. Such operations as lifting, turning, cutting, welding, cleaning, and inspecting will be required. Even the job of replacing a light bulb in a hot area can be critical and quite costly in elapsed time. 
We have chosen to build the components of the system in need of regular replacement in modular form so that they may be easily disconnected, removed, and replaced.

Work on the details of maintenance will be left until actual design begins, because the maintenance equipment is highly specific to the particular component design. Early in the design phase, maintenance scenarios for each component must be developed to anticipate both planned and unplanned maintenance procedures. These must be integrated into the overall system.

During this conceptual design phase, we have categorized major nuclear subsystem components into three general classes: those expected to operate for the design life of the system without repair or replacement, those with a high probability of minor random failures during the life of the system, and those requiring regular replacement because of radiation damage or wear. An abbreviated listing of categorized systems is shown in Table 19.

Table 19. Categories of maintenance.

\begin{tabular}{|c|c|c|c|}
\hline System & $\begin{array}{l}\text { Life of } \\
\text { system }\end{array}$ & $\begin{array}{c}\text { Probable random } \\
\text { failures }\end{array}$ & $\begin{array}{c}\text { Regular } \\
\text { replacement }\end{array}$ \\
\hline Magnets & $\mathbf{x}$ & & \\
\hline Shield & $\mathrm{x}$ & & \\
\hline Neutral beams & & & $\mathbf{x}$ \\
\hline Cryopumps & & $\mathbf{x}$ & \\
\hline Blanket & & & $\mathrm{x}$ \\
\hline $\begin{array}{l}\text { Vacuum vessels } \\
\text { Direct converters }\end{array}$ & $\mathrm{x}$ & & $x$ \\
\hline $\begin{array}{l}\text { Tritium system } \\
\text { Heat exchanger }\end{array}$ & & $\begin{array}{l}x \\
x\end{array}$ & \\
\hline ECRH & & $x$ & $\mathrm{x}$ \\
\hline Hot mántenance & & $x$ & \\
\hline
\end{tabular}

The most regularly replaced items will be the neutral-beam sources; a replacement scheme is described below. In the power-producing mode, the central-cell blanket sections represent the largest components needing regular replacement. Descriptions of two candidate blanket designs may be found under Nuclear System. 
Replacement of Neutral-Beam Sources. Ion sources require frequent servicing and repair. Because the units become highly radioactive by neutron activation, outer shields are required to permit personnel to enter the reactor area after shutdown. Our plan calls for the major repair work on ion sources to be performed in a remotely operated hot cell located outside the main reactor room. We propose the following system for routine removal of ion sources for repair:

- Fig. 14 shows neutral-beam assembly with an ion source shielded with a removable cap.

- The first step in the procedure is to remotely remove the shield cap and replace it with a shielded removal device [Fig. 40(a)]. All high-voltage, service, and vacuum disconnects would be made with this unit in place. Peraonnel would have access to the area because the unit is shielded.

- This shielded unit and ion source would be removed by remote means [Fig. 40(b)] and the original shield cap then replaced over the opening [(Fig. 40(c)] to permit personnel access. To assemble a new unit, the procedure is reversed.

The internal moving parts of the vacuum gate valves and the direct converter grid elements could be repaired in a similar marner.

The question of what one does if unscheduled maintenance is required for the components in the neutralizer and bend magnet vessels should be considered. Parts in the neutralizer vacuum vessel, such as the neutralizer and cryopanels, could be replaced if the end shields and the end flange of the vacuum vessel were first removed. Parts in the bend-magnet vessel such as the bend magnet, beam dumps, and cryopanels, could be replaced if the neutralizer vessel and shield, the vasuum valve, and the end $f$ lange of the bend chamber flange were first removed. To remove these highly radioactive parts, which may be bulky, heavy and inaccessible, would require temporary shields and portable remotehandling gear. Since this problem is beyond the scope of this report, we have not made a detailed analysis of the required equipment.

PLANT FACILITIES

Included in plant facilities are most of the conventional structures and subsystems; these are listed in Table 20. The most specialized item in this group is the reactor building, which houses the nuclear system and providez a biological shield and tritium barrier. 

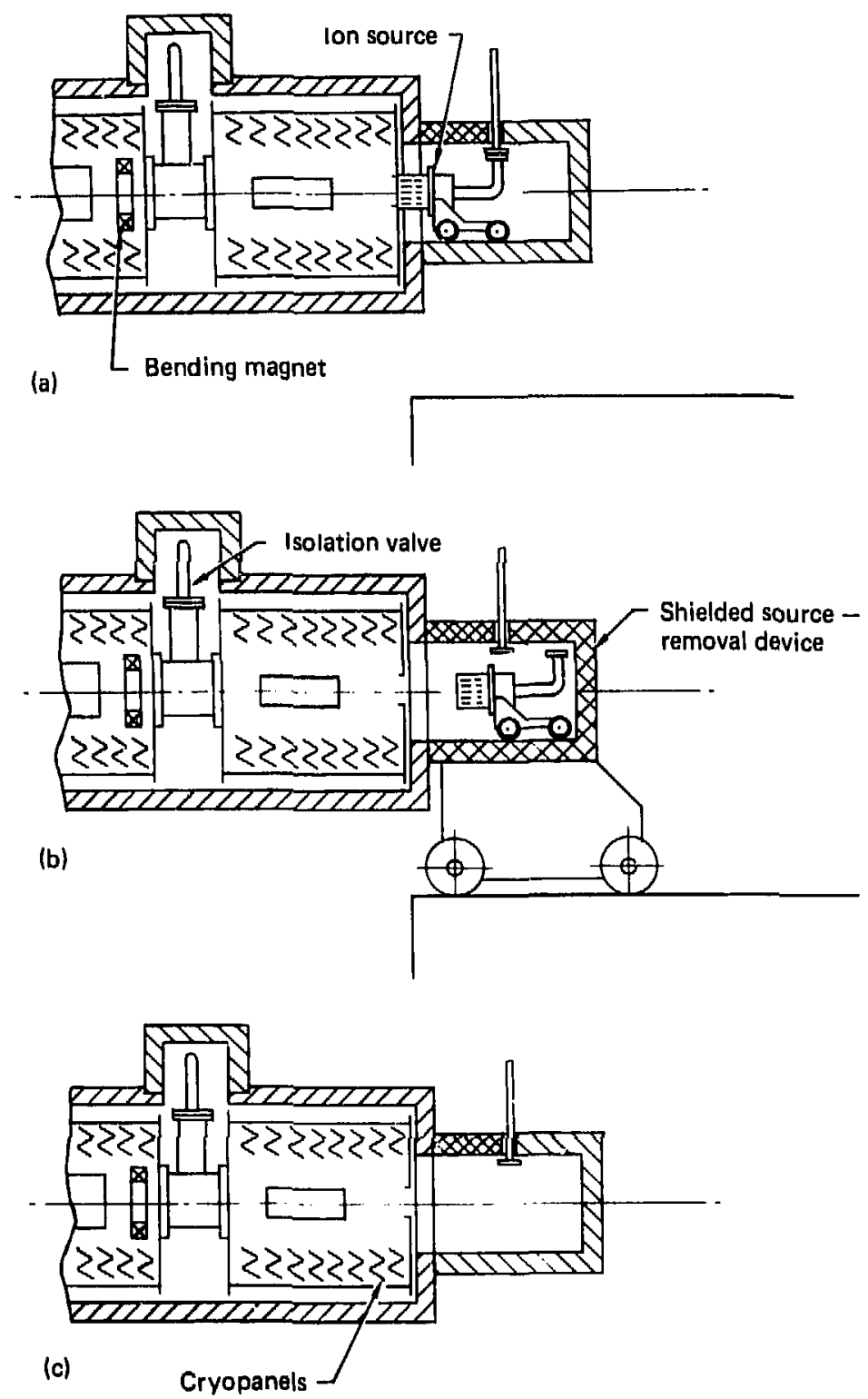

Fig. 40. Removal of the HEPB ion source from TMNS: (a) a shielded apparatus replaces the shield cap and (b) the ion source has been removed. 
Table 20. TMNS plant facilities (level 3 WBS).

\begin{aligned} \hline 3.0 & Plant facilities \\ 3.1 .0 & Site \\ .1 & Improvements \\ .3 & Uecurity \\ 3.2 .0 & Reactor building \\ .1 & Reactor vault \\ .2 & Nuclear auxiliary spaces \\ .3 & Offices \\ 3.3 .0 & Ancillary structures \\ 3.4 .0 & Heat rejection \\ .1 & Cooling towers \\ .2 & Coolant circulation \\ 3.5 .0 & Electrical power \\ .1 & Input substation \\ .2 & Specialized substations \end{aligned}

$\underline{\text { Site }}$

Location. Locating a machine of this size with its inherent logistical and safety considerations is a task that will require a significant study of its own. The logistical problems include meeting requirements for transportation, staging areas, electrical power, and cooling water. Safety issues include potential danger from seismic activity, severe storms or floods; exposure to tritium and other radiation; danger associated with energy storage in cryogenic systems and magnetic fields; and exposure to high background magnetic fields.

Logistical Considerations. Transportation requirements during the construction phase will affect costs. The size break between factory and site fabrication will depend on the maximum dimensions and weights that can be transported. At a minimum, the site will require rail access, and an argument can be made for locating TMNS adjacent to a navigable waterway. 
Staging areas for this large a construction project must be carefully planned in order to minimize interference among concurrent operations. For example, some of the support facilities may be completed early so that they can be used to house on-site fabrication. When the project has been completed, most of the open staging area will be required for site boundary setback.

The availability of electrical power and cooling water will be important considerations in selecting a site: however, ac the levels required they will not be the driving considerations (the MFTF-B substation could drive TMNS).

Safety Considerations. Seismic safety is an important consideration in locating any facility with a large potential for radivactive release, and TMNS is no exception. The seismic criteria for these facilities will be set by the appropriate regulatory agencies. We believe that the TMNS system can be built to any reasonable earthquake standard.

The other natural disasters such as severe storms and floods impose their own design and location criteria. These requirements will have less effect on the design and cost than those for seismic activity.

Because potential releases of tritium and other radioactive substances are considerations from the standpoints of weather conditions and site boundary limits, an overall evaluation of the tritium- and radiation-control program for TMNS would necessarily consider location.

The potential hazards due to maximum credible energy release from the cryogenic and magnet system may also af ect location.

The large magnetic field surrounding the machine will not be a consideration in the site location; however, it will be a strong factor in laying out the site to minimize exposures during routine operations.

\section{Reactor Building}

A conceptual site plan is shown in Fig. 4l, dotted lines show the magnetic-field. The facility is dominated by the reactor building, which houses the nuclear and nuclear auxiliay systems. 


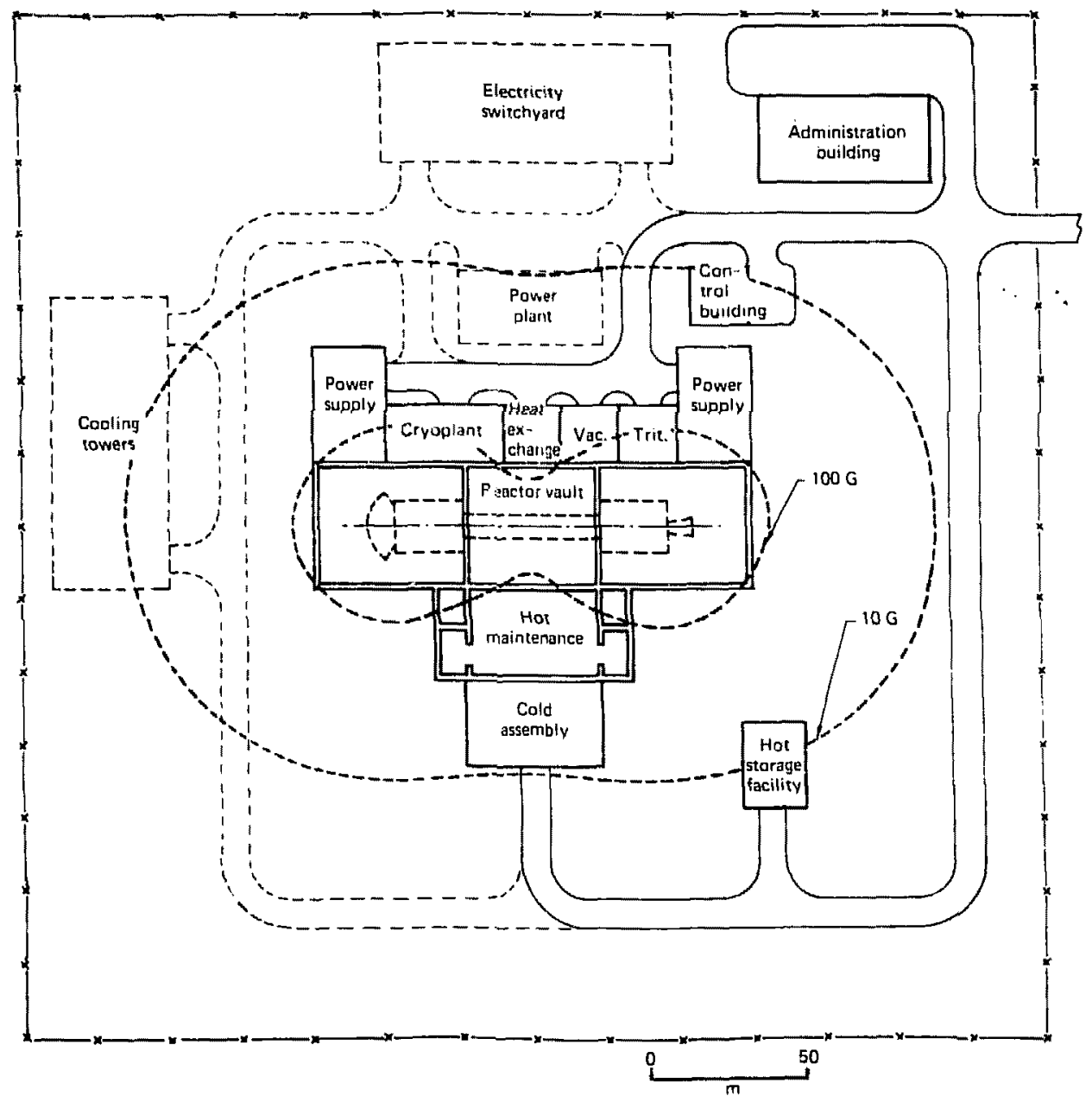

Fig. 41. Conceptual site plan for the TMNS facility. Heavy dashed lines show two magnetic field contours around the facility. 
The reactor building consists of shielded vaults for containing radiation, sealed spaces for containing tritium, and conventional structures for housing subsystems. Its overall dimensions ars $140 \mathrm{~m}$ by $150 \mathrm{~m}$. The shielded spaces include the reactor vault and the hot maintenance facility. The sealed spaces include those for the vaults, the tritium system, external vacuum system, primary heat exchangers, and cryoplant.

The reactor vault is divided into three sections. The maintenance scenario for TMNS is based on manned access to the vaults when the machine is shut down and the tritiun has been removed. By breaking the vault in three sections, we can have different levels of maintenance going on simultaneously. For example, we will not have to evacuate the whole vault when we have the machine open (emitting gamma rays) in only one or two sections.

The hot maintenance facility is adjacent to the central cell since it is from here that the largest routinely removed components are located. The end vaults are connected to the hot maintenance facility through transfer vestibules.

The sealed spaces are those that have the potential for tritium release. They are separated from each other so that a leak may be located. These areas are also man-rated during shutdow.

To minimize lengths of cable, the conventional structures housing the power supplies are located at each end of the reactor vault.

\section{Ancillary Structures}

There are three principal ancillary structures (all conventional structures): the Control Building, the Hot Storage Facility, and the Administration Building:

- The Control Building houses the operating personnel and is located away from the reactor building to avoid the magnetic field, which would effect the instrumentation and contrcl system.

- The Hot Storage Fac lity is mere?y a controlled-access space for accumulating sealed and shielded radioactive components and materials prior to shiprent .

- The Administration Building houses the staff and space for visiting experimenters and public information displays. 
The heat-removal system absorbs the waste heat of the system and discharges it to the atmosphere. In this study, we assume that 426-HW cooling towers are used; however, discharge to a body of water would be an acceptable alternative.

Electrical Power

The electrical power systemi takes grid power and converts it to voltages usable by the TMNS system. The principal user is the neutral-beam system. The ECRH system and the cryoplant are also large consumers. The total power input is $162 \mathrm{MW}$.

The electrical power system would have the additional task of delivering a small amnunt of power $(\sim 8 \mathrm{MW})$ to the grid if TMNS employs a steam plant and can operate in the positive power mode. 


\section{CONCLUSIONS}

The present preliminary design for TMNS is based on a set of physics parameters and on the assumption that several key technological developments will proceed on a timely schedule. Granted this base, we conclude that the TMNS facility as described could be engineered and contructed during the next decade, at a cost of approximately $\$ 1$ billion. However, the performance of the TMNS device in the present configuration is predicted to be restricted by the central-cell $\beta_{c}$ limit arising from MHD ballooning estimates. Since we want TMNS to be prototypical of a TMR (which also suffers from a similar ballooning limitation), we have decided to defer the next luvel of engineering design for TMS until a solution to the ballooning problem is found. At the same time, we need to establish a method for removing thermalized alpha particles. To address these problems, the present study of advanced mirror systems at LLNL is concentrating on tandem systems with axisymetric end cells. A further advantage of a successful axisymnetric design would be simpler, less expensive construction for the high-tield end-cell magnets. We have identified the high-field yin-yang magnets as the major factor in the facility cost, as well as one of the more difficult items for engineering design. Although it seems unlikely that we will be able to drop our field requirements to the point where we can avoid using costly $\mathrm{Nb}_{3} \mathrm{Sn}$ superconductor, simplification of these high-field magnets to an axisymetric form would probably reduce the amount of conductor required and would certainly simplify design and reduce the cost of the force-restraining structure.

The second-largest cost items in our TMNS estimate are for the neutralbeam and ECRH systems. By present estimates, the ECRH power is particulary expensive $(\$ 5 / \mathrm{W})$. We may look for future improvements in the microwave generators to drop this price or it may be desirable to select a set of operating parameters requiring less ECRH power. The barrier-pump beams are also a large cost item because of the large number required. Reduced barrier volume in an improved barrier-cell design would help. The invention of a new barrier-pumping method (such as one involving rf power or radial ion drifts in a perturbed magnetic field) could also change this requirement drastically.

Despi:-e such potential sevings, a large step in device size, complexity and cost is inevitable as we move from a physics experiment such as MFTF-B to 
a TMNS facility. The introduction of a $D-T$ burn requires a substantial increase in machine size just to provide the necessary shielding and blanket volumes. We must also begin the use of remote maintenance techniques. Other performance requirements, particularly for high plasma $Q$, push the magnet and ECRH technologies to high levels. Neither are axisymetric end-cell designs likely to reduce these technology requirements significantlyn

Some reduction in cost could be realized by accepting a reduced device performance, for instance by shortening the central cell. Such variations can be scoped using results from the present study. The goal of our continuing studies however is to look for an improved end-cell configuration that will permit us to retain or perhape even expand our performance guidelines for TMNS and if possible, at lower projected cost. Ultimately, the size of the step chosen for TMNS, as we move toward a reactor regime, is a matter for judgment contiected with long-range planning. 


\section{ACKNOWLEDGMENTS}

We wish to thank B. Johnston for performing the tests to determine MHD stability limits. B. Arfin provided valuable input for our assessment of ECRH development, and $K$. Krause provided an estimate of ECRH costs. 
$-106-$ 


\section{REFERENCES}

1. K.I. Thomassen and V.N. Karpenko, Tandem Mirror Fusion Test Facility MFTF-B--Conceptual Design Report and Project Proposal, Lawrence Livermore National Laboratory, Livermore, CA, LLL-Prop-163, Rev. 1 (1980).

2. Physics Basis for MFTF-B, D.E. Baldwin, B.G. Logan, and T.C. Simonen, Eds., Lawrence Livermore National Laboratory, Livermore, CA, UCID-18496, Pares 1 and 2 (1980).

3. G.A. Carlson, B. Arfin, W.L. Barr, B.M. Boghosian, J.L. Erickson, J.H. Fink, G.W. Hamilton, B.G. Logan, J.O. Myale, and W.S. Neef, Jr., Tandem Mirror Reactor with Thermal Barriers, Lawrence Livermore National Laboratory, Livermore, CA, UCRL-52836 (1979).

4. F.H. Coensgen, T.C. Simonen, A.K. Chargin, and B.G. Logan, TMX Upgrade Major Project Proposal, Lawrence Livermore National Laboratory, Livermore, CA, LLL-Prop-172 (1980).

5. INTOR International Tokamak Reactor--Zero Phase, Report of the International Tokamak Reactor Workshop, Vienna, 1979 (IAEA, Vienna, 1980).

6. The Nationa1 Mirror Fusion Program Plan, R.R. Borchers and C.M. Van Atta, Eds., Lawrence Livermore National Laboratory, Livermore, CA, UCAR-10042-80 (1980).

7. D.E. Baldwin, B.G. Logan, and T.K. Fowler, An Improved Tandem Mirror Fusion Reactor, Lawrence Livermore National Laboratory, Livermore, CA, UCID- 18156 (1979).

8. D. E. Baldwin and B.G. Logan, "Improved Tandem Mirror Fusion Reactor," Phys. Rev. Lett. 43, 1318 (1979).

9. R.W. Moir, W.L. Barr, G.A. Carlson, W.L. Dexter, J.N. Doggett, J.H. Fink, G. W. Hamilton, J.D. Lee, B.G. Logan, W.S. Neef, Jr., M.A. Peterson, and M.E. Rensink, Preliminary Design Study of the Tandem Mirror Reactor (TMR), Lawrence Livermore National Laboratory, Livermore, CA, UCRL-52302 (1977).

10. S.C. Schulte, W.E. Bickford, C.E. Willingham, S.K. Ghose, and M.G. Walker, Fusion Reactor Design Studies--Standard Unit Costs and Cost Scaling Rules, Facific Northwest Laboratory, Richland, WA, PNL-2987 (1979). 
11. D.Steiner and P.H. Rutherford, ETF Interim Design Review--Presentations at the Opening Plenary Session, Rockville, MD, 1980 (Union Carbide Corporation, 1980 ).

12. R.H. Cohen, G. Rowlands, and J.H. Foote, "Adiabaticity in Mirror Machines," Phys. Fluids 21, 627 (1978).

13. G.A. Carlson, "The Design for Tandem Mirror Reactors with 1.ermal Barriers, in Proc. 4th Topical Meeting on Fusion Technology, King of prussia, PA, 1980 (ANS, in press): also Lawrence Livermore National Laboratory, Livermore, CA, UCRL-84518 (1980).

14. G.D. Porter, "Effect of Gas Recycling and Secondary Electron Emission," in Physics Basis for MFTF-B, D.E. Baldwin, B.G. Logan, and T.C. Simonen, Eds., Lawrence Livermore National Laboratory, Livermore, CA, UCID-18496 (1980), Part 2, P. IV-15l.

15. R.S. Devoto and M. Ohnishi, Confinement of Alpha Particles in Tandem Mirrors, Lawrence Livermore National Laboratory, Livermore, CA, UCID-18784 (1980).

16. B.G. Logan, B. Arfin, W.L. Barr, B.M. Boghosian, G.A. Carloon, T.C. Chu, J.L. Erickson, J.H. Fink, T.K. Fowler, G.W. Hamilton, T. Kaiser, R.W. Moir, J.0. Myall, W.S. Neef, Jr., R.W. Conn, G.A. Emert, F. Kantrowitz, J. Kesner, L.L. Lao, J. Santarius, and K.S. Shaing, "Tandem Mirror Reactors with Thermal Barriers," in Proc. 8th Intern. Conf. on Plasma Physics and Controlled Nuclear Fusion Research, Brussels, Belgium, 1980 (LAEA, Vienna, in press); also Lawrence Livermore National Laboratory, Livermore, CA, UCRL-83505 (1980).

17. G. Hamilton, "Charge-Exchange Pumping of Thermal Barriers," in Physics Basis For MFTF-B, D.E. Baldwin, B.G. Logan, and T.C. Simonen, Eds., Lawrence Livermore National Laboratory, Livermore, CA, UCID-18496 (1980), Part 2, P. IV.H.

18. J.H. Fink, Neutral Beam Injectors for 1990 and 2005, Lawrence Livermore National Laboratory, Livermore, CA, UCRL-53112 (in preparation).

19. W.R. Baker and D.B. Hopkins, "Present and Future Technology of High Voltage Systems Eor Neutral Beam Injectors," presented at the Plasma Heating Development Requirements Workshop, Gaithersburg, MD, 1978 (unpublished); al so Lawrence Berkeley Laboratory, Berkeley, CA, LBL-7261 (1978). 
20. J.W. Shearer, T.A. Cutler, L.W. Dilgard, J. Fabyan, P.M, Holl, G.D. Porter, and KJ.S. Colonias, Magnetic Shielding of Neutral Beam Sources in MFTE, Lawrence Livermore National Laboratory, Livermore, CA, UCRL-52824 (1979).

21. M.E. Read, B. Arfin, J.M. Baird, K.R. Chu, D. Dialetis, A.T. Drobot, V.L. Granatstein, K.J. Kim, and A. Palevsky, "Prospects for Multimegawatt Gyrotrons," Bull. Am. Phys. Soc. 25, 911 (1980).

22. V.V. Alikaev, V.A. Flyagin, V.I. Khizhnyak, A.G. Luchinin, G.S. Nusinovich, V.G. Usov, and S.N. Vlasov, "Gyrotrons for the Electron-Cyclotron Plasma Heating in Large Tokamaks," in Proc. Joint Varenna-Grenoble Intern. Symp. on Heating in Toroidal Plasmas, Grenoble, France, 1978 (Erench Atomic Energy Agency, Grenoble, France, 1978), p. 339.

23. K.R. Chu, A.T. Drobot, H.H. Szu, and P. Sprangle, "Theory and Simulation of the Gyrotron Traveling Wave Amplifier Operating at Cyclotron Harmonics," IEEE Trans. Microwave Theory Tech. MTT-28, 313 (1980).

24. R.M. Gilgenback, M.E. Read, K.E. Hackett, R. Lucey, B. Hui, V.L. Granatstein, and K.R. Chu, "Heating at the Electron Cyclotron Frequency in the ISX-B Tohamak," Phys, Rev, Lett. 44, 647 (1980).

25. T.H. Batzer, R.C. Burleigh, G.A. Carlson, W.L. Dexter, G.W. Hamilton, A.R. Harvey, R.G. Hickman, M.A. Hoffman, E.B. Hooper, R.W. Moir, R.L. Nelson, L.C. Pittenger, W.J. Silver, B.H. Smith, C.E. Tay:or, R.W. Werner, and T.P. Wilcox, Conceptual Design of a Mirror Reactor for a Fusion Engineering Research Facility (FERF), Lawrence Livermore Laboratory, Livermore, CA, UCRL-51617 (1974).

26. J.M. Mintz, T.S. Elleman, and K. Verghese, "Tritium Diffusion in Fusion Reactor Blankets," Nucl. Technol. 31, 172 (1976).

27. J.L. Anderson, "The Tritium Systems Test Assembly of the Los Alamos Scientific Laboratory," in Proc. 3th Topical Meeting on the Technology of Controlled Nuclear Fusion, Santa Fe, NM, 1978 (ANS, 1978), p. 674 . 